CHARACTERIZATION OF ULTRA-FINE GRAINED STEEL SAMPLES PRODUCED BY HIGH PRESSURE TORSION VIA MAGNETIC

BARKHAUSEN NOISE ANALYSIS

A THESIS SUBMITTED TO

THE GRADUATE SCHOOL OF NATURAL AND APPLIED SCIENCES $\mathrm{OF}$ MIDDLE EAST TECHNICAL UNIVERSITY

BY

SADIK BAYRAMOĞLU

IN PARTIAL FULFILLMENT OF THE REQUIREMENTS

FOR

THE DEGREE OF MASTER OF SCIENCE

IN

METALLURGICAL AND MATERIALS ENGINEERING

JUNE 2009 
Approval of the thesis:

\section{CHARACTERIZATION OF ULTRA-FINE GRAINED STEEL SAMPLES PRODUCED BY HIGH PRESSURE TORSION VIA MAGNETIC BARKHAUSEN NOISE ANALYSIS}

submitted by SADIK BAYRAMOĞLU in partial fulfillment of the requirements for the degree of Master of Science in Metallurgical and Materials Engineering Department, Middle East Technical University by

Prof. Dr. Canan Özgen

Dean, Graduate School of Natural and Applied Sciences

Prof. Dr. Tayfur Öztürk

Head of Department, Metallurgical and Materials Engineering

Prof. Dr. C.Hakan Gür

Supervisor, Metallurgical and Materials Eng. Dept., METU

Prof. Dr. Igor V. Alexandrov

Co-Supervisor, Physics Dept., Ufa State Aviation Tech. Univ., USATU

\section{Examining Committee Members:}

Prof. Dr. Macit Özenbaş

Metallurgical and Materials Engineering Dept., METU

Prof. Dr. C. Hakan Gür

Metallurgical and Materials Engineering Dept., METU

Prof. Dr. Tayfur Öztürk

Metallurgical and Materials Engineering Dept., METU

Prof. Dr. Cevdet Kaynak

Metallurgical and Materials Engineering Dept., METU

Prof. Dr. A. Bülent Doyum

Mechanical Engineering Dept., METU

Date:

15. 06.2009 
I hereby declare that all information in this document has been obtained and presented in accordance with academic rules and ethical conduct. I also declare that, as required by these rules and conduct, I have fully cited and referenced all material and results that are not original to this work.

Name, Last name: Sadık BAYRAMOĞLU

Signature 


\title{
ABSTRACT \\ CHARACTERIZATION OF ULTRA-FINE GRAINED STEEL SAMPLES PRODUCED BY HIGH PRESSURE TORSION VIA MAGNETIC BARKHAUSEN NOISE ANALYSIS
}

\author{
Bayramoğlu, Sadık \\ M.S., Department of Metallurgical and Materials Engineering \\ Supervisor: Prof. Dr. C. Hakan Gür \\ Co-supervisor: Prof. Dr. Igor V. Alexandrov
}

June 2009, 84 Pages

High Pressure Torsion (HPT) is one of the most widely used severe plastic deformation methods which enable to obtain a crack free ultra-fine grained bulk material with improved mechanical properties like increased strength and toughness. In the process, a disc shaped sample is pressed between two anvils and deformed via surface friction forces by rotating one of the anvils. The aim of this study is to nondestructively characterize the variations in the deformation uniformity of the severely deformed steel disks. Two sets of low carbon steel samples were obtained by applying the unconstrained and constrained HPT process up to 6 turns. Magnetic Barkhausen Noise (MBN) method was used in order to evaluate the samples in a nondestructive manner via a commercial device. The results of the MBN measurements were verified with those of conventional methods such as; x-ray diffraction (XRD), metallographic examination and hardness measurements. The initial stages of HPT revealed the effects of conventional plastic deformation on MBN; however with further straining, grain size refinement prevailed and caused increase in MBN signals.

Keywords: Magnetic Barkhausen Noise, Severe Plastic Deformation, High Pressure Torsion 
ÖZ

\title{
YÜKSEK BASINÇLI BURULMAYLA ÜRETILMIŞ AŞIRI İNCE TANELİ ÇELIK NUMUNELERIN MANYETIK BARKHAUSEN GÜRÜLTÜ ANALIZIYYLE KARAKTERIZZASYONU
}

\author{
Bayramoğlu, Sadık \\ Yüksek Lisans, Metalurji ve Malzeme Mühendisliği Bölümü \\ Tez Yöneticisi: Prof. Dr. C. Hakan Gür \\ Ortak Tez Yöneticisi: Prof. Dr. Igor V. Alexandrov
}

Haziran 2009, 84 Sayfa

Yüksek Basınçlı Burulma (YBB), iyileştirilmiş tokluk ve mukavemet gibi mekanik özelliklere sahip, çok ince taneli, hasarsız mamul elde etmeye olanak sağlayan aşırı plastik deformasyon işlemlerinden biridir. İşlemde, disk şeklindeki numune iki kalıp arasında bastırılıp, yüzeydeki sürtünme yükleri sayesinde bir kalıbın döndürülmesiyle deforme edilir. Bu çalışmanın amacı, aşırı deforme edilmiş çelik disklerdeki deformasyon dağılımını tahribatsız olarak karakterize etmektir. Yalın karbon çeliği disklere, serbest ve sınırlandırılmış YBB işlemleri 6 çevirime kadar uygulanarak iki set halinde numuneler elde edilmiştir. Manyetik Barkhausen Gürültü (MBG) yöntemi numuneleri tahribatsız olarak değerlendirmek için ticari bir cihaz yardımıyla uygulanmıştır. MBG ölçümlerinin sonuçları, X-1şını kırınımı, metalografik inceleme ve sertlik ölçümleri gibi klasik yöntemlerin sonuçlarıyla doğrulanmıştır. YBB'nin ilk aşamaları, klasik plastik deformasyon işlemlerinin MBG'ye olan etkilerini göstermiştir; ancak artan gerinmeyle tane boyutu küçülmesi baskın hale gelmiş ve MBG sinyallerinin artmasına yol açmıştır.

Anahtar Kelimeler: Manyetik Barkhausen Gürültüsü, Aşırı Plastik Deformasyon, Yüksek Basınçlı Burulma 
To my family 


\section{ACKNOWLEDGEMENTS}

I would like to express my gratitude to my supervisor Prof. Dr. C. Hakan Gür for his guidance, understanding and continuous support throughout the study.

I would also like to thank to my co-supervisor Prof. Dr. Igor V. Alexandrov and his assistant Marina Abramova from Ufa State Aviation Technical University, Russia for the processing of the HPT samples and for sharing their experiences about High Pressure Torsion.

My special thanks go to H. İlker Yelbay and Serdar Savaş for their comments on MBN measurements.

The technical assistance of Dr. İbrahim Çam from METU-Central Laboratory during the MBN measurements and SEM studies; helps of Mr. Necmi Avc1, Onur Rauf Bingöl during XRD measurements and, Emre Ergül for both XRD measurements and chemical analysis of the samples are gratefully acknowledged.

I wish to thank my friends Onur Rauf Bingöl, Hüseyin Ergün, Emre Ergül, Betül Pelin Maradit, Alp Aykut Kibar, Mert Akkuş, Murat Tolga Ertürk, Göksu Gürer and, colleagues H. İlker Yelbay, Serdar Savaş, Orcan Kolankaya and Seyhan Çamlıüney from METU WTNDT / Nondestructive Testing Unit for sharing all the good and the bad times throughout the study.

Finally, I would like to dedicate this work to my parents Filiz and Ali Bayramoğlu, and my sister Beste Bayramoğlu who always encouraged me to continue. 


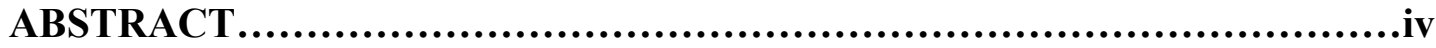

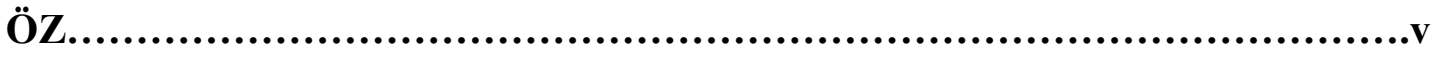

ACKNOWLEDGMENTS.............................................................

TABLE OF CONTENTS..........................................................viii

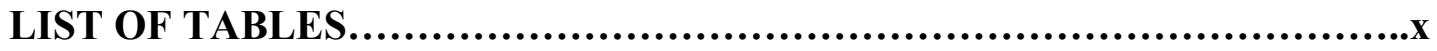

LIST OF FIGURES...................................................................

\section{CHAPTER}

\section{INTRODUCTION}

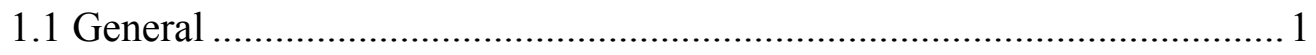

1.2 Innovation Potential of SPD Materials...................................................

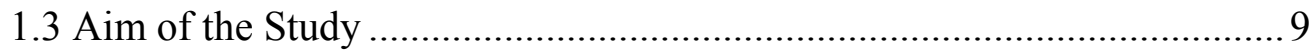

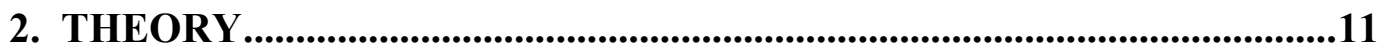

2.1 Severe Plastic Deformation..................................................................11

2.2 High Pressure Torsion Process..............................................................12

2.3 Magnetic Barkhausen Noise Technique...................................................15

3. LITERATURE REVIEW ...............................................................................25

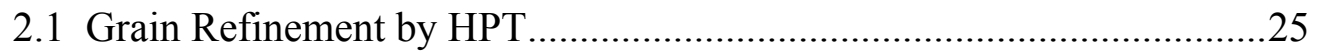

2.2 Effect of Stacking Fault Energy on Grain Refinement ...........................26

2.3 Hardness Distributions After HPT ……………………………………...27

2.4 Ultrafine Grained Steels Processed by HPT …………………………...28 
2.5 Magnetic Behavior After HPT

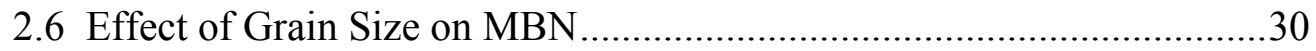

2.7 Effect of Tensile Deformation and Cold Rolling on MBN .....................31

2.8 Change of MBN in the Elastic and Plastic Region of Deformation.........32

4. EXPERIMENTAL PROCEDURE ..................................................................34

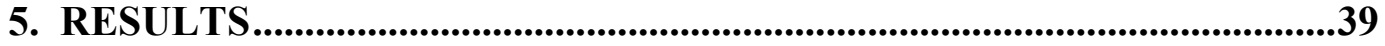

5.1 The Samples Produced by Unconstrained HPT .....................................39

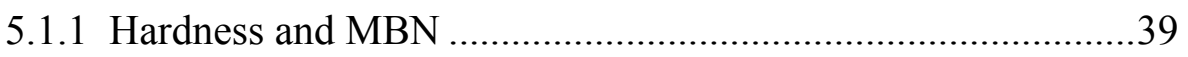

5.1.2 Microstructure …..................................................... 41

5.2 The Samples Produced by Constrained HPT …....................................43

5.2.1 True Strain and Hardness ........................................................43

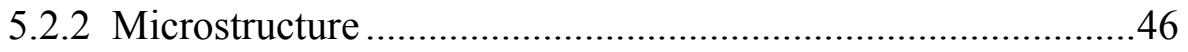

5.2.3 X-Ray Diffraction Pattern ....................................................50

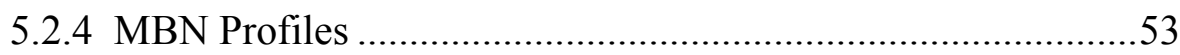

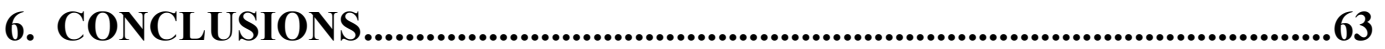

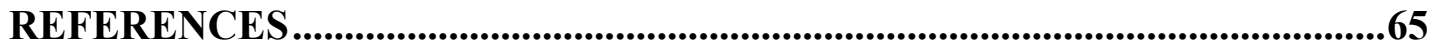

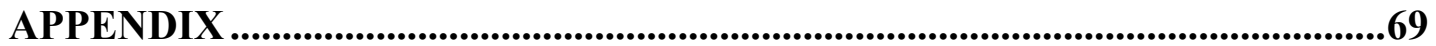




\section{LIST OF TABLES}

Table 4.1 Chemical composition of the samples in wt. \%, the rest is Fe .34

Table A.1 The results of the hardness measurements for unconstrained HPT samples with standard deviation $\left[s=\sqrt{\frac{1}{N-1} \sum_{\dot{I}=1}^{N}\left(x_{\dot{I}}-\bar{x}\right)^{2}}\right]$

Table A.2 The results of the hardness measurements for constrained HPT samples with standard deviation $\left[s=\sqrt{\frac{1}{N-1} \sum_{\dot{I}=1}^{N}\left(x_{\dot{I}}-\bar{x}\right)^{2}}\right]$ .70 


\section{LIST OF FIGURES}

Figure 1.1 Schematic illustrations of various SPD processes. (a) High-Pressure Torsion, (b) Equal Channel Angular Pressing, (c) Accumulative Roll Bonding, (d) Repetitive Corrugation and Straightening, (e) Torsion Extrusion and (f) Cyclic Extrusion Compression 3

Figure 1.2 Simple sketch of the HPT tool 6

Figure 1.3 Schematic of the apparatus used by Bridgman in which torsional straining is combined with longitudinal compression..... 6

Figure 1.4 Test systems for the High Pressure Torsion, HPT, process: (a) unconstrained HPT, (b) idealized constrained HPT, (c) practical constrained HPT ...6

Figure 1.5 Innovation probability of SPD materials in various sectors versus specific strength

Figure 2.1 Schematic model of dislocation structure evolution at different stages during severe plastic deformation

Figure 2.2 Special HPT facility to produce cylindrical components 15

Figure 2.3 Magnetic domains of $\mathrm{BaFe}_{12} \mathrm{O}_{19}$ have been imaged with a scanning tunneling microscope

Figure 2.4 Domain processes occurring as a material is magnetized from demagnetized state to saturation magnetization.

Figure 2.5 Alignment of individual magnetic moments within a $180^{\circ}$ domain wall 17

Figure 2.6 Domain wall movement when a magnetic field is applied .19 
Figure 2.7 In situ Lorentz-microscopic observation of migration of the domain walls in a doubly oriented silicon iron sheet with the application of the external magnetic field into the film plane. The large arrow indicates the direction of applied magnetic field

Figure 2.8 Hysteresis loop for magnetic material showing discontinuities that produce Barkhausen noise

Figure 2.9 Schematic figure of the experimental setup of MBN measurement......21

Figure 2.10 (a) Schematic figure showing the change in magnetic field $H$ with time, variation in flux density over the same period, and the generation of the Barkhausen noise burst as flux density changes. (b) Typical BN signal .21

Figure 4.1 Schematic representation of the hardness measurements for the second set of samples, which has been produced by constrained HPT .35

Figure 4.2 The MBN measurement system used in this study .37

Figure 4.3 The sensor used for the MBN measurements .37

Figure 4.4 The experimental setup prepared for the second set of samples, which have been produced by constrained HPT, in order to move the sensor horizontally by $1 \mathrm{~mm}$ intervals via comparator at the right side. .37

Figure 4.5 Hardness distribution for $\mathrm{N}=2$ (a) and $\mathrm{N}=4$ (b) from the second set of samples, which have been produced by constrained HPT, showing that both sides of the samples are almost equally strained .38

Figure 5.1 Hardness profile along the diameter of the samples produced by unconstrained HPT (N: number of turns).

Figure 5.2 MBN profiles of the samples produced by unconstrained HPT (N: number of turns) 40

Figure 5.3 Optical micrograph of the undeformed sample of the $1^{\text {st }}$ set of samples (Etched in 2\% Nital solution for 15 seconds and in Picral solution for 30 seconds).41 
Figure 5.4 Optical micrographs (OM) and SEM images of the most severely deformed sample $(\mathrm{N}=6)$, in the $1^{\text {st }}$ set of samples produced by unconstrained HPT, from the center and periphery of the disk (Etched in 2\% Nital solution for 15 seconds and in Picral solution for 30 seconds)

Figure 5.5 Theoretical variation of strain along the diameter of the constrained HPT samples (N: number of turns).

Figure 5.6 Hardness profile along the diameter of the constrained HPT samples (N: number of turns)

Figure 5.7 Average microhardness values along the diameter vs. Number of turns

Figure 5.8 Average curvature of microhardness measurements for both constrained and unconstrained HPT 45

Figure 5.9 Optical micrograph of the undeformed sample (Etched in 2\% Nital solution for 15 seconds and in Picral solution for 30 seconds) 46

Figure 5.10 Optical micrographs of the 1, 3 and 5 times rotated samples from the center and periphery of the disks (Etched in 2\% Nital solution for 15 seconds and in Picral solution for 30 seconds)

Figure 5.11 SEM images of the most severely deformed sample $(\mathrm{N}=5)$ in the $2^{\text {nd }}$ set of samples, which have been produced by constrained HPT, from the center and periphery of the disk (Etched in 2\% Nital solution for 15 seconds and in Picral solution for 30 seconds) 48

Figure 5.12 Continuous Cooling Diagram for AISI 1017-1022 steels .49

Figure 5.13 XRD pattern of constrained HPT samples. .51

Figure 5.14 Sub-grain size distribution of constrained HPT samples..... .51

Figure 5.15 MBN profile of the constrained HPT samples at the center of the disks (N: number of turns) .53 
Figure 5.16 MBN profiles of the samples at $\pm 4 \mathrm{~mm}$ away from the center of the disks (N: number of turns)

Figure 5.17 MBN profiles of the samples at the farthest measurable distance $( \pm 7$ $\mathrm{mm}$ ) away from the center of the disks.....

Figure 5.18 $\mathrm{MBN}$ profile of $\mathrm{N}=1$ for two distinct radii .56

Figure 5.19 $\mathrm{MBN}$ profile of $\mathrm{N}=5$ for two distinct radii .56

Figure 5.20 Average RMS of MBN along the radius after different HPT turns (N: number of turns) .58

Figure 5.21 Comparison of average RMS values at the selected points along the radius as a function of the number of HPT turns .58

Figure 5.22 Comparison of the variation of average RMS and sub-grain size of the constrained HPT samples as a function of the number of HPT turns. .60

Figure 5.23 Comparison of the variation of average RMS and hardness values at the center and $7 \mathrm{~mm}$ away from the center of the disks as a function of the number of HPT turns .60

Figure 5.24 Representative magnetic hysteresis loops at the centre of the samples (N: number of turns)

Figure 5.25 Representative magnetic hysteresis loops at the farthest measurable distance $(7 \mathrm{~mm})$ away from the center of the samples ( $\mathrm{N}$ : number of turns). .62 


\section{CHAPTER 1}

\section{INTRODUCTION}

\subsection{General}

Severe Plastic Deformation (SPD) is the technology that enables conventional macro grained metals to be directly transformed into Ultra Fine Grained (UFG) or nano size grained materials by inducing extreme plastic straining to a bulk material under a high hydrostatic pressure without any significant shape change in the material. This is achieved by introducing very high shear deformations into the material and grains are continuously fragmented during deformation. In case of traditional deformation methods such as rolling or extrusion, grain size saturates at much lower strains and the obtained grain size cannot reach to values below micron size, besides the dimensions of the components change significantly. The major aim of SPD processes is to obtain high strength and lightweight materials without any significant shape change so that even very small parts can be used safely. Moreover, the increase in strength does not result in a decrease in toughness, which differ the SPD processes from many other deformation and heat treatment processes, however the size of the samples is a disadvantage as they can only be used as micro-components.

SPD materials generally have a mean grain size of about $100-200 \mathrm{~nm}$ and a grain interior possesses usually some substructure due to a highly distorted crystal lattice. Moreover, the X-ray analysis demonstrates a crystalline size of about $50 \mathrm{~nm}$ [1]. That is why SPD materials are considered as a kind of bulk nanostructured materials. 
High Pressure Torsion (HPT) and Equal Channel Angular Pressing (ECAP) are the first SPD methods which are used for the production of ultra-fine grained materials. There are many other methods developed; Accumulative Roll Bonding (ARB) to produce sheet samples, Repetitive Corrugation and Straightening (RCS) to process metal sheets and rods in a continuous manner, Torsion Extrusion to produce severely strained cylindrical samples and Cyclic Extrusion Compression (CEC) for billet samples. Schematic illustrations of these methods are shown in Figure 1.1.

SPD methods should meet some requirements for the formation of an ultra fine grained structure in the bulk sample. Firstly, it is important to obtain ultra finegrained structures with prevailing high-angle grain boundaries since only in this case can a qualitative change in properties of materials occur. Secondly, the formation of ultra fine grained structure within the whole volume of a sample is necessary in order to achieve stable properties of the processed materials. Thirdly, the samples, which are exposed to large plastic deformations, should not have any mechanical damage or cracks [1]

R.Z. Valiev et al. [3] stated that the structural features of SPDed metals are characterized not only by the formation of ultra fine grains, but also by the presence of non-equilibrium grain boundaries with high density of deformation induced dislocations and vacancies, high lattice distortions and possibly also to changes in local phase composition.

High Pressure Torsion (HPT) (torsion straining under high hydrostatic pressure) is one of the most widely used severe plastic deformation (SPD) methods which enable to obtain ultra-fine grains, improved mechanical properties like increased strength and toughness without the shape change of the sample and with a crack free surface. In the HPT process, a disc shaped sample is put between two anvils, and strained under the hydrostatic pressure. One of the anvils is rotated and the sample is deformed via surface friction forces (Figure 1.2). 


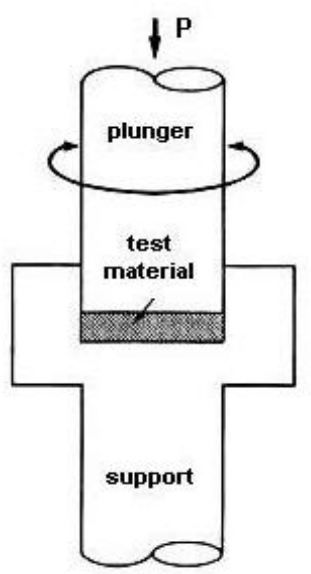

(a)

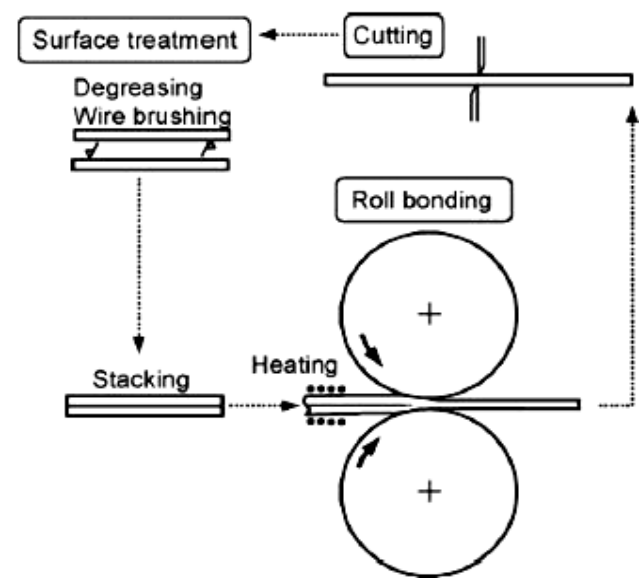

(c)

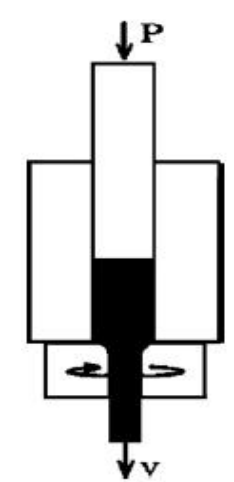

(e)

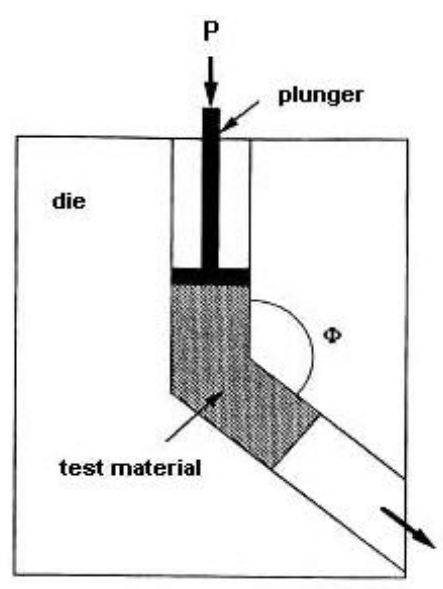

(b)

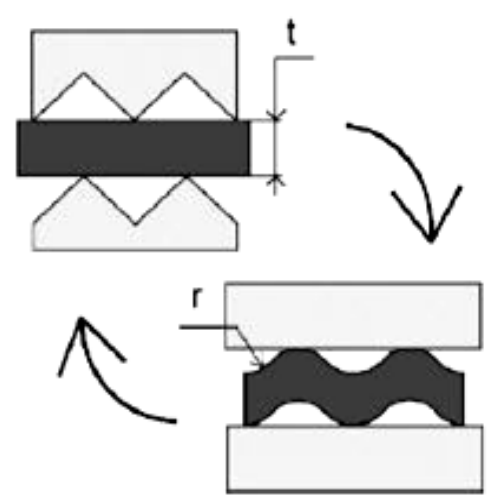

(d)

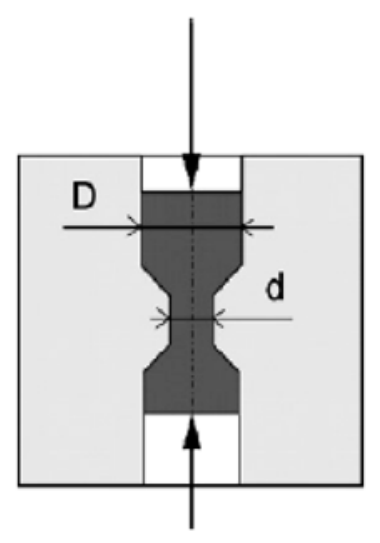

(f)

Figure 1.1 Schematic illustrations of various SPD processes. (a) High-Pressure Torsion, (b) Equal Channel Angular Pressing [1], (c) Accumulative Roll Bonding, (d) Repetitive Corrugation and Straightening, (e) Torsion Extrusion and (f) Cyclic Extrusion Compression [2] 
The HPT process, which was introduced by P.Bridgeman in the 1930's (Figure 1.3) and further developed by R.Z. Valiev in 1980's, provides a continuous shear deformation and it is a very effective method due to its simple construction, adjustable hydrostatic pressure and ability to apply large degrees of deformation. Due to the specific geometric shape of the sample, the main volume of the material is strained in conditions of quasihydrostatic compression under the applied pressure. As a result, in spite of large strain values, the deformed sample is not destroyed. The large amount of strain and the applied hydrostatic pressure are responsible in achieving ultra-fine grains.

In the HPT process, the temperature at which the process is conducted, strain rate, friction between the material and the anvils, and the magnitude of hydrostatic pressure are some of the parameters that should be adjusted to obtain homogenous microstructure. $1 / 2$ rotations are even enough to obtain a significant change in microstructure although several rotations should be applied to obtain homogenous microstructures. The final microstructure is determined not only by the material itself (initial microstructure, phase composition and type of crystal lattice) but also by the process parameters such as strain rate, temperature and pressure. In general, decrease in temperature, increase in pressure and alloying all contribute to refinement of structure and obtaining a minimal grain size [1].

There are two types of HPT tools which are termed as unconstrained and constrained HPT. The simple sketches of the constrained and unconstrained HPT tools are shown in Figure 1.4. In the case of unconstrained HPT, material can flow outside of the space in between the anvils. However, deformation is more homogenous from the center through the periphery of the disks after the large number of turns.

The constrained HPT is used in order to decrease the reduction in thickness with compared to unconstrained version and to obtain a nearly constant pressure during deformation. Therefore the constrained version is generally used for HPT. In practical constrained HPT (Figure 1.4(c)), deformation is similar to idealized HPT (Figure 1.4(b)); the main difference is in the shape of anvils. The anvils in the 
constrained version have a cylindrical cavity and their diameter should be identical with the diameter of the sample. The sum of the height of the cavities should be smaller than the initial height of the sample. Small amount of material flows in the ring shaped region between the anvils and the friction in this single region prevents the material to flow out of the HPT tool which leads to back pressure and therefore induces a well defined hydrostatic pressure within the processing zone of the tool [4]. This design of the HPT tool also prevents the failure of anvils during processing. The cavity in the anvils allows getting the samples with the same thickness along the diameter, without cracks, but in this case the deformation conditions are softer than the unconstrained and the idealized constrained HPT.

Sandblasting is applied to the surfaces of cavities on the anvils in order to obtain a clean surface and to achieve micro-roughness so that there is sufficient friction for deformation.

During the deformation small amount of material flows out, the height of the sample is somewhat reduced due to compression stresses. The reduction in thickness of the sample depends on the difference between the volume of sample and anvils, the applied load and strength of material. The amount of compression deformation is much smaller than the torsional strain and due to the inhomogeneous elastic deformation of the tool; the height of the sample is somewhat bigger than it is at the edge. Moreover, this effect increases with increasing pressure. In order to avoid sliding between the anvils and the HPT sample, the required pressure is very high and it should be larger than the hardness of the material, or in other words, at least 3 times larger than the yield stress of the material in order to get a perfect fitting between the rough anvils and the sample [4]. 


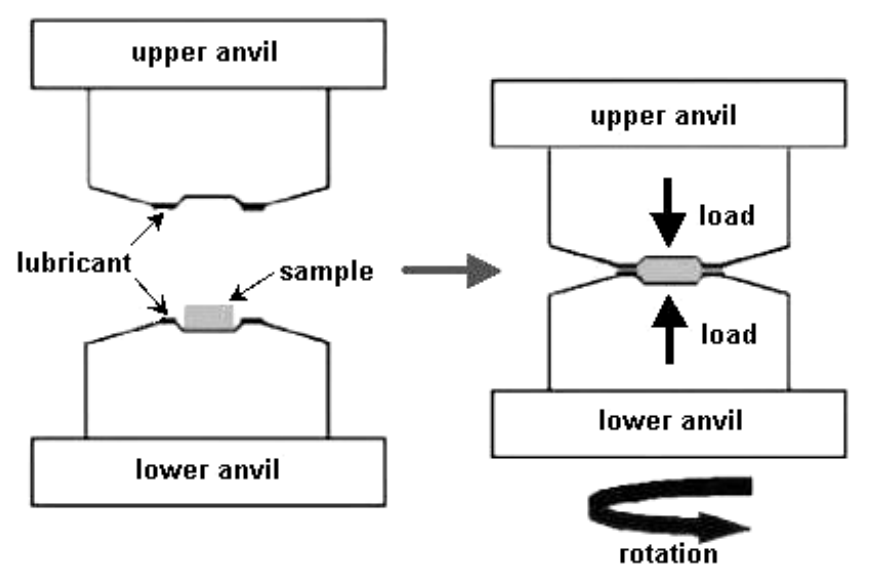

Figure 1.2 Simple sketch of the HPT tool

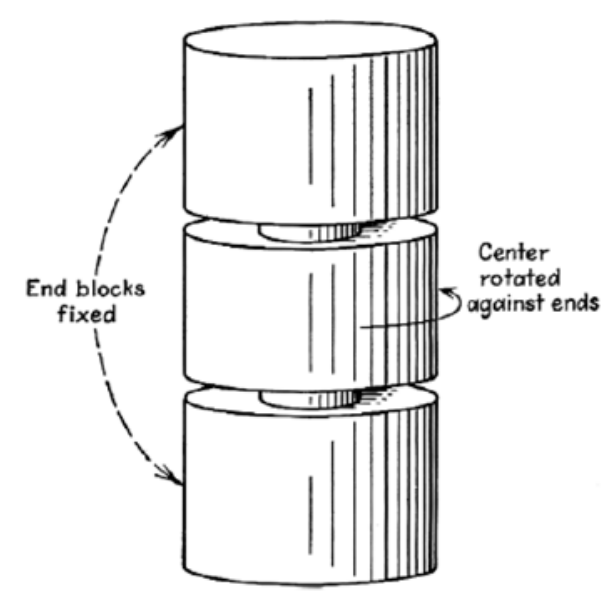

Figure 1.3 Schematic of the apparatus used by Bridgman in which torsional straining is combined with longitudinal compression [5]
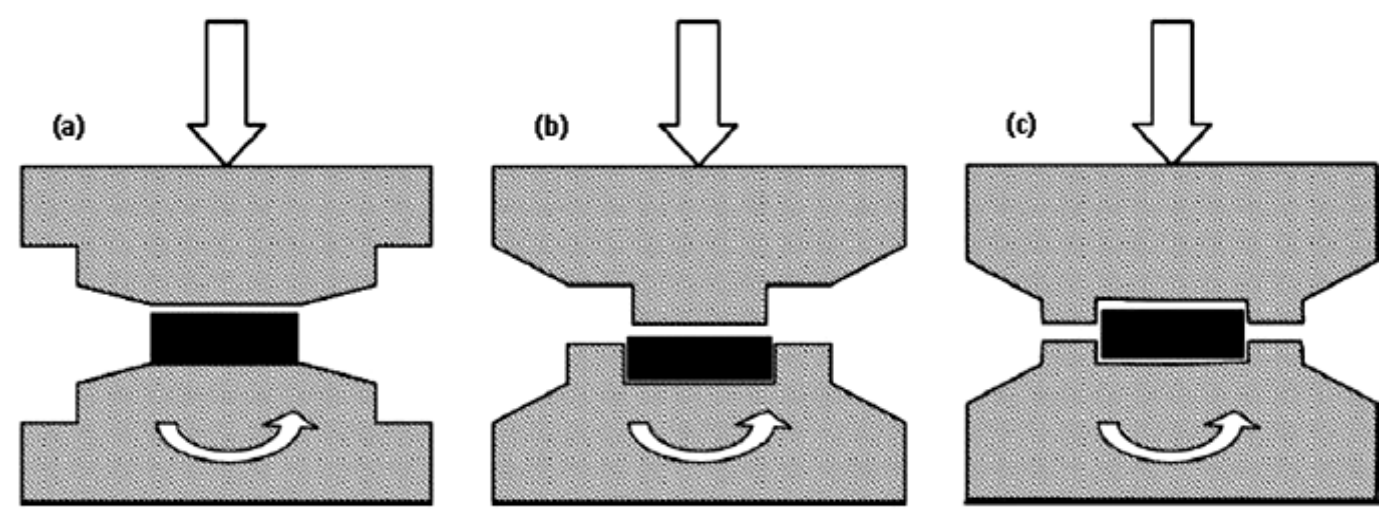

Figure 1.4 Test systems for the High Pressure Torsion, HPT, process: (a) unconstrained HPT, (b) idealized constrained HPT, (c) practical constrained HPT [5] 


\subsection{Innovation Potential of SPD Materials}

The industrial applications of SPD materials are limited due to the small sizes of the samples which result in discontinuous process with low production efficiency and relatively high cost. Moreover, the ends of the samples are usually cut as they impair the uniformity of the microstructure and contain macro-cracks. Nevertheless, there are applications in some markets where material performance is more important than the cost such as defense industry, surgical implants, aerospace, sport equipment and energy storage industries [3]. There are some examples of applications; ECAPed Al and $\mathrm{Cu}$ are used sputtering targets which are used for metallization of silicon wafers in the production of semiconductor devices; UFG stainless steel, $\mathrm{Co}-\mathrm{Cr}$ and $\mathrm{Ti}$ alloys used as surgical implants and, screws, plates in orthopedic applications [2]. SPD materials can be used for the production of gears for MEMS applications and SPDed steels may be used in cryogenic applications [3]. Moreover in the defense applications, UFG materials can be used armor plates which are lighter and stronger than conventional materials, which also lead to more efficient fuel consumption and better ballistic properties. UFG materials can be used as sports equipments such as high performance bicycles, sailing equipment, golf tennis, etc. as the high strength and low weight would be beneficial. Figure 1.5 shows the innovation probability of SPD materials in various sectors where superior materials properties are required.

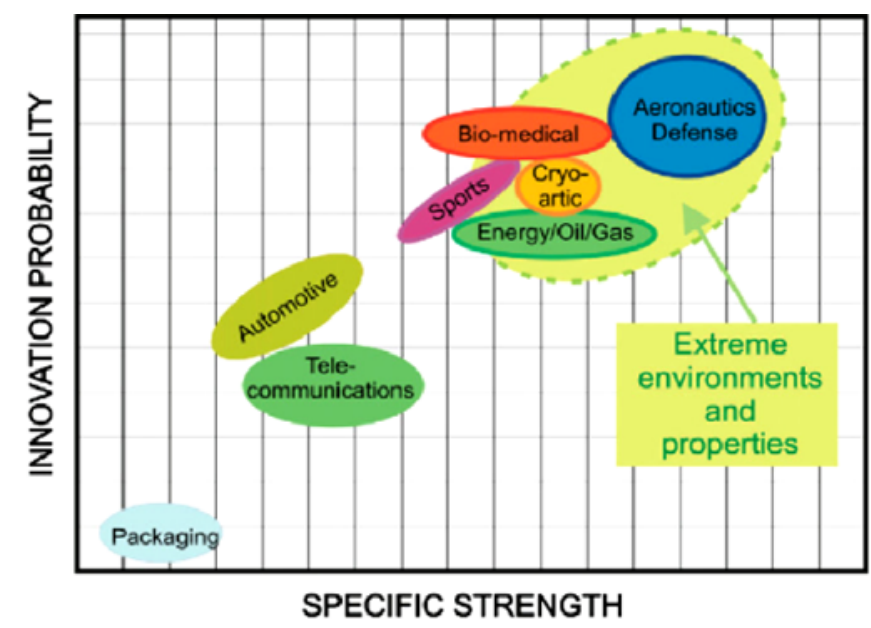

Figure 1.5 Innovation probability of SPD materials in various sectors versus specific strength [5] 
Although the size of HPT samples is small, they are ideally suited where small components are effectively used such as;

- small bulk nanomagnets with enhanced soft and hard magnetic properties,

- arterial stents,

- devices for microelectromechanical system (MEMS) applications,

- $\quad$ surgical implants.

Recent investigations also showed that severe torsion straining can be used successfully not only for the refinement of a microstructure but also for the consolidation of powders [1].

The comparison of the features of the HPT process to other severe plastic deformation processes can be summarized as follows:

- HPT permits a defined continuous application of strain whereas most SPD processes offer only a stepwise application of strain.

- The most important advantage of HPT is the simple way in which extremely high shear strain can be achieved.

- Relative brittle or high strength materials can be severely deformed, which is often impossible by other SPD processes.

- Strain rate at a specific radius can be precisely controlled.

- Heating and cooling of the anvils permits a well defined deformation temperature.

- The total torque vs. angle of rotation can be easily measured. This permits an estimation of the development of the flow stress.

Despite these advantages, the main disadvantage is the radial dependence of strain. In industrial applications, homogenous material properties are desired. However in HPT, only the material is deformed up to its saturation regime. Moreover the limit of the size of the HPT samples is another main disadvantage for industrial applications.

Finally, it should be noted that, a new severe torsion process, which is torsion extrusion, has been proposed for mass production where there exist no limit in length 
of cylindrical samples [4], however it should be developed in order to achieve higher levels of strain and more homogenous deformation.

\subsection{Aim of the Study}

Severe plastic deformation (SPD) methods enable to obtain ultra fine grained (UFG) materials by inducing extreme plastic straining to the bulk materials. As the SPDed materials possess desirable mechanical and physical properties that cannot be achieved by conventional deformation methods, SPD technology has gained much attention in the last 20 years. High Pressure Torsion (HPT) and Equal Channel Angular Pressing (ECAP) are the first SPD methods that were used to obtain UFG materials. The major disadvantage of the HPT samples is their small size. The size of the disk shaped HPT samples is limited in order to achieve near-homogenous distribution at the final stages of deformation for both horizontal and vertical sections. There are constrained and unconstrained versions of HPT systems, the unconstrained version being the more severe one.

Magnetic Barkhausen noise $(\mathrm{MBN})$ is a nondestructive method by which the microstructural condition and the residual stress state of a ferromagnetic material can be characterized. As the MBN method enables fast and nondestructive materials characterization, it is a good alternative to the traditional methods like metallographic examination or hardness measurement. In this study, the monitoring ability of the microstructural variations due to SPD via high pressure torsion (HPT) by the MBN method was investigated.

Transmission Electron Microscopy (TEM) and X-Ray diffraction (XRD) are usually utilized for describing the microstructure of the samples after HPT. However, TEM is a destructive method and XRD indirectly gives integral information about the structure. Therefore, MBN technique can be an alternative method in order to analyze the microstructure of SPD materials in a nondestructive manner. 
The aim of this study is to nondestructively characterize the variations in the deformation uniformity of the severely deformed disks. Plastic deformation changes the magnetic properties in steel samples, because of the interaction of dislocations, grain boundaries, microstructural phases and residual stresses with domain walls. The effect of HPT on MBN at the initial stages of deformation can be compared with the effect of conventional deformation methods due to low strain. By going from low plastic strains to high plastic strains, the distribution of dislocations will change and subgrain (or cell) structure will prevail. As strain increases further; the exact effect of SPD methods will be dominant, which is grain size reduction. So, the effect of HPT is expected to be dependent on the amount of straining.

Two sets of low carbon steel samples were obtained by applying the constrained and unconstrained HPT up to 6 turns. Magnetic Barkhausen Noise (MBN) method was used in order to nondestructively evaluate the specimens. The results of conventional methods X-ray diffraction (XRD), metallographic examination and hardness measurements were compared with the results of MBN measurements. 


\section{CHAPTER 2}

\section{THEORY}

\subsection{Severe Plastic Deformation}

The evolution of the defect structure of materials during SPD is shown in Figure 2.1. When the dislocation density in the cell walls achieves some critical value, a cellular structure (Figure 2.1(a)) transforms to a granular one and a partial annihilation of dislocations of different signs occurs at the cell boundaries (Figure 2.1(b)). As a result, excess dislocations of single sign remain (Figure 2.1(c)) [1].

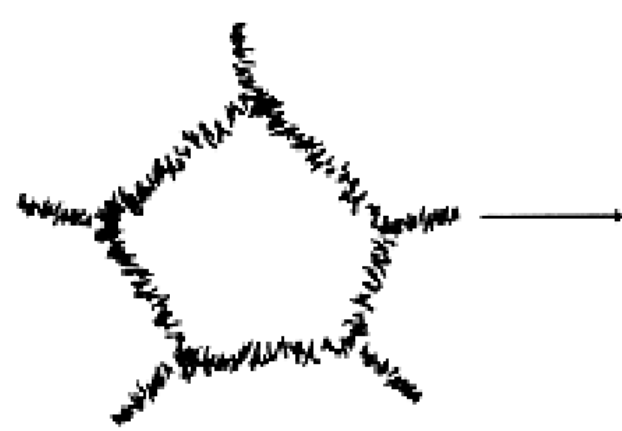

(a)

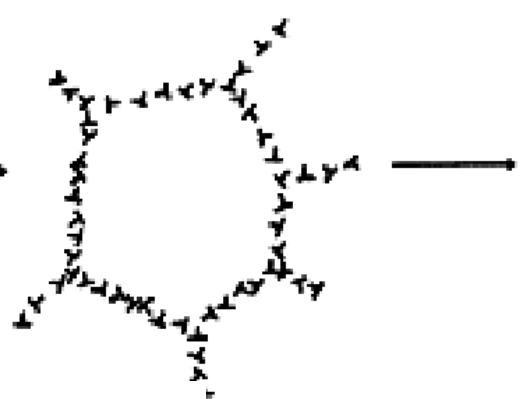

(b)

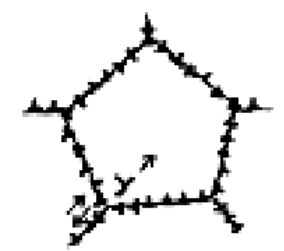

(c)

Figure 2.1 Schematic model of dislocation structure evolution at different stages during severe plastic deformation [1]

Ultra fine grain materials generally follow well-known Hall-Petch relationship;

$$
\sigma_{y}=\sigma_{0}+\frac{k}{\sqrt{d}}
$$


Where $\sigma_{y}$ is yield stress, $\sigma_{0}$ is the stress required to initiate dislocation motion, $k$ is a constant of yielding and $d$ is the grain size. However there are some exceptional cases. The Hall-Petch relationship may not be valid in nanograin size due to the change in deformation mechanism and weakening of grain boundaries [6]. The $k$ coefficient in the Hall-Petch relation decreases with grain refinement for some pure metals, and for $\mathrm{Cu}$ it passes through zero and takes even negative value [7]. This deviation from the Hall-Petch relation is attributed to the change in deformation mechanism after a critical grain size; deformation by grain boundary sliding. J. Schiøtz [8] has made molecular dynamics simulations and concluded that the grain boundary mobility is enhanced during deformation which leads to grain boundary migration and coarsening of the grain structure, so hardness decreases with the decreasing grain size. H. Conrad and J. Narayan [9] also concluded the change of deformation mechanism from dislocation slip to grain boundary sliding after the computer simulation the results of which fit the experimental data.

The limited ductility of severely deformed samples is in nature as it is expected from strain hardened materials. However their ductility cannot be improved by subsequent heat treatment as in the case of conventional deformation and subsequent annealing. Improved ductility can be obtained only the grain size reaches micron size after annealing, i.e. after considerable decrease in strength [2]. A combination of SPD and conventional deformation processes like cold rolling or extrusion with subsequent annealing may be conducted in order to achieve sufficient ductility without decreasing strength much. Moreover, R.Z. Valiev and I.V. Alexandrov stated that concurrent increase of strength and ductility can be attained by applying large degrees of deformation, i.e. when true strain exceeds 6-8 [10].

\subsection{High Pressure Torsion Process}

There are various relationships for calculation of the torsional strain during deformation. The incremental shear strain $d \gamma$ is calculated by the Equation (2.2): 


$$
d \gamma=\frac{d l}{t}=\frac{r \cdot d \theta}{t}
$$

where $d l, \theta, r$ and $t$ are displacement, the rotation angle in radians, the distance from the axis of the disk and the thickness of the disk, respectively.

Equation (2.3) is commonly used to calculate the shear strain in pure torsional deformation:

$$
\gamma=\frac{2 \pi N r}{t} \quad(2 \pi N=\theta)
$$

where $r$ is the distance from the axis of the disk type sample, $N$ is the number of rotations, $t$ is the thickness of the sample. In order to compare the shear strain in torsional deformation with the strain by other types of deformations such as rolling, Equation (2.3) is converted to equivalent Von Mises strain, as seen in Equation (2.4):

$$
\varepsilon_{e q}=\frac{\gamma}{\sqrt{3}}=\frac{2 \pi N r}{\sqrt{3} t}
$$

And the true logarithmic strain:

$$
\varepsilon_{\text {true }}=\ln \left(1+\varepsilon_{e q}\right)=\ln \left(1+\frac{2 \pi N r}{\sqrt{3} t}\right)
$$

Equation (2.6) was proposed in order to avoid negative strain values at small amounts of deformation [11]:

$$
\varepsilon_{\text {torsion }}=\ln \left(1+\gamma^{2}\right)^{1 / 2}
$$

These equations are written by assuming the thickness is independent of the rotation angle, $\theta$. Moreover, these equations give approximate results to real strain values. According to these equations, strain value changes linearly from zero at the center to 
its maximum value at the diameter. However, micro hardness measurements show that hardness values at the center of the samples increases as the torsional straining i.e. number of turns increases. Moreover, the initial thickness of the samples is reduced under high compression during deformation. So, the real strain values would be higher than the calculated ones due to the usage of $t$ as initial thickness.

Equation (2.7) is a better alternative to the equations above as it incorporates the reduction in thickness of the sample due to applied pressure [12] and its validity was also verified experimentally by M.V. Degtyarev et al. [11]:

$$
\varepsilon_{\text {true }}=\ln \left[1+\left(\frac{2 \pi N r}{t}\right)^{2}\right]^{\frac{1}{2}}+\ln \frac{t_{0}}{t}
$$

Although there are four different relationships for the variation of strain from the center through the periphery of the disks, Equation (2.7) is more realistic as it incorporates the reduction in thickness of the sample. Moreover, in case of HPT, it is better to consider the number of rotations instead of torsional strain.

At the same time the results of many investigations show that after several rotations under high hydrostatic pressure, severe deformation results in similar refinement of a microstructure in the center of samples as well.

The samples produced by HPT generally vary $10-20 \mathrm{~mm}$ in diameter and $0.2-10 \mathrm{~mm}$ in thickness. However, there is no limit for the diameter of the HPT disk, only the ratio of thickness $(\mathrm{t})$ to diameter $(\mathrm{d})$, should be less than a certain value in order to obtain homogenous deformation in most parts of the sample in the axial direction. According to R. Pippan et al. [4] this value (t/d) can even be approximately $1 / 5$. However, G. Sakai et al. [13] constructed a special HPT facility (Figure 2.2) in order to process cylindrical HPT samples with a $10 \mathrm{~mm}$ diameter and $8.57 \mathrm{~mm}$ height as well. 


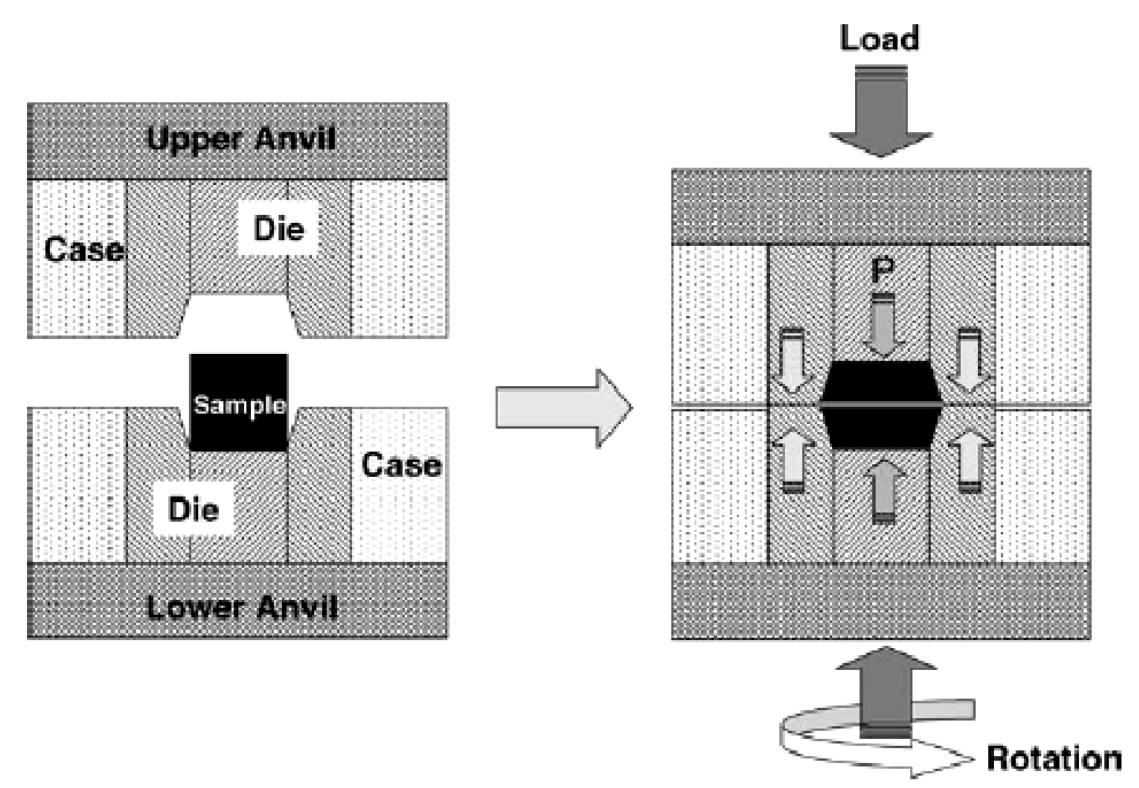

Figure 2.2 Special HPT facility to produce cylindrical components [13]

As mentioned before, the required pressure should be very high in order to avoid sliding between the anvils and the HPT sample, and it should be larger than the hardness of the sample material. The maximum pressure that can be applied is determined by the hardness of the tool material, for instance the limit for the usually used tools steels is approximately $8 \mathrm{GPa}$. Although there is no limit for the diameter of the disks, the required amount of torque should be considered as the necessary torque increases with $\mathrm{d}^{3}$. R. Pippan et al. [4] stated that, with the $400 \mathrm{kN}$ force, they were able to produce samples with the diameters up to $15 \mathrm{~mm}$ for low strength materials such as $\mathrm{Al}, \mathrm{Cu}$ and $\mathrm{Ni}$, and samples with the diameters up to $6 \mathrm{~mm}$ for the high strength materials such as rail steel.

\subsection{Magnetic Barkhausen Noise Technique}

The motion of an electric charge produces a magnetic field, as in the case of electrical current flowing through a wire. So, the spinning of electrons and the orbital motion around the nucleus of an atom produces a magnetic field. The direction of the spinning and orbital motion determine the direction of the magnetic field. The strength of this field is called the magnetic moment. 
In materials having completely filled levels contribute zero magnetic moment, since pairs of electrons in each level have opposite spin and cancel each other. Ferromagnetic materials like iron, cobalt and nickel occupy 4 s levels leaving vacant orbits in $3 \mathrm{~d}$ shell. Therefore in ferromagnetic materials, instead of canceling each other, moments line up by an exchange force of quantum mechanical nature [14].

In ferromagnetic materials, the magnetic moments of a relatively large number of atoms are aligned parallel to each other to create areas of strong magnetization within the material. These areas, which are approximately a millimeter in size, contain billions of aligned atoms and are called magnetic domains. A magnetic domain is the region in which the magnetic fields of atoms are aligned and grouped together. Figure 2.3 shows the shape of magnetic domains of $\mathrm{BaFe}_{12} \mathrm{O}_{19}$.

In an unmagnetized object all the magnetic domains are in different directions. When a magnetic field is applied to a ferromagnetic material, the domains which are aligned favorably with respect to the field grow while the size of the others decreases. At intermediate magnetic field, unfavorably aligned domains rotate from their initial direction of magnetization to one of the crystallographic easy axis (easy direction of magnetization), which is nearest to the field direction. And at higher magnetic fields, domains in which the magnetic moments are aligned along the preferred magnetic crystallographic easy axes lying close to the field direction are gradually rotated to the field direction. At saturation, this result in a single-domain sample [15]. It would quickly become unmagnetized when its magnetic domains returned to a random order so that the magnetic field strength in the piece of material is zero. Figure 2.4 shows the domain processes occurring during the magnetization of a ferromagnetic material. 


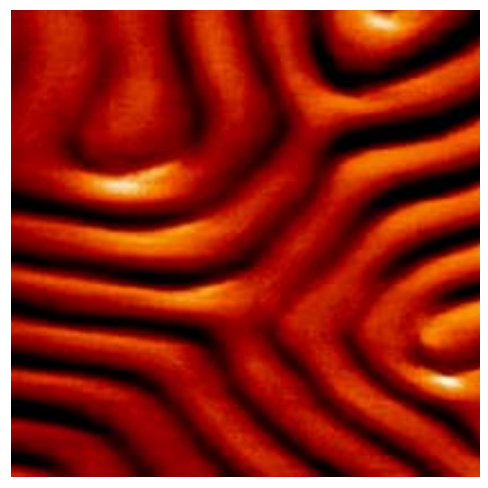

Figure 2.3 Magnetic domains of $\mathrm{BaFe}_{12} \mathrm{O}_{19}$ have been imaged with a scanning tunneling microscope [16]
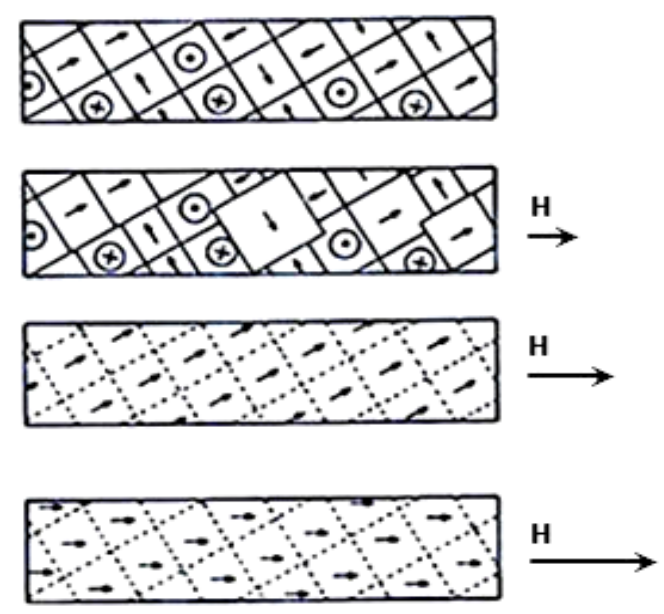

Figure 2.4 Domain processes occurring as a material is magnetized from demagnetized state to saturation magnetization [15]

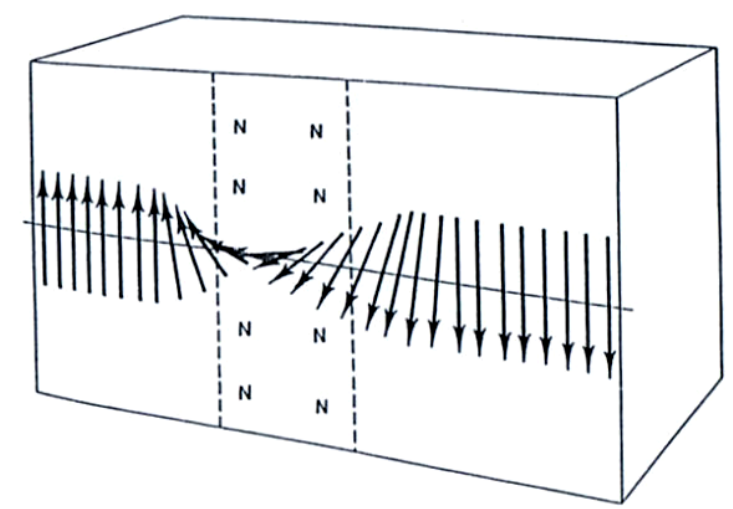

Figure 2.5 Alignment of individual magnetic moments within a $180^{\circ}$ domain wall [15] 
There are transition regions between domains, in which there is a reorientation of magnetic moments. These transition regions are referred as domain walls or Bloch walls as it was first suggested by Bloch [15]. Figure 2.5 and Figure 2.6 show the schematic view of alignment of magnetic moments within a $180^{\circ}$ domain wall and movement of domain walls when a magnetic field is applied to a ferromagnetic material respectively.

Figure 2.7 shows of migration of the domain walls in a doubly oriented silicon iron sheet with the application of the external magnetic field into the film plane which was observed by Lorentz-microscopy.

Under an applied magnetic field, those magnetic domains with magnetization vectors most closely aligned with the applied field increase in size at the expense of less favorably oriented domains (Figure 2.6). However, domain walls are not necessarily free to move under the influence of the external field. The displacement of walls can be temporarily retarded by local pinning sites such as dislocation tangles, cells, inclusions, and grain boundaries. As the domain walls are not free to move due to those pinning sites, local magnetization variations occur (Figure 2.8) which gives rise to Barkhausen effect. It occurs at intermediate fields, in the steep part of the magnetization curve, and is evidenced by small discontinuous changes in magnetization. If a coil of conductive wire is placed near the sample during the domain wall movement, the resulting change in magnetization will induce an electrical pulse in the coil. When all of these pulses produced by all domain movements are added together, Barkhausen noise $(\mathrm{BN})$ is generated. 


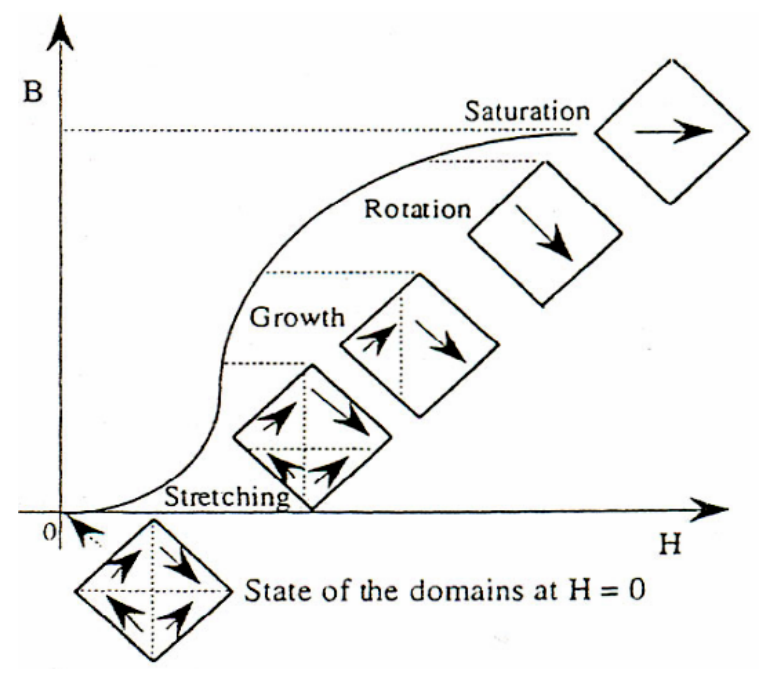

Figure 2.6 Domain wall movement when a magnetic field is applied [14]
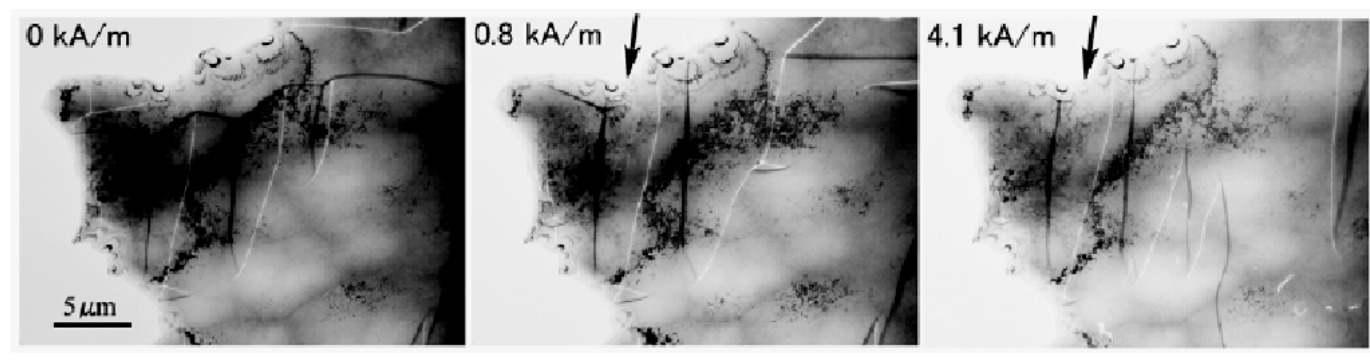

Figure 2.7 In situ Lorentz-microscopic observation of migration of the domain walls in a doubly oriented silicon iron sheet with the application of the external magnetic field into the film plane. The large arrow indicates the direction of applied magnetic field [17]

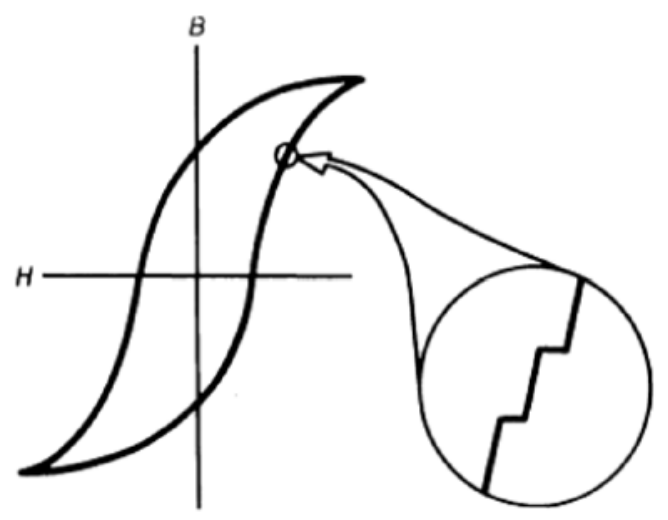

Figure 2.8 Hysteresis loop for magnetic material showing discontinuities that produce Barkhausen noise [18] 
As the Barkhausen noise is strongly affected by the microstructural condition, residual stress state and grain size of ferromagnetic materials, Magnetic Barkhausen Noise (MBN) method can be used in order to nondestructively evaluate the specimens.

This effect was first observed in 1919 by Heinrich Georg Barkhausen when a secondary coil was wound on a piece of iron and connected to an amplifier and loudspeaker. As the magnetic field increased smoothly a series of clicks were heard over the loudspeaker which were due to the small voltage pulses induced in the secondary coil [15].

The simple experimental setup for MBN measurements is depicted in Figure 2.9. Typical signals give $\mathrm{BN}$ in volts versus applied magnetic field $(\mathrm{H})$, although some commercial devices may also give other parameters. Typical Barkhausen noise signal gives the RMS envelope (Figure 2.10). BNA represents the maximum amplitude of the envelope and $\mathrm{H}$ peak the corresponding magnetic field. There are other parameters that can be obtained from MBN measurements. Frequency/Amplitude spectrum gives the frequency distribution of the signal; pulse height distribution shows the size distribution of pulses in terms of height (V); a hysteresis curve which is representative because small region of samples are magnetized during MBN. It should be noted that the total volume of the sample should be magnetized to saturation magnetization in order to obtain a correct hysteresis loop.

During MBN measurements eddy currents arise which affect the depth to be analyzed. Practically, the depth that can be analyzed by MBN measurements varies between 0.05-0.5 mm.

Both domain rotation and discontinuous domain boundary motion contribute to the Barkhausen effect; however discontinuous domain boundary motion is the dominant factor [15]. 


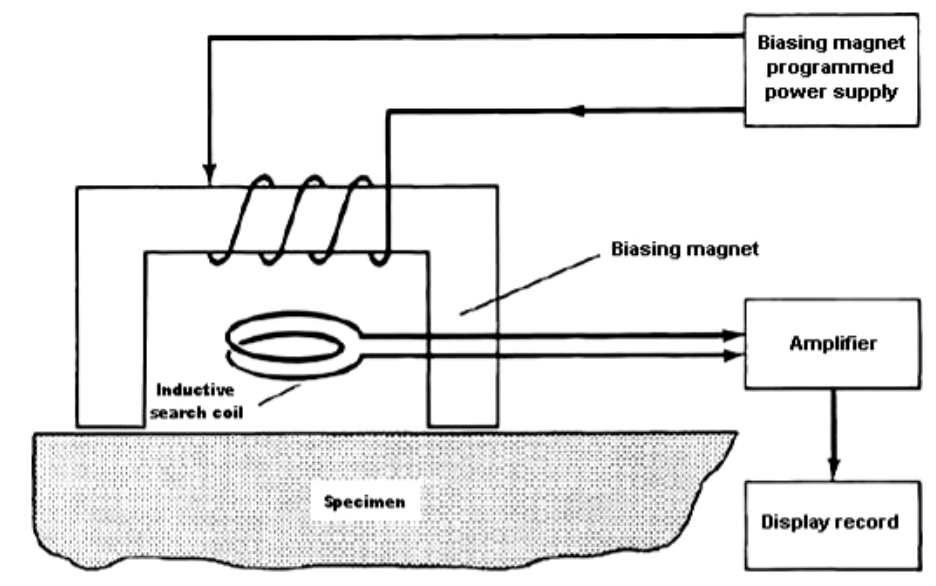

Figure 2.9 Schematic figure of the experimental setup of MBN measurement [18]

(a)
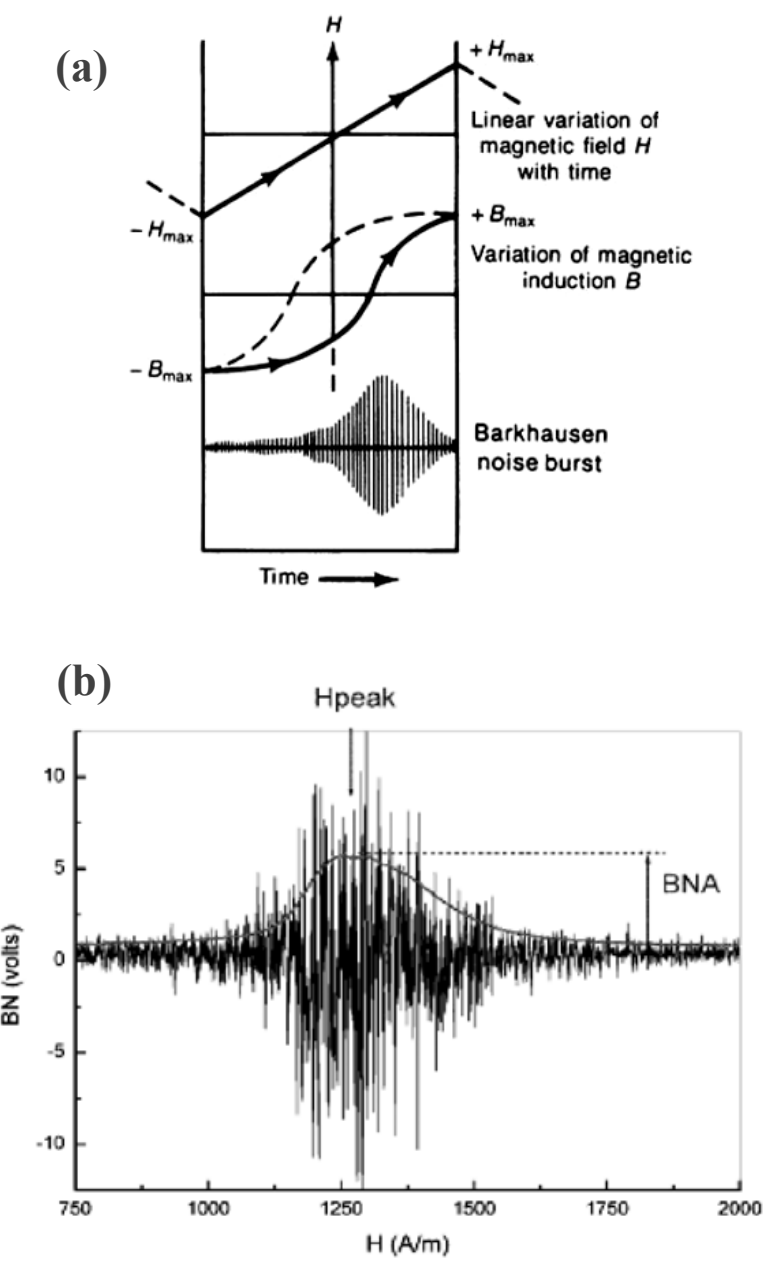

Figure 2.10 (a) Schematic figure showing the change in magnetic field $H$ with time, variation in flux density over the same period, and the generation of the Barkhausen noise burst as flux density changes [18], (b) Typical BN signal [19] 
There is another effect of sudden discontinuous domain-wall motion which is called Magnetoacoustic emission or acoustic Barkhausen effect. This effect consists of bursts of low-level acoustic energy generated by sudden discontinuous changes in magnetization involving localized strains or magnetostriction (strain arising from the magnetization of a ferromagnetic material), which can be detected by an ultrasonic transducer. While the Barkhausen effect can occur due to the discontinuous motion and rotation of either $180^{\circ}$ or non- $180^{\circ}$ domain walls, magnetoacoustic emission occurs only by the discontinuous motion or rotation of non- $180^{\circ}$ domain walls. As the relative density of $180^{\circ}$ and non- $180^{\circ}$ domain walls are affected by the application of uniaxial stress, this method has been suggested as a means of detecting stress in ferromagnetic materials [15].

When a domain wall is released from a pinning site, it jumps suddenly and sweeps a volume that is proportional to the change in magnetization $d M$. The rate of change in magnetization $d M / d t$ induces an electromotive force (emf) in the nearby induction coil. In the case of multiple unpinning events, the $\mathrm{BN}$ signal $\left(V_{B N}\right)$ is given by Equation (1.8);

$$
V_{B N}=N A_{c} \mu_{0} n(H) \frac{d M}{d t}
$$

Where $n(H)$ is the number of unpinning events, which varies as the magnetization proceeds and is therefore in general a function of $H$. The second component of Equation (1.8), "N $A_{c} \mu_{o} d H / d t$ ", does not contribute to the detected BN signal after the signal is filtered by a band-pass filter with a lower cut-off frequency much higher than the magnetizing field frequency [20]. There are three major factors that govern $n(H)$ of Equation (1.8);

- the grain size of the sample,

- the size of defects which act as pinning sites for domain walls,

- the physical nature of the pin that dictates the restoring force acting on the wall. 
The term, $n(H)$, depends on the number of defects that interact with domain wall. Large planar pinning sites for domain walls, such as grain boundaries or large structural defects, can be treated as a population of localized highly dense small pins. In such a case, the value of $n(H)$ will be relatively large for a single event of the unpinning of domain wall from a large planar pinning site, and the $\mathrm{BN}$ signal thus generated is expected to be large according to Equation (1.8). This idea can also be applied to the nucleation of domain wall that usually occurs at some of the large planar defects.

The grain size $(D)$ of the sample strongly influences the number of defects within its matrix. D.H.L. $\mathrm{Ng}$ et al. [20] have found a combination of the relationships of the number of dislocations $(N)$ and grain size $(D)$ with coercive force. The combination of these relationships is:

$$
N \sim D^{-1}
$$

Therefore, for a given type of a material, a large grain sample will have fewer defects, thus the number of emission sites (or $n(H)$ ) for $\mathrm{BN}$ is lower. Moreover, it is known that $D$ also governs the volume fraction of the grain boundaries $\left(V_{\mathrm{GB}}\right)$ and the relationship between them is given by [20]:

$$
V_{G B} \sim D^{-1.1}
$$

Thus, a small-grain sample will have a large area of grain boundary which will act as pinning sites that hinder the motion of DW.

It is reasonable to assume that the number of unpinning events $n(H)$ at a given field is larger if the pinning force $(f)$ that hinders the motion is weaker, because many of the DWs can then be released easily. To summarize the qualitative model, $V_{B N}$ is large for small grain sample that has a higher number of defects (pinning sites or grain boundary) since the number of unpinning events of DWs is relatively high. 
The model used by D.H.L. Ng and coworkers [20] states that the BN signals are governed by both the rate of change of magnetization $d M / d t$ and the number of unpinning events $n(H)$ of the domain walls. The stronger BN signal emitted from the small grain sample is due to the presence of extra grain boundaries. These boundaries can be considered as a large population of localized small pins, when the domain wall is released, large BN signal is obtained because the number of domain wall unpinning events is large. Thus, the size of the grains strongly affects the BN signals. 


\section{CHAPTER 3}

\section{LITERATURE REVIEW}

\subsection{Grain Refinement by HPT}

The key factor in structure refinement in SPD is the material fragmentation by new high angle grain boundaries with their transformation to spatially organized and stable grains. Strain induced high angle boundaries (HABs) should be spatially organized in stable and sufficiently equilibrium configurations. Deformation proceeds by localization of deformation, fast appearance of HABs and intensive rotation of material fragments. When localization proceeds, the density of HABs and other defects increase greatly. Rolling with high reductions results in planar high angle deformation bands associated with cells/subgrains but not with new grains. For tradition forming operations such as rolling or extrusion with large reductions and dry friction, near simple deformation mode is attained in the vicinity of contact surfaces where corresponding structure refinement may be observed at some conditions [21].

The enhancement of strength and ductility of UFG metals is attributed to the increase of the fraction high angle grain boundaries [22]. Another important feature of ultrafine grain materials produced by SPD techniques is the occurrence of nonequilibrium grain boundaries which is important for alloys produced by SPD because it may contribute to the formation of grain boundary segregations and precipitations that result in poor mechanical properties. The brittle behavior of the aluminum alloy $1570\left(\mathrm{Al}-5.7 \% \mathrm{Mg}-0.32 \% \mathrm{Sc}-0.4 \% \mathrm{Mn}\right.$ ) which was HPTed at $200^{\circ} \mathrm{C}$ is attributed 
to decay of the solid solution-strain age hardening accompanied by segregation of alloying elements along boundaries of formed UFG grains [22].

In the nanometer range of grains, deformation is generally is due to (i) a change in the bulk of a solid or crystal, (ii) displacement of one part of the crystal relative to the other and (iii) simple shear of one part of the crystal relative to the other [7].

R.Z. Valiev and I.V. Alexandrov [23] reported that the processed materials are characterized either by the presence of ultrafine grains and also by the specific defect structure attributed to high density of extrinsic grain boundary dislocations resulting in crystal lattice distortions. A.P. Zhilyaev et al. [12] concluded that the homogeneous microstructures of pure Ni samples produced by HPT contain larger fractions of low-angle, twin and special boundaries, but a smaller fraction of highangle random boundaries than anticipated in a random distribution.

Lugo et al. [24] studied the effect of both Equal Channel Angular Pressing (ECAP) and HPT to grain size distribution and they found that the grain size distribution of ECAPed and HPTed samples was more homogenous. Moreover, the final grain size obtained by HPT is smaller than the one obtained by ECAP. The effect of applied hydrostatic pressure on mechanical properties was also studied by Wetscher et al. [25], they studied with Armco iron and pure copper, and experienced that the necessary torque to deform the sample increases with pressure and the effect of hydrostatic pressure is very small on the tensile strength of the samples which are deformed to the saturation regime.

\subsection{Effect of Stacking Fault Energy on Grain Refinement}

Stacking fault is a defect in which there is a change from the regular sequence of positions of atomic planes. Stacking fault energy (SFE) affects the ability of dislocations for cross slip from one slip plane to another. So, SFE modifies the recovery rate and the magnitude of the strain to be induced for SPD. Lower the SFE the greater the separation between the partial dislocations and the wider the stacking 
fault [26]. In order to deform the materials that have low SFE, such as stainless steel, higher strains should be imposed as the dislocation climb and cross-slip would be difficult. Recovery rate is slower so the microstructural evolution will be slower and higher strains will be needed in order to achieve microstructural homogeneity [5]. However, in the case of materials that have high SFE, such as aluminum, the partial dislocations are not widely separated and they can easily leave the slip plane. So, the recovery rate is faster. Thus, in materials with lower SFEs it becomes more difficult for the dissociated dislocations to recombine and cross-slip, and this impedes the recovery process and leads to a smaller value of average grain size.

\subsection{Hardness Distributions After HPT}

A.P. Zhilyaev et al. [12] stated that reasonably homogeneous microstructures may be attained throughout the samples, including in the central region, when the applied pressure and the number of revolutions $(\mathrm{N})$ are both sufficiently high, at $\sim 6 \mathrm{GPa}$ and $\sim 5$ revolutions. Increasing hydrostatic pressure enables obtaining ultra-fine grained and nanograined material due to the restricted diffusion which results in increased dislocation density and decreased dislocation annihilation. However, there is no further increase in hardness after a certain value of hydrostatic pressure which is explained by the generation and annihilation of dislocations simultaneously [27].

C. Xu et al. [28] worked with commercial purity and high purity aluminum and they concluded that there is a gradual evolution towards homogeneous hardness distributions across the HPT disks up to 5 turns. Moreover, the higher hardness values at the central regions of the disks in the initial stages of processing were attributed to fast dynamic recovery of material. This is related with high stacking fault energy of pure aluminum, so that partial dislocations are not widely separated and dislocation climb and cross-slip is easier.

For materials having low stacking fault energies and slow recovery rates, it is anticipated that higher levels of hardness will be reached in the peripheral region in 
the early stages of HPT as shown by numerous experiments. By contrast, materials such as high purity aluminum have high stacking fault energy so that the measured hardness initially will be high in the central region because of the advent of dynamic recovery in the peripheral region [5].

\subsection{Ultrafine Grained Steels Processed by HPT}

According to the study of S.V. Dobatkin, P.D. Odessky and S.V. Catalina [29], HPT of low carbon steels at a temperature below $0.3 \mathrm{~T}_{\mathrm{m}}\left({ }^{\circ} \mathrm{C}\right)$ to the true strain of 4-6 leads to the formation of nanocrytalline structure with a grain size of $<100 \mathrm{~nm}$ or a mixture of oriented substructure and nanograins. The inital martensitic state results in finer grains with compared to ferritic-pearlitic initial microstructure due to the much higher dislocation density and the presence of fine carbides. Moreover, micro hardness value for certain steel in a certain initial state is almost not dependent on deformation temperature between $20^{\circ} \mathrm{C}$ and $500^{\circ} \mathrm{C}$.

E.G. Astafurova et al. [30] studied the microstructural characterization of $\mathrm{Fe}-1.12$ Mn $-0.08 \mathrm{~V}-0.07 \mathrm{Ti}-0.1 \mathrm{C}$, wt. \% steel HPTed by 5 turns at room temperature with a $6 \mathrm{GPa}$ pressure, and the corresponding logarithmic true strain of 6.3 . They reported a hardness increase from $1.92 \mathrm{GPa}$ to $6.44 \mathrm{GPa}$ after HPT for ferriticpearlitic initial microstructure and $3.02 \mathrm{GPa}$ to $7.22 \mathrm{GPa}$ after HPT for martensitic initial microstructure. For the X-ray measurements, they concluded that HPT decrease the intensity of X-ray peaks and makes them wider compared to nondeformed states.

Yu. Ivanisenko et al. [31] compared the annealing behavior of HPTed and quenched UIC 860 (0.6-0.8 wt. \% C, 0.8-1.3 wt. \% Mn) steel. They concluded that the HPTed steel have $10 \mathrm{~nm}$ grain size and consists of a supersaturated solid solution of carbon in ferrite. The hardness of the HPTed steel is somewhat higher than the as-quenched sample and it preserves its hardness up to $350^{\circ} \mathrm{C}$ because of that carbide precipitation upon tempering is retarded in HPTed sample due to the location of carbon atoms in dislocation cores at non-equilibrium grain boundaries. 
Severe plastic deformation of high carbon $(1.2 \mathrm{wt}$. \% C) steel is also an interesting example of the formation of the metastable states. The investigated steel was in a normalized state and had a pearlite structure with an excess content of cementite. HPT $(e=7, P=6 \mathrm{GPa}$ ) resulting in the formation of an extremely disperse structure with a grain size of $20 \mathrm{~nm}$ which was accompanied by complete dissolution of cementite. The obtained nanostructure presented the supersaturated solid solution of carbon in $\alpha$-iron [1].

Although the mechanical properties of HPTed metals are mostly mentioned, there is also evidence for the kinetic properties of metallic properties such that the kinetics of plasma nitriding of several steels is accelerated significantly by a pre-treatment using HPT [3].

\subsection{Magnetic Behavior After HPT}

The formation of ultra fine grain structure leads to changes in fundamental magnetic characteristics such as the saturation magnetization and coercivity.

S. Scheriau et al. [32] studied the effect of SPD to magnetic properties of FeSi, FeCo, and FeNi alloys and they concluded that with decreasing grain size the soft magnetic behavior shifts towards hard magnetic behavior. And for grain sizes smaller than $\sim 80$ $\mathrm{nm}$ the magnetic properties become again soft magnetic which is explained by the smaller grain size than the ferromagnetic exchange length which is on the order of domain wall width. Their experiments showed that very low values of coercivity can be obtained by SPD if the grain size is smaller than $\sim 50 \mathrm{~nm}$. In the study Yu. Ivanisenko et al. [31] Magnetic behavior of HPTed and quenched UIC 860 (0.6-0.8 wt. \%C, 0.8-1.3 wt. \%Mn) steel were compared and HPTed sample showed a little higher saturation magnetization than the quenched one.

A significant increase in the coercive force $\mathrm{H}_{\mathrm{c}}$ was also observed in hard magnetic alloys processed by SPD. This is very important for practical application and manufacture of permanent magnets. However, the origin of $\mathrm{H}_{c}$ changes in these 
alloys has a more complex character and it is caused not only by the formation of a nanostructure but also by changes in the phase composition [1].

\subsection{Effect of Grain Size on MBN}

As grains become coarser, domain size increases and domain density decreases. Consequently MBN peak height and RMS values decrease. The increase in grain size leads to decrease of grain boundary area per unit volume and so to the difficulty in nucleation of domains. This results decrease in Barkhausen jumps and decrease in MBN activity. However, grain boundary segregation in some specimens alters the magnetic structure and increase the MBN activity [14].

Sakamoto et al. [33] concluded that the root mean square (RMS) value of MBN signals occurred in ferrite grains is inversely proportional to the square root of the grain size:

$$
R M S=C_{g} \cdot d^{-\frac{1}{2}}
$$

Where $d$ is the average grain size, $C_{g}$ is a constant which depends on grain size and given by:

$$
C_{g}=\frac{(d H / d t)}{8 \sqrt{2 \pi} H_{\max }}(N . \Delta \Phi)\left(\frac{9.3 C_{v} t_{t o t a l} \gamma^{\frac{5}{4}}}{I_{s} K^{\frac{1}{4}}}\right)^{2}
$$

where $H$ is the magnetic field strength, $N$ the total number of voltage pulses in the cross sectional unit area of a specimen, $\Delta \Phi$ is the quantity of magnetic flux change in a micro region, $C_{v}$ is a constant, $t_{\text {total }}$ is the total time of generation of pulses, $\gamma$ the wall energy per unit area, $I_{s}$ the saturation magnetization and $K$ the magnetic anisotropy constant. 
In the study of J. Anglada-Rivera and coworkers [34], it was concluded that size of magnetic domains is proportional to square root of grain diameter. Thus, for samples with fine grain, the number of domains and walls that can move is much bigger.

\subsection{Effect of Tensile Deformation and Cold Rolling on MBN}

M. Küpferling et al. [35] investigated the effect of tensile deformation and cold rolling on MBN signals. They found that power spectrum of the noise increases with tensile straining and cold working for high frequencies however it decreases for low frequencies as low frequencies enable to get data from the core of the samples. Moreover they added that plastic deformation deteriorates the soft magnetic properties of steels, leading to a decrease of permeability, increase in coercivity, decrease in remanance for tensile strained interstitial-free (IF) steels.

Another study of the effect of tensile deformation on MBN was done by A. Dhar and coworkers [36]. They studied the effect of uniaxial plastic deformation on hot rolled AISI 1020 steel plates and explained the results by dislocations-domain wall interactions. They concluded that there is an initial increase in MBN energy (integration of the square of the voltage signal with respect to time) with increasing plastic strain followed by a decrease at higher plastic deformations. At higher deformations $\mathrm{MBN}$ energy was found to be independent of strain.

T. Liu et al. [37] studied the effect of cold working on MBN for mild steel $(0.15 \% \mathrm{C})$ and concluded that as the rolling ratio increases, the dislocation density grows bigger and domain wall passes much more pinning sites and gives rise to stronger MBN. High rolling ratio induces a large number of smaller cell structures namely the boundary area increases, which results in low MBN signal. Therefore, the total MBN response tends to saturate at high rolling ratio. For the frequency spectrum, cold rolling does not tend to change the peak position, but amplitude increases.

At high plastic strains dislocation tangles form, which are areas of high dislocation density, form very strong pinning sites which cannot be unpinned by the applied 
field, and render many of the domain walls immobile. Consequently, BN decrease. With further increase in strain, the same situation continues as the cellular structure of dislocations evolves, which consists of high density dislocation walls. These are the higher pinning energy centers that retard the domain wall motion and give rise to decrease in $\mathrm{BN}[38]$.

\subsection{Change of MBN in the Elastic and Plastic Region of Deformation}

X. Kleber and A. Vincent [38] studied the effect of elastic and plastic region of deformation to Armco Iron (AI) (0.01 C, 0.1 Mn, 0.01 P, 0.008 S, 0.03 Cu and 0.006 $\mathrm{N}$ wt. \%) and a low carbon steel (0.07 C, 0.43 Si, 1.38 Mn, 0.01 P and 0.037 Al wt. $\%)$. In elastic region, the higher MBN activity under a tensile stress is linked with easy $180^{\circ}$ domain walls movements. However for compressive stress there is creation and motion of $90^{\circ}$ domain walls, which explains the low MBN activity and the appearance of second peak in MBN fingerprint. In tensile region, a critical stress exists after which magnetization along [111] can arise; activity linked with $180^{\circ}$ domain walls is decreased. In plastic region, influence of plastic deformation should be discussed both in terms of residual stresses (type II, microstresses) which are left due to the inhomogenity of plastic deformation and in terms of domain wall dislocation interactions.

For Armco Iron (AI), there is a steep increase of BNA versus plastic strain that occurs both following tensile and compressive deformations which can only be attributed to the dislocation tangles domain wall interactions. BNA \& MBN signatures induced by plastic deformation are quite consistent with a major influence of internal stresses if intragranular origin in $\operatorname{LCS}(0.07 \mathrm{C}, 0.43 \mathrm{Si}, 1.38 \mathrm{Mn}, 0.01 \mathrm{P}$ and $0.037 \mathrm{Al}$ wt. \%), while the dislocation (tangles, cell walls) - domain wall interactions would control the MBN increase observed in AI.

Inhomogenity of plastic deformation from grain to grain is the first source of residual stress (intergranular residual stress) which is prevalent in the range $0.1-1 \%$ of 
deformation, for $\varepsilon_{\mathrm{p}}>1 \%$ intragranular residual stresses become prevalent. Such stresses are linked to the spatial heterogeneity of dislocation distribution.

M. Alberteris Campos et al. [39] studied the effect of tensile deformation on AISI 1070 steel and concluded that the area of MBN energy increased up to elastic limit, then showed a decrease through plastic region.

In the study of J. Anglada-Rivera and coworkers [34], MBN activity increased up to critical stress as the $180^{\circ}$ domain walls are favored. After exceeding the critical stress, induced stress anisotropy starts. This effect increases the pinning sites and so obstructs the movement of domain walls which leads to gradual decrease of the maximum amplitude of MBN voltage. 


\section{CHAPTER 4}

\section{EXPERIMENTAL PROCEDURE}

Two sets of samples were prepared by cutting from two steel rods, with $10 \mathrm{~mm}$ and $20 \mathrm{~mm}$ diameter. The chemical compositions of the samples have been found by applying arc emission spectroscopy via WAS Foundry Master Spectroscope to the reference samples from three different regions. The average values of the results are given in Table 1 , the error in analysis is $0.2 \%$.

Table 4.1 Chemical composition of the samples in wt. \%, the rest is Fe

\begin{tabular}{|ccc|}
\hline Element & $1^{\text {st }}$ set & $2^{\text {nd }}$ set \\
$\mathrm{C}$ & 0.203 & 0.172 \\
$\mathrm{Si}$ & 0.266 & 0.118 \\
$\mathrm{Mn}$ & 0.565 & 0.364 \\
$\mathrm{P}$ & 0.017 & 0.013 \\
$\mathrm{~S}$ & 0.028 & 0.020 \\
$\mathrm{Ni}$ & 0.157 & 0.026 \\
$\mathrm{Cr}$ & 0.079 & 0.012 \\
$\mathrm{Mo}$ & 0.029 & 0.010 \\
$\mathrm{Cu}$ & 0.009 & 0.008 \\
\hline
\end{tabular}

After austenitizing $\left(880^{\circ} \mathrm{C} / 20 \mathrm{~min}\right)$, the samples were quenched, and then, annealed at $600^{\circ} \mathrm{C}$ for 1 hour to relieve residual stresses and to obtain uniform microstructure. Heat treated rod was cut into disks; the initial thickness of the first set of samples 
was $1 \mathrm{~mm}$ and the second set of samples was $1.15 \mathrm{~mm}$ which were measured via a caliper with $0.1 \mathrm{~mm}$ sensitivity. The variation of thickness throughout the crosssection of the samples is minor, for instance the thickness of the most severely deformed sample in the second set of samples varies between 0.8-0.9 mm. The torsional deformation with $6 \mathrm{GPa}$ pressure has been applied to all samples at $300^{\circ} \mathrm{C}$ with an average speed of $0.01251 / \mathrm{s}(=0.751 / \mathrm{min})$. The first set of samples with 10 $\mathrm{mm}$ diameter have been produced by unconstrained HPT and the second set of samples with $20 \mathrm{~mm}$ diameter have been produced by constrained HPT (Figure 1.4).

Vickers microhardness measurements were conducted by a Shimadzu microhardness tester. $4.903 \mathrm{~N}$ load was applied for 10 seconds and the measurable region was up to $\pm 8 \mathrm{~mm}$ and $\pm 4 \mathrm{~mm}$ away from the center of the samples for $20 \mathrm{~mm}$ and $10 \mathrm{~mm}$ disks respectively. The error was calculated as $3 \%$ by making hardness measurements on the reference sample supplied by the device manufacturer. The distance between each measurement point was $1 \mathrm{~mm}$ for $20 \mathrm{~mm}$ disks and $0.5 \mathrm{~mm}$ for $10 \mathrm{~mm}$ disks, and 3 measurements were taken for each point, so there are 51 measurement points on each sample. The schematic representation of the hardness measurements for the second set of samples, which has been produced by constrained HPT, is shown in Figure 4.1.

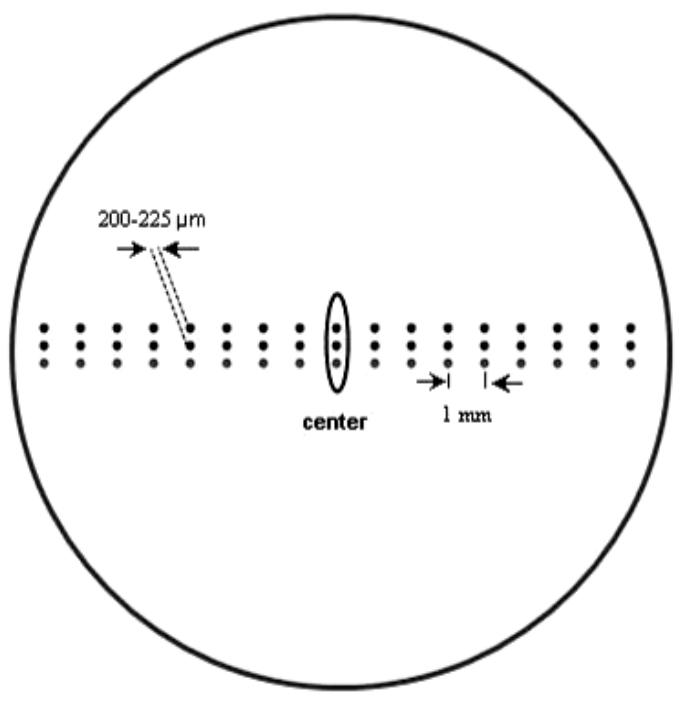

Figure 4.1 Schematic representation of the hardness measurements for the second set of samples, which has been produced by constrained HPT 
Nikon optical microscope was used to characterize the microstructure of the samples. Scanning Electron Microscope (SEM) examination was also done in order to see the microstructure of the mostly deformed samples in both set of the samples with a higher magnification by using a QUANTA 400F Field Emission SEM. Conventional metallographic sample preparation procedure was followed and the samples were etched in 2\% Nital solution for 15 seconds and in Picral solution for 30 seconds.

X-Ray Diffraction (XRD) measurements were conducted by Rigaku X-Ray Diffractometer under room temperature conditions, $\sim 25^{\circ} \mathrm{C}$. The target metal was $\mathrm{Cu}$ the wavelength of which is, $\lambda_{\mathrm{Cu} \mathrm{K} \alpha}=1.5405 \AA$. Initially, a full scan were collected for the reference sample over ranges $2 \theta=30^{\circ}-160^{\circ}$ scans by 0.5 minutes per degree and then 2 peaks were selected for detailed analysis in the ranges $2 \theta=80^{\circ}-85^{\circ}$ and $2 \theta=114^{\circ}-119^{\circ}$. The XRD for the two peaks in these intervals was done by 8 minutes per degree.

Magnetic Barkhausen Noise (MBN) measurements were conducted by Stresstech $\mu$ Scan 500-2 device (Figure 4.2) which consists of a sensor, a computer with network interface and software for data acquisition. During the measurements, excitation frequency of the magnetic field was $125 \mathrm{~Hz}$, magnetizing voltage was 10 $\mathrm{V}$, filtering was done between $0.5-500 \mathrm{kHz}$ and the number of bursts (the number of magnetizing half cycles or Barkhausen Noise bursts that will be stored for signal analysis) was 186. The sensor used for the MBN measurements was S1-138-13-01 (Figure 4.3). MBN measurements of the first set of samples, which have been produced by unconstrained HPT, were done only on the center of the disks due to the small size. However, MBN measurements for the second set of samples, which have been produced by constrained HPT, were done by moving the sensor with $1 \mathrm{~mm}$ intervals through the radius with the help of the experimental setup prepared (Figure 4.4). By using the sensor shown in Figure 4.3 and the experimental setup in Figure 4.4, the farthest measurable distance was $7 \mathrm{~mm}$ away from the center for the second set of samples. All the measurements were done parallel to deformation direction as the density of $180^{\circ}$ domain walls increase in the deformation direction and give rise to higher MBN signals. 


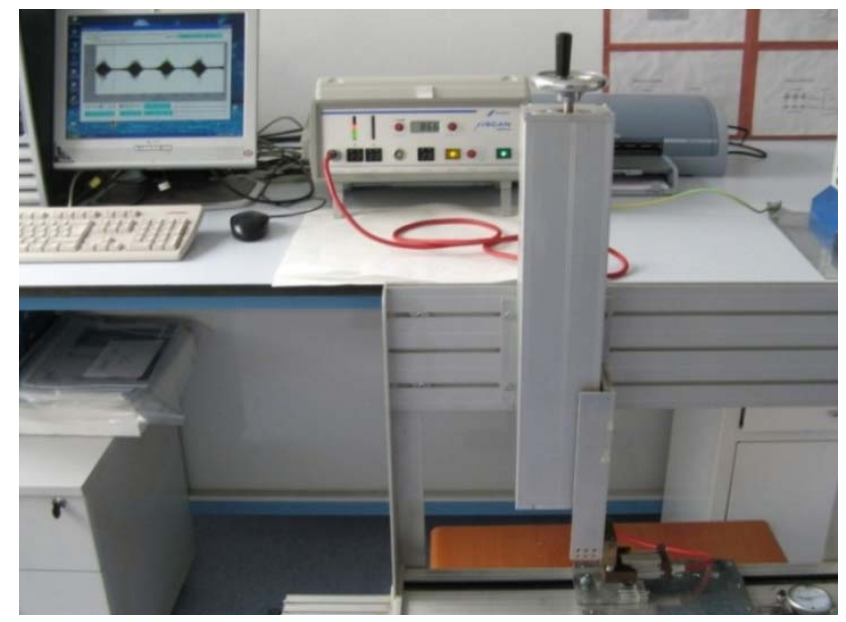

Figure 4.2 The MBN measurement system used in this study

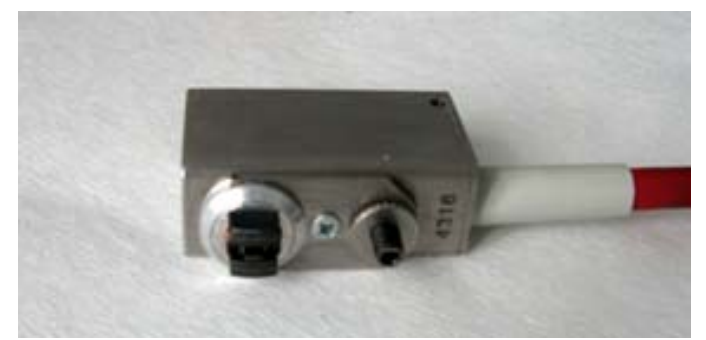

Figure 4.3 The sensor used for the MBN measurements

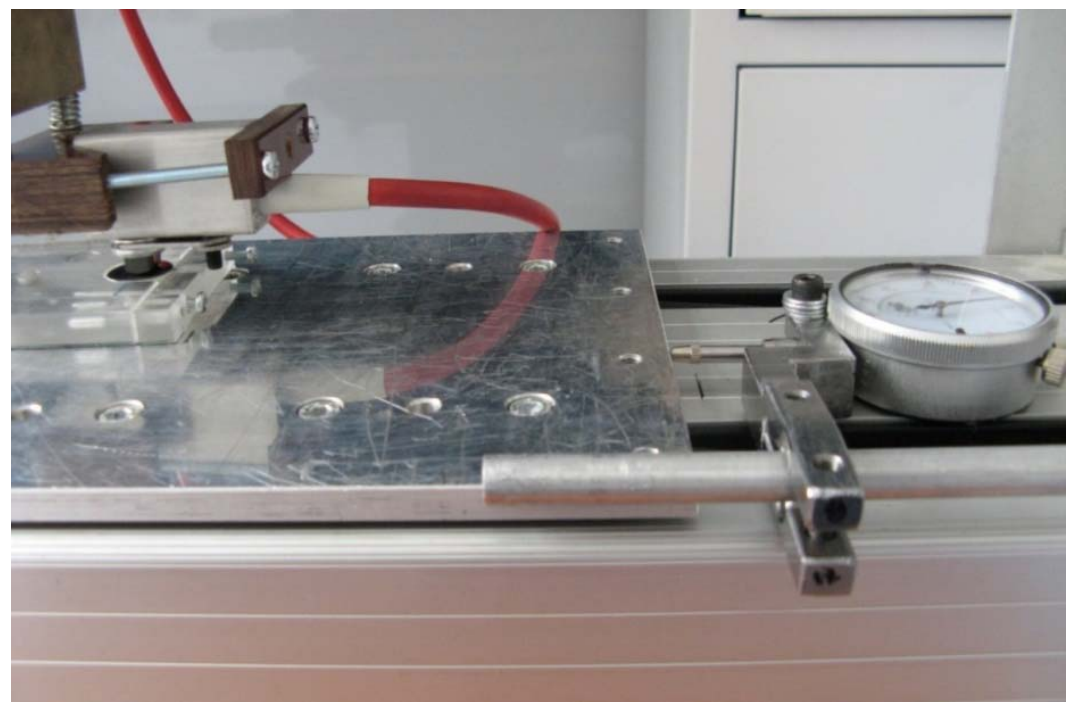

Figure 4.4 The experimental setup prepared for the second set of samples, which have been produced by constrained HPT, in order to move the sensor horizontally by $1 \mathrm{~mm}$ intervals via comparator at the right side 
All the microhardness and MBN measurements were done through the upper side of the disks which stands below the rotating anvil during HPT. However, both sides of the disks are almost equally strained (Figure 4.5).

(a)

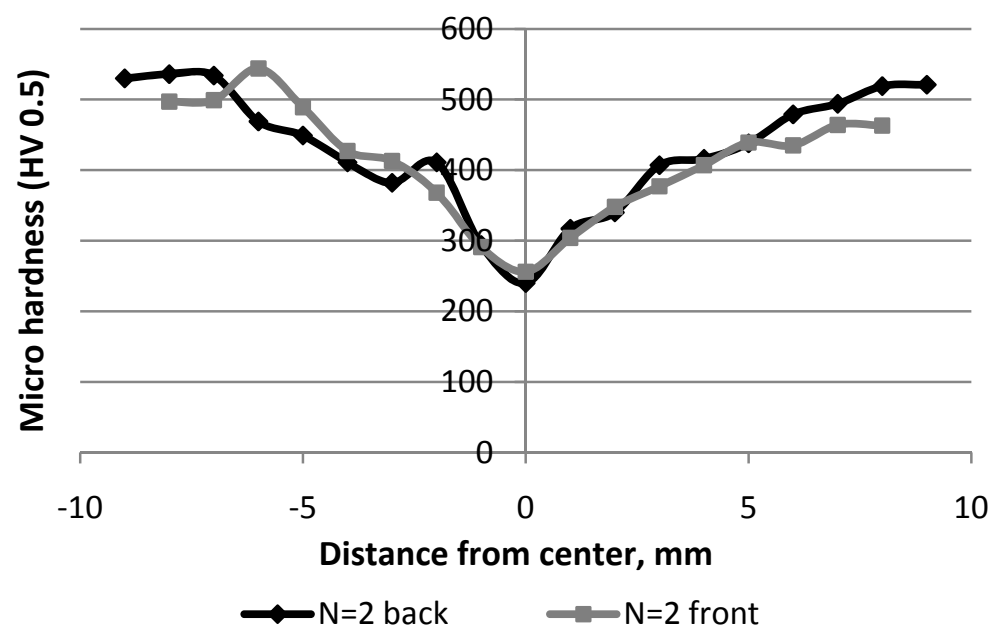

(b)

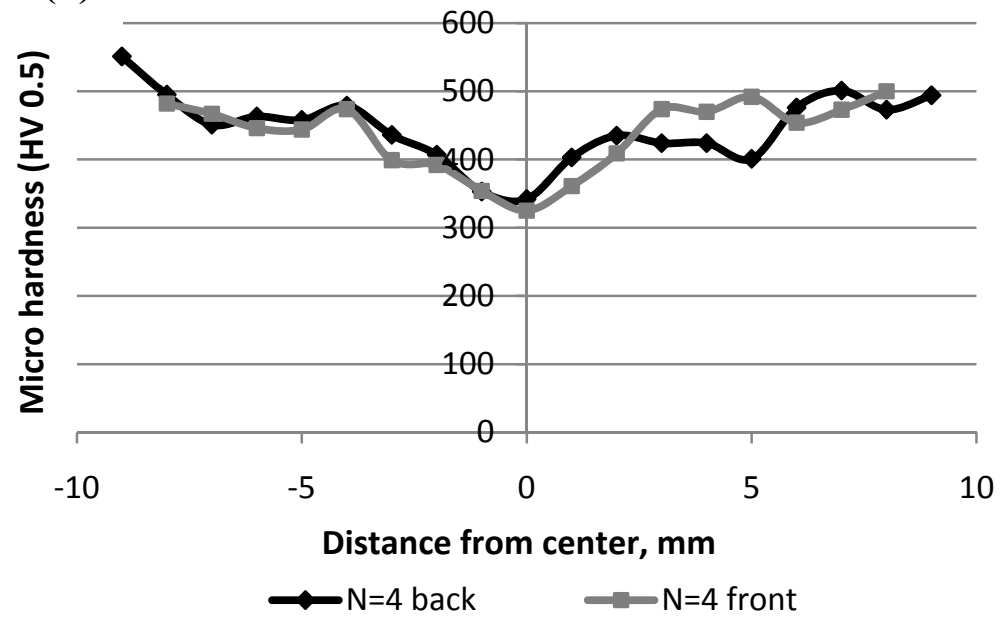

Figure 4.5 Hardness distribution for $\mathrm{N}=2$ (a) and $\mathrm{N}=4$ (b) from the second set of samples, which have been produced by constrained HPT, showing that both sides of the samples are almost equally strained 


\section{CHAPTER 5}

\section{RESULTS}

\subsection{The Samples Produced by Unconstrained HPT}

\subsubsection{Hardness and MBN}

The results of the microhardness and MBN measurements for the first set of samples, which have been produced by unconstrained HPT (Figure 1.4(a)), are given in Figure 5.1 and Figure 5.2 respectively.

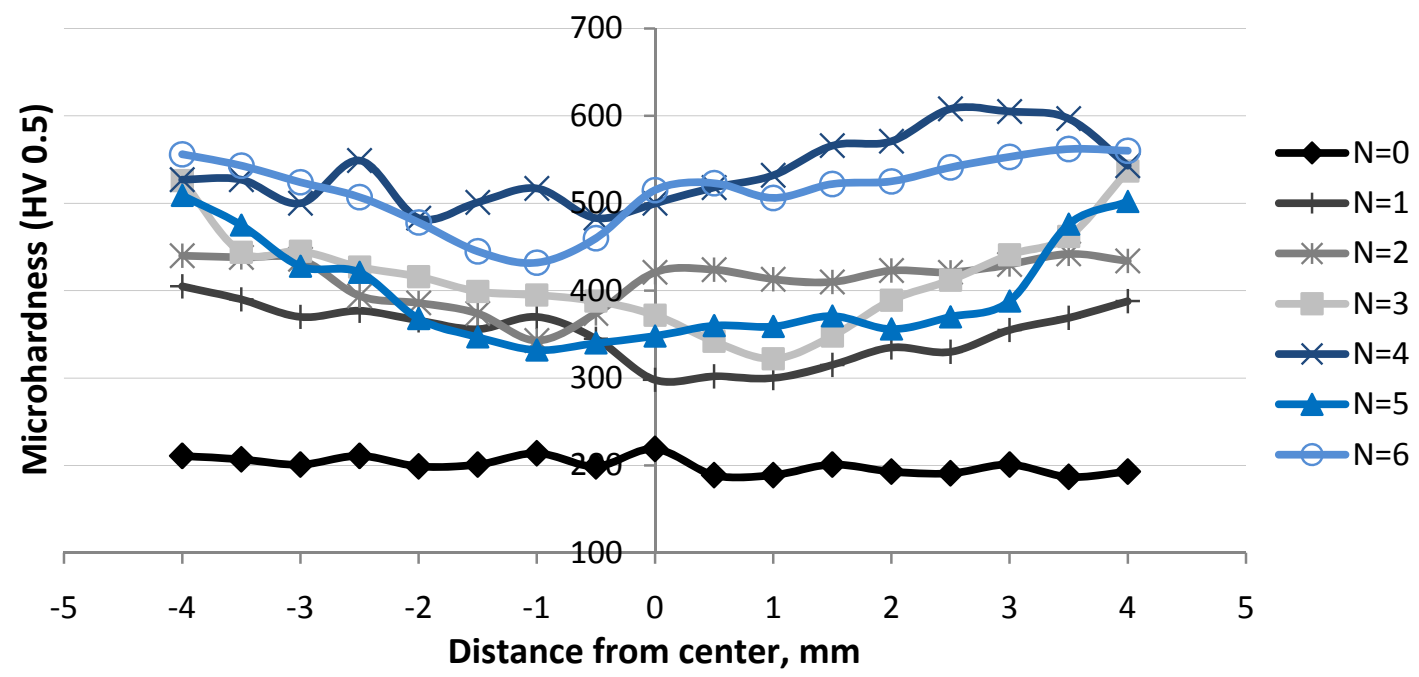

Figure 5.1 Hardness profile along the diameter of the samples produced by unconstrained HPT (N: number of turns) 


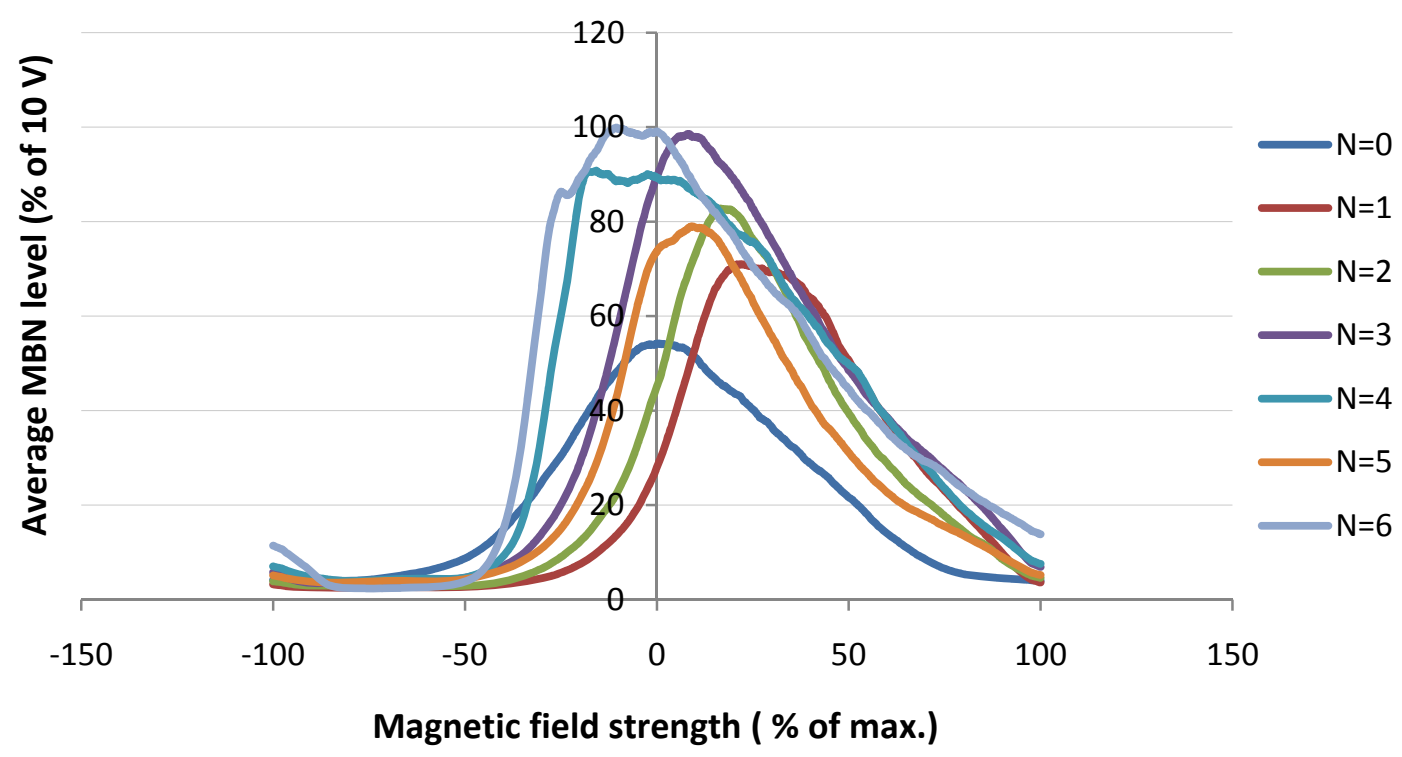

Figure 5.2 MBN profiles of the samples produced by unconstrained HPT (N: number of turns)

The hardness results with standard deviation values are given in Appendix Table A.1. Microhardness measurements reveal the increase in hardness through higher number of turns and the inhomogeneous deformation of unconstrained HPT as the hardness profile of two distinct radiuses does not show symmetry. MBN profiles show the increasing MBN level through higher number of turns which is an expected result due to the reduction in grain size. As grain size decreases, domain size decreases and domain density increases. Moreover, decrease in grain size leads to increase of grain boundary area per unit volume and so the nucleation of domains becomes easier. Consequently, the number of unpinning events increase (Equation (1.8)), thus MBN peak height increase. However, MBN measurements for this set of samples are done just only on the center of the disks due to the small size of the samples. So, these results may not reflect the real MBN response of the samples.

In the unconstrained HPT, samples may flow outside the space between the anvils and this leads to unexpected results as it is seen for the sample $\mathrm{N}=5$ for both microhardness measurements (Figure 5.1) and MBN measurements (Figure 5.2). 


\subsubsection{Microstructure}

Figure 5.3 shows the microstructure of the undeformed (reference) sample of the $1^{\text {st }}$ set of samples which consists of Widmanstätten ferrite and pearlite. The effect of severe plastic deformation is depicted in the microstructure of the deformed samples (Figure 5.4). Section 5.2.2 explains the microstructures in detail.

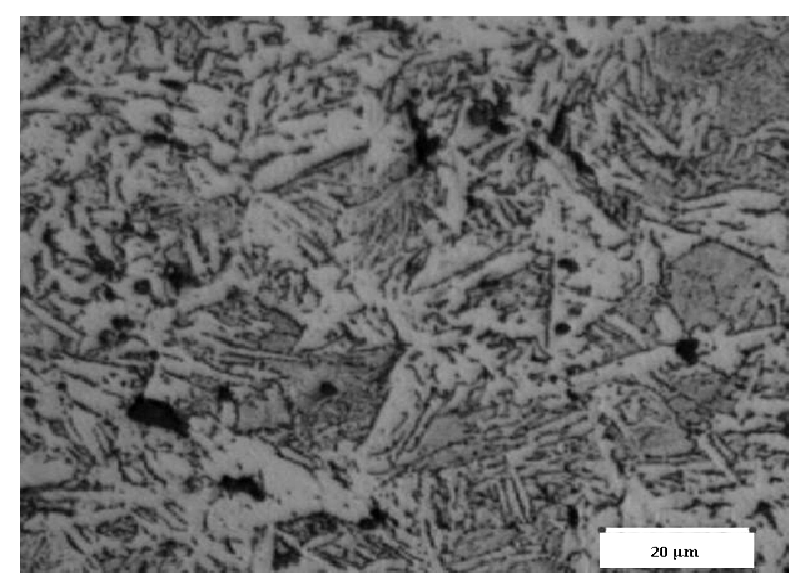

Figure 5.3 Optical micrograph of the undeformed sample of the $1^{\text {st }}$ set of samples (Etched in 2\% Nital solution for 15 seconds and in Picral solution for 30 seconds) 


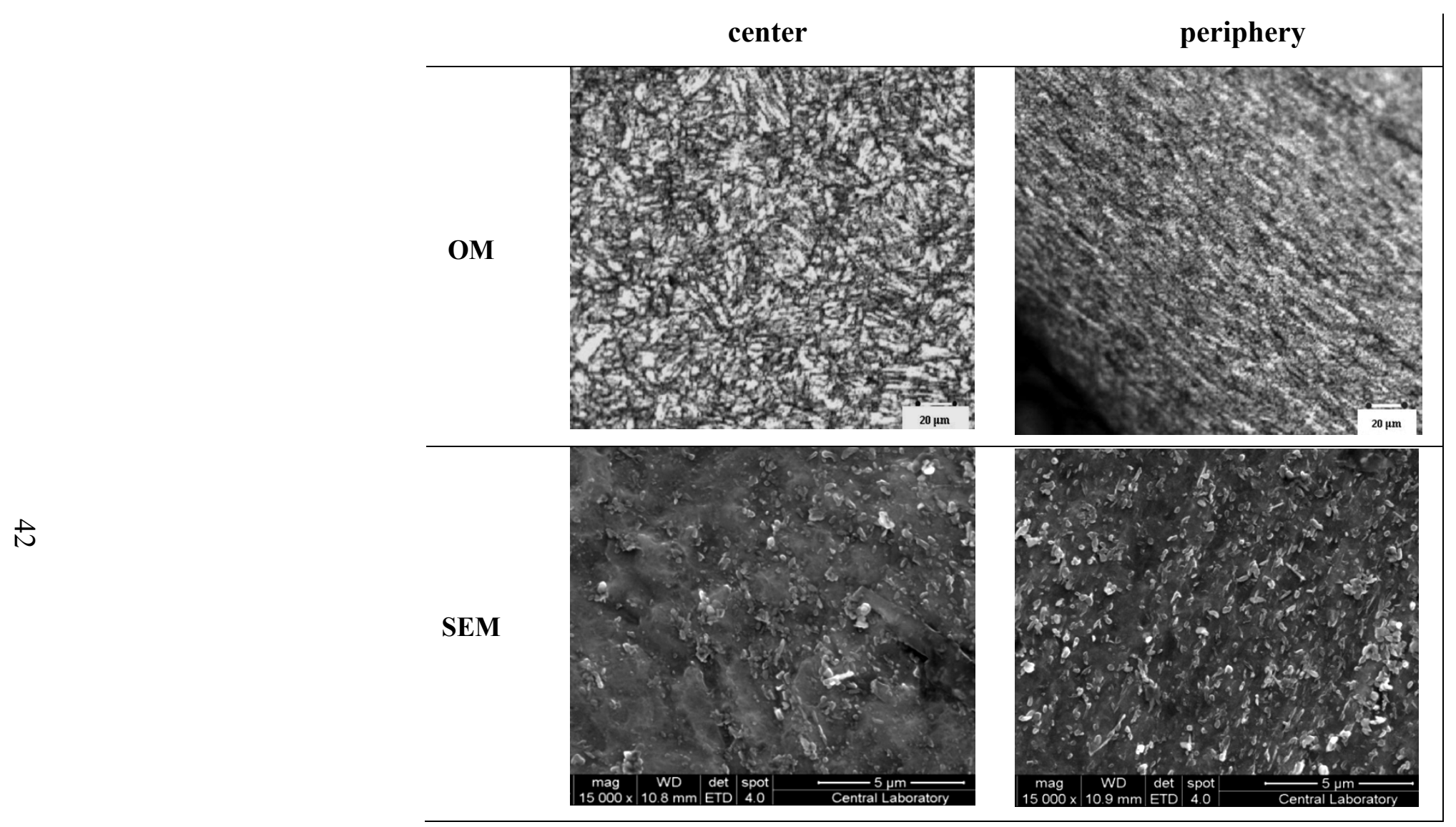

Figure 5.4 Optical micrographs $(\mathrm{OM})$ and SEM images of the most severely deformed sample $(\mathrm{N}=6)$, in the $1^{\text {st }}$ set of samples produced by unconstrained HPT, from the center and periphery of the disk (Etched in 2\% Nital solution for 15 seconds and in Picral solution for 30 seconds) 


\subsection{The Samples Produced by Constrained HPT}

\subsubsection{True Strain and Hardness}

The radial dependence of strain is known for HPT samples. By using the Equation (2.7), the variation of strain across the diameter of the samples is calculated and depicted in Figure 5.5. This equation is more appropriate for HPT since it incorporates the reduction in thickness due to applied pressure.

There is an increase in strain with increase in number of turns. Moreover, hardness distribution of the HPT samples should be compatible with the strain distribution. The hardness results with standard deviation values are given in Appendix Table A.2. Figure 5.6 shows the variation of microhardness values across the diameter (measurable region was up to $\pm 8 \mathrm{~mm}$ ) of the samples. The average of the hardness values, along the diameter of the disks, is given in Figure 5.7 in order to seen the variation of hardness between the samples. The radial dependence and the increase of hardness through the periphery of the disks can be easily seen from both of the figures. Figure 5.6 also shows the asymmetry between two distinct radiuses which is due to the inherent property of the HPT; inhomogenity of the process. The decrease of hardness for the sample $\mathrm{N}=6$ is due to the dynamic recovery occurred during the deformation. The increase in the temperature of the HPT process $\left(300^{\circ} \mathrm{C}\right)$ at large strains may lead to dynamic recovery. So, lower strains are needed for further straining. Dynamic recovery can occur by a combination of processes such as crossslip of the dislocations, dislocation climb and subgrain growth. 


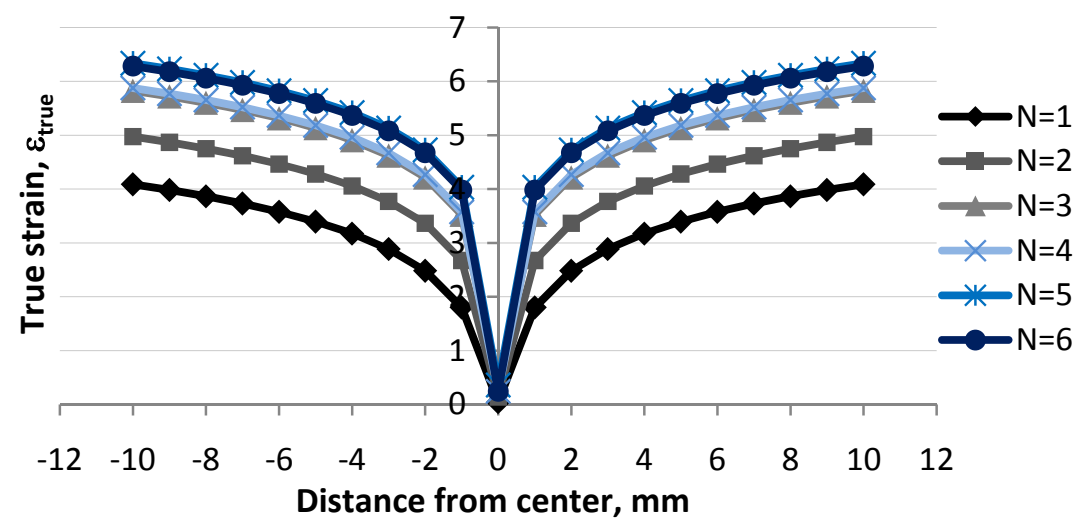

Figure 5.5 Theoretical variation of strain along the diameter of the constrained HPT samples (N: number of turns)

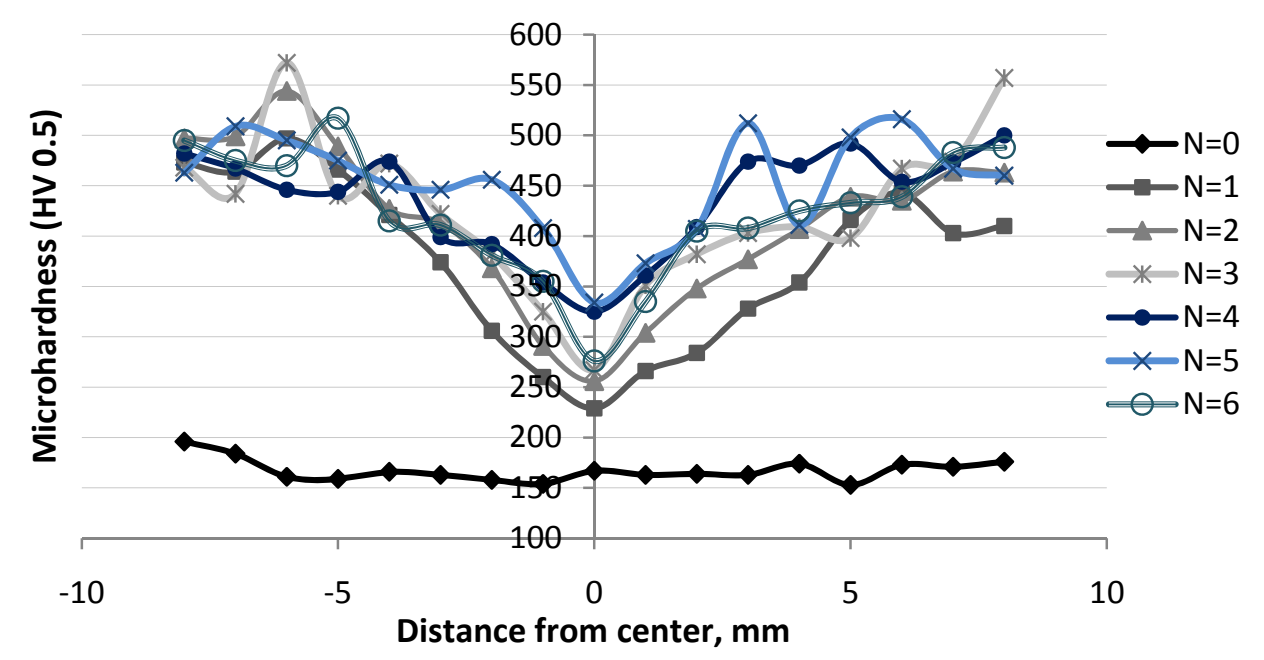

Figure 5.6 Hardness profile along the diameter of the constrained HPT samples (N: number of turns)

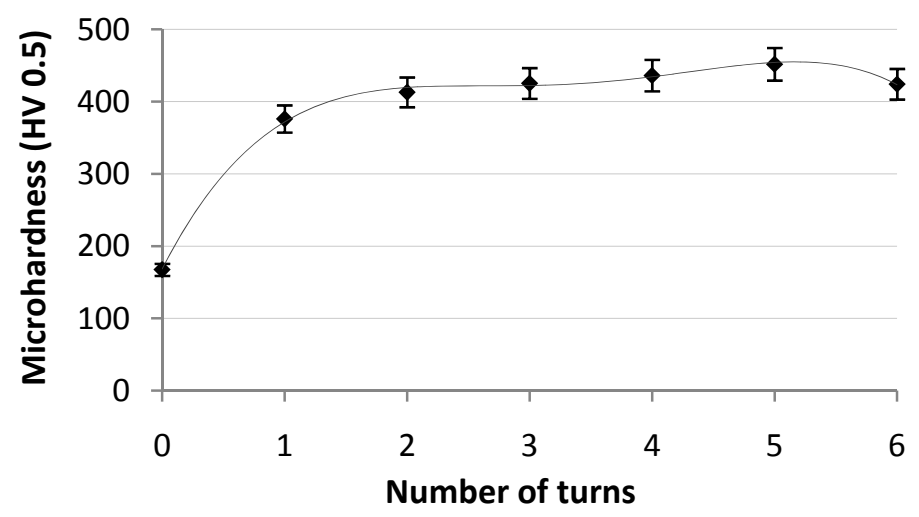

Figure 5.7 Average microhardness values along the diameter vs. Number of turns 
A repetitive process like HPT results in fluctuations visible in the hardness results shown. The presence of this type of undulating deformation can be demonstrated by plotting the average curvature of the microhardness measurements across the diameter of the disk as a function of the number of whole revolutions. An example of this plot is shown in Figure 5.8 for both set of samples. The value of the average curvature is defined as the ratio of the average value of $\mathrm{H}_{v}$ at the periphery of the disk to the average value of $\mathrm{H}_{\mathrm{v}}$ at the center. The experimental points plotted in Figure 5.8 are taken from the data in Figure 5.6 and Figure 5.1.

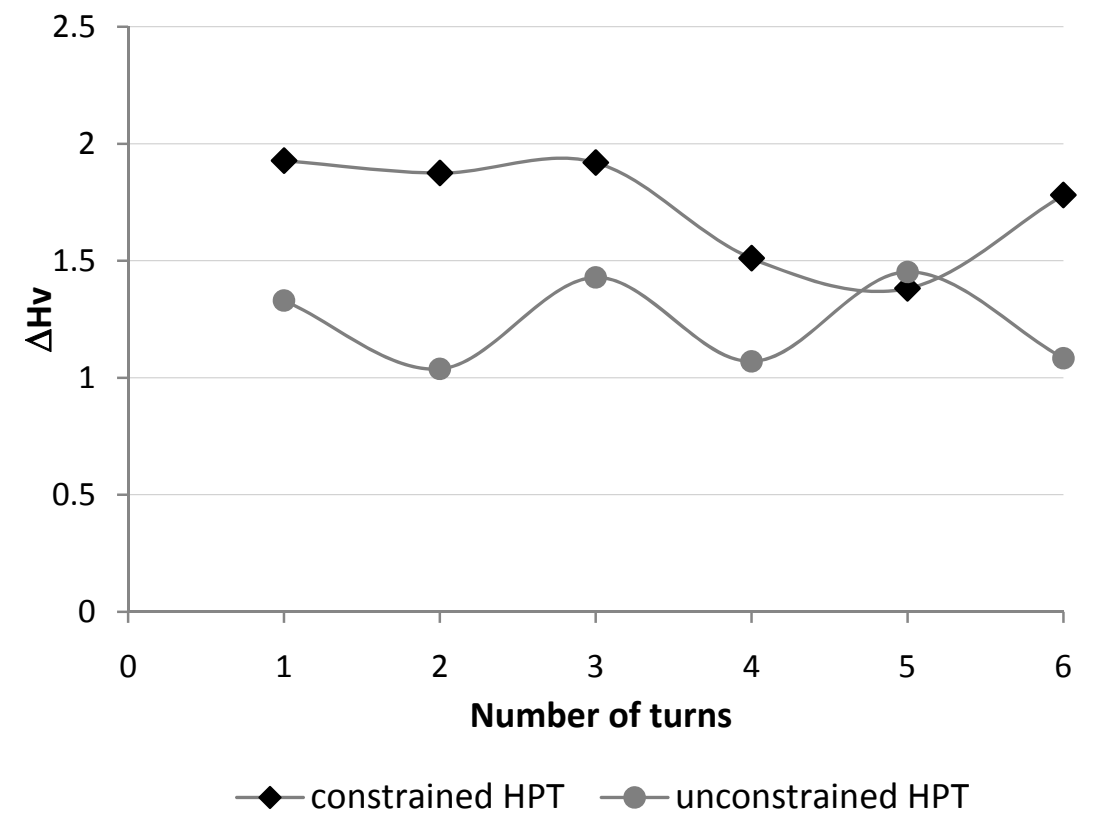

Figure 5.8 Average curvature of microhardness measurements for both constrained and unconstrained HPT

Figure 5.8 demonstrates that there are variations in the local hardness curvature across the disks such that these values undulate within the range of $\sim 1.38-1.92$ for constrained HPT samples and 1.04-1.45 for unconstrained HPT samples. Despite these local variations in microhardness, the significant feature of processing by HPT is the clear demonstration that reasonably homogeneous microstructures may be attained throughout the samples, including in the central region, when the applied pressure $P$ and the number of revolutions $N$ are both sufficiently high. 


\subsubsection{Microstructure}

Figure 5.9 shows the microstructure of the undeformed (reference) sample which consists of Widmanstätten ferrite and pearlite. The effect of severe plastic deformation is depicted in the microstructure of the deformed samples (Figures 5.10 and 5.11).

Figure 5.12 shows the continuous cooling transformation diagram of AISI 10171022 steels. The final microstructure of the samples can be predicted by drawing vertical lines through the bar diameters written on the quenchants. The second dotted line on Figure 5.10, which is drawn for the second set of samples (20 mm diameter), shows that amount of bainite is very small; but the cooling rate is between upper bainite and fine pearlite which explains the occurrence of Widmanstätten ferrite in the microstructure [40].

Widmanstätten ferrite grows by a para-equilibrium kind of transformation, in which the larger atoms in substitutional sites move in a discipline manner (without diffusion) whereas the faster moving interstitial atoms diffuse and partition between the phases; a displacive mechanism whose rate is controlled by the diffusion of carbon in the austenite ahead of the $\alpha_{\mathrm{w}} / \gamma$ interface [40].

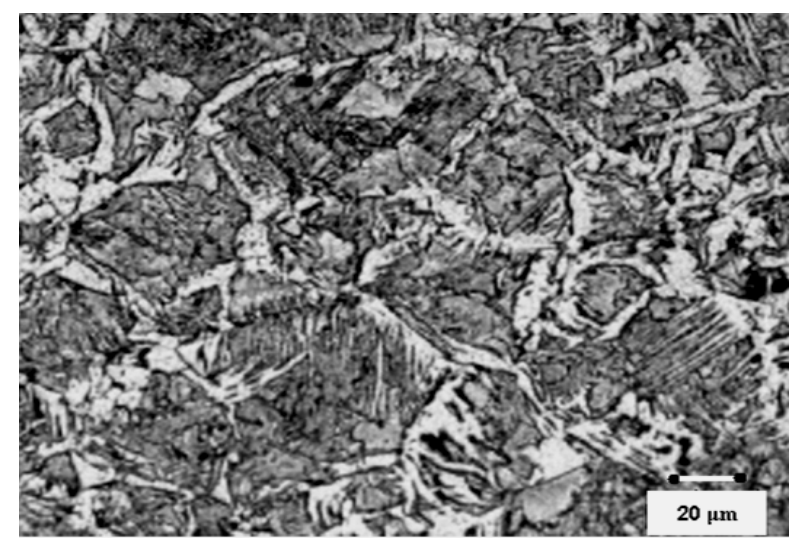

Figure 5.9 Optical micrograph of the undeformed sample (Etched in 2\% Nital solution for 15 seconds and in Picral solution for 30 seconds) 


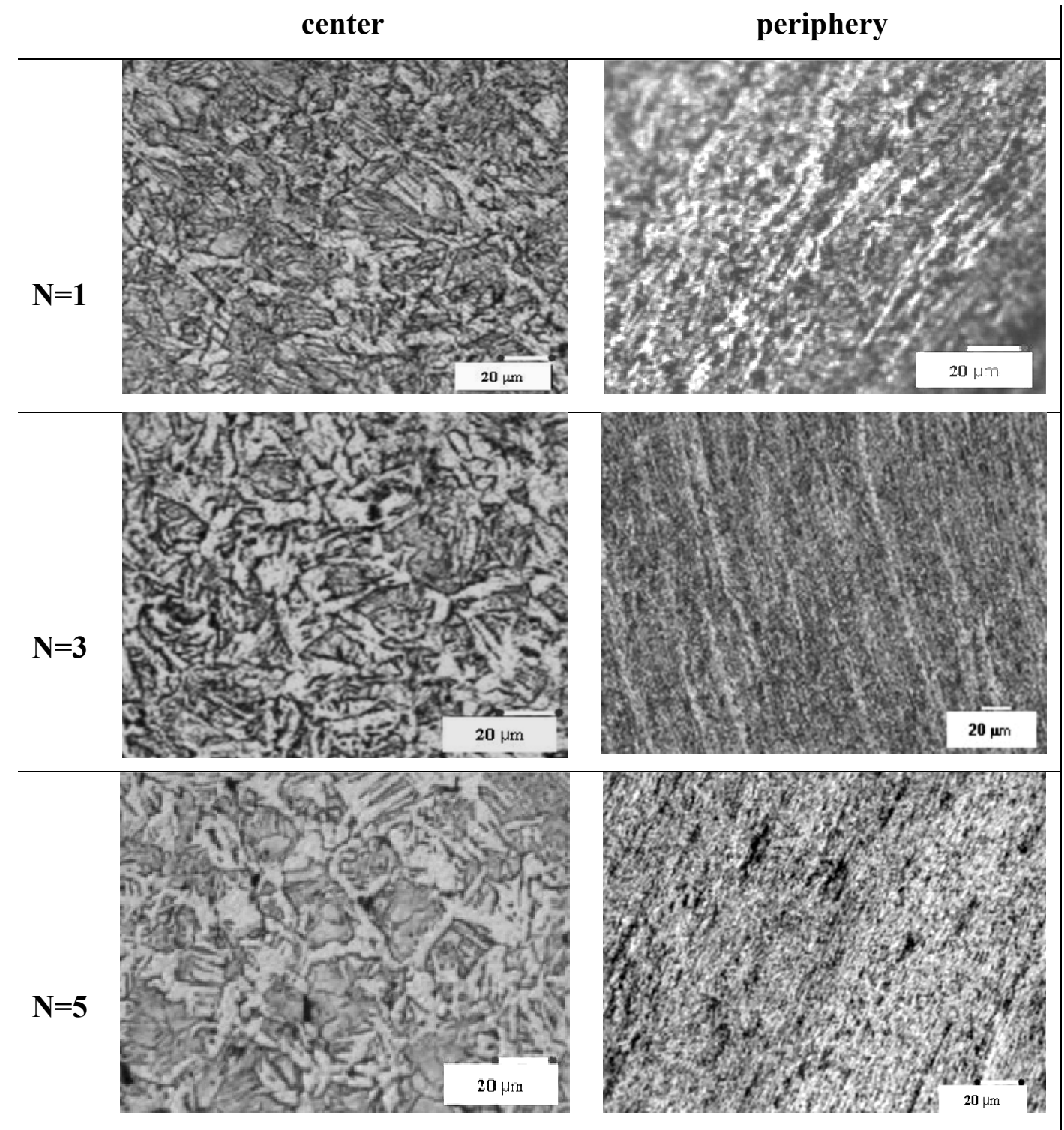

Figure 5.10 Optical micrographs of the 1, 3 and 5 times rotated samples from the center and periphery of the disks (Etched in 2\% Nital solution for 15 seconds and in Picral solution for 30 seconds) 


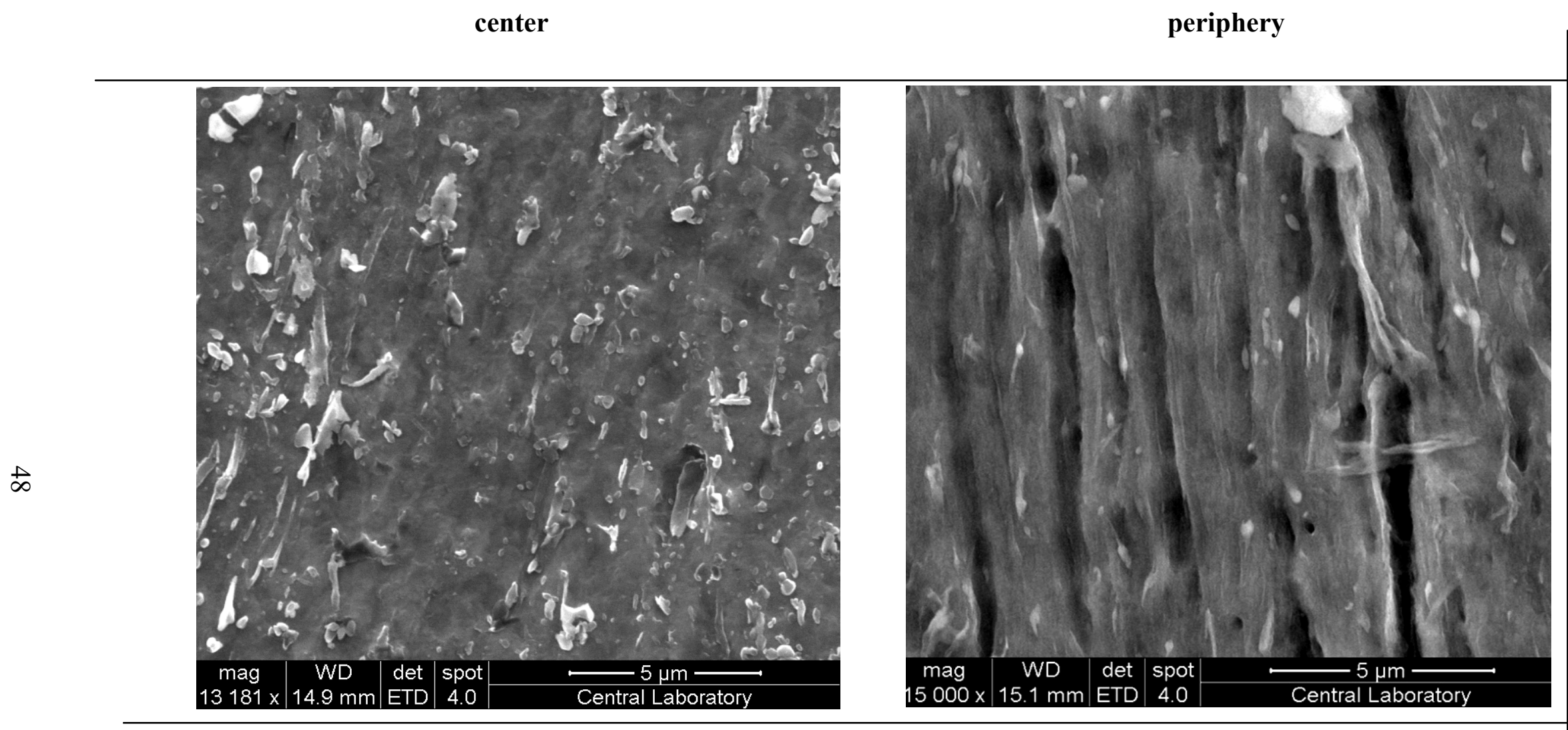

Figure 5.11 SEM images of the most severely deformed sample $(\mathrm{N}=5)$ in the $2^{\text {nd }}$ set of samples, which have been produced by constrained HPT, from the center and periphery of the disk (Etched in 2\% Nital solution for 15 seconds and in Picral solution for 30 seconds) 


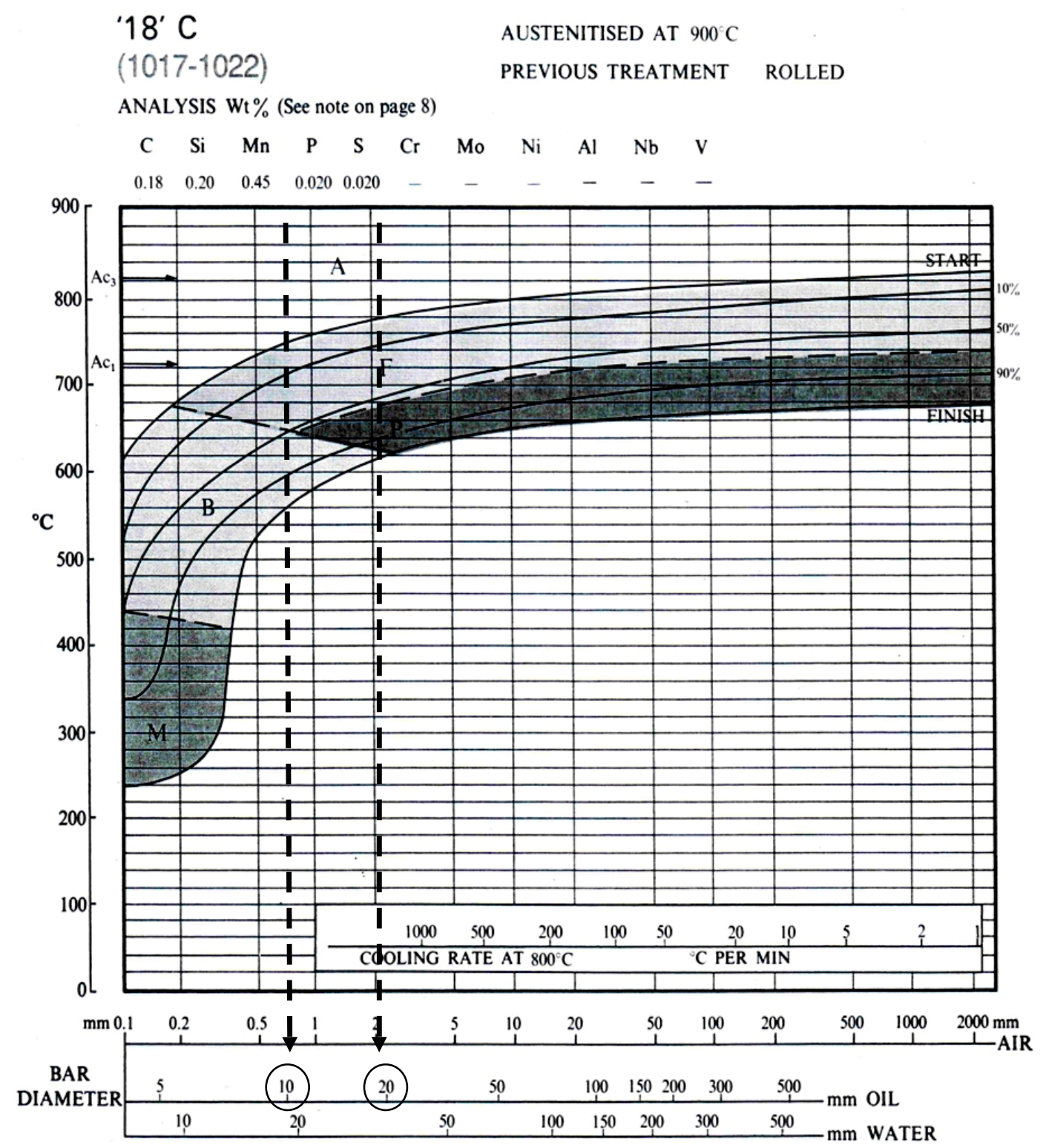

Figure 5.12 Continuous Cooling Diagram for AISI 1017-1022 steels [41]

It should be noted that this diagram is used for AISI 1017-1022 steels which were previously rolled and then austenitized at $900^{\circ} \mathrm{C}$. Moreover, it refers only to the centre of a bar [41]. Although the position of the curves changes by the initial treatment of the sample, such as austenitizing temperature, soaking time, and rolling, this diagram is very useful in order to depict the cooling behavior of the samples used in this thesis study. 


\subsubsection{X-Ray Diffraction Pattern}

X-ray patterns of nanostructured materials processed by SPD methods differ significantly from those of corresponding coarse-grained materials. These differences are revealed, first of all, in changes of integral intensity of background, changes of width and intensity of X-ray peaks and appearance of crystallographic texture. Another feature of X-ray diffraction patterns in nanostructured SPD Materials is a significant decrease in the intensity of X-ray peaks and their strong broadening [1].

X-Ray Diffraction (XRD) results of the constrained HPT samples for (211) and (310) are given in Figure 5.13. All the XRD was done by 8 minutes per degree. The XRD profiles clearly show the decrease in intensity. The increase in the number of turns should result in the monotonous development of the axial texture (the intensity should increase for some peaks and decrease for another peaks) and broadening of all peaks due to the refinement of the microstructure and the increase in the dislocation density which should cause the decrease in the intensity. It is observed that the intensity of the selected peaks decreases with the saturation.

The choice of the diffraction peak selected for residual stress measurement impacts significantly on the precision of the method. The second peak on Figure 5.13 is a meaningful choice to comment on the residual stress condition because higher the diffraction angle, the greater the precision [42]. Peak positions of the deformed samples are almost same with the position of reference sample which means the effect of residual stress is negligible.

The sub-grain size calculations were done by using the Scherrer formula [43]:

$$
t=\frac{K \lambda}{B \cos \theta}
$$

where $t, K, \lambda, B, \theta$ is sub-grain size, shape factor, wavelength, peak broadening and half of the diffraction angle respectively. The numerical value of shape factor, $K$, is between $0.70-1.70$ and it depends on many factors: 
- The crystallite shape,

- The indices of the reflecting planes,

- The particular definition of broadening, $B$, (whether the half-maximum or integral breadth of a peak)

- The particular definition of $t$, crystallite dimension.

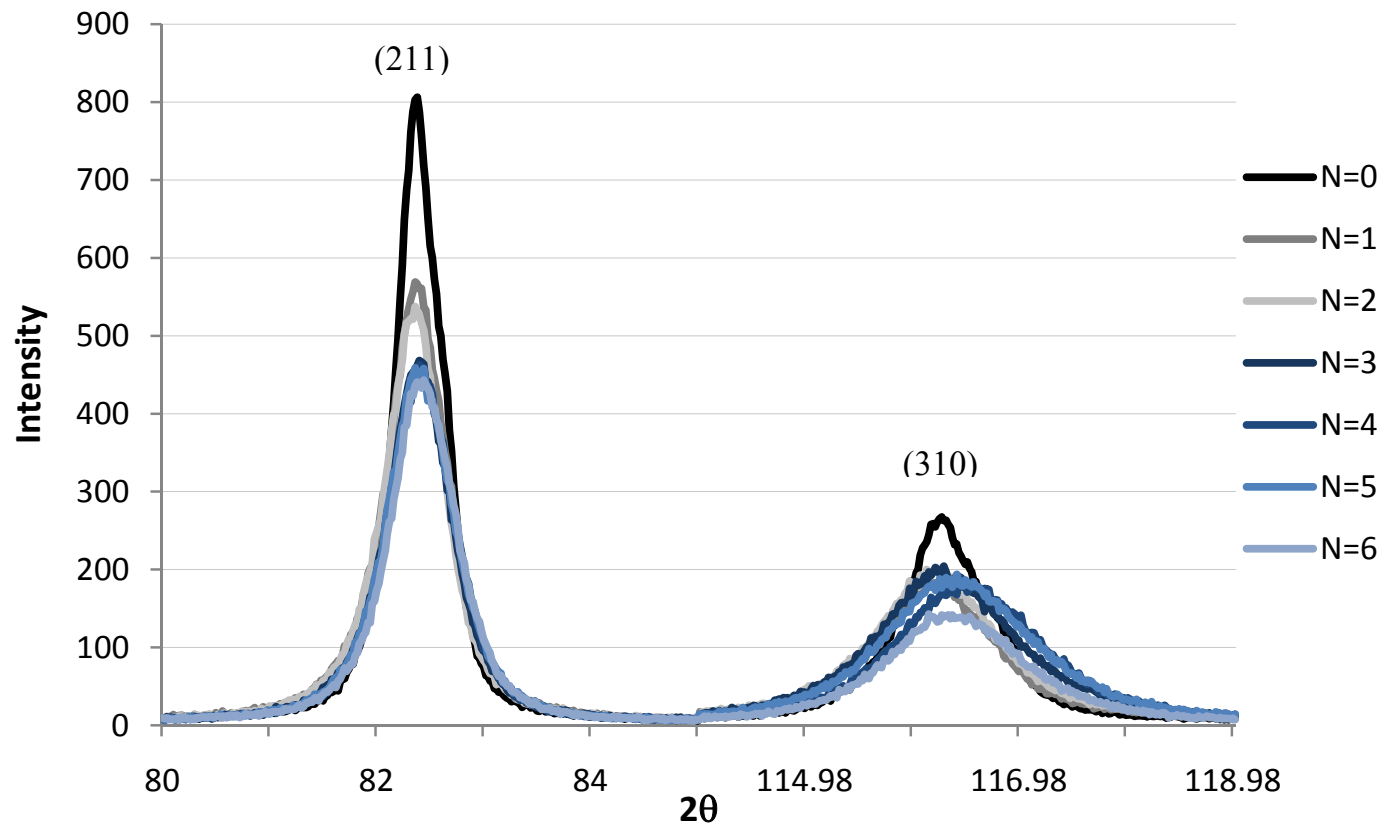

Figure 5.13 XRD pattern of constrained HPT samples

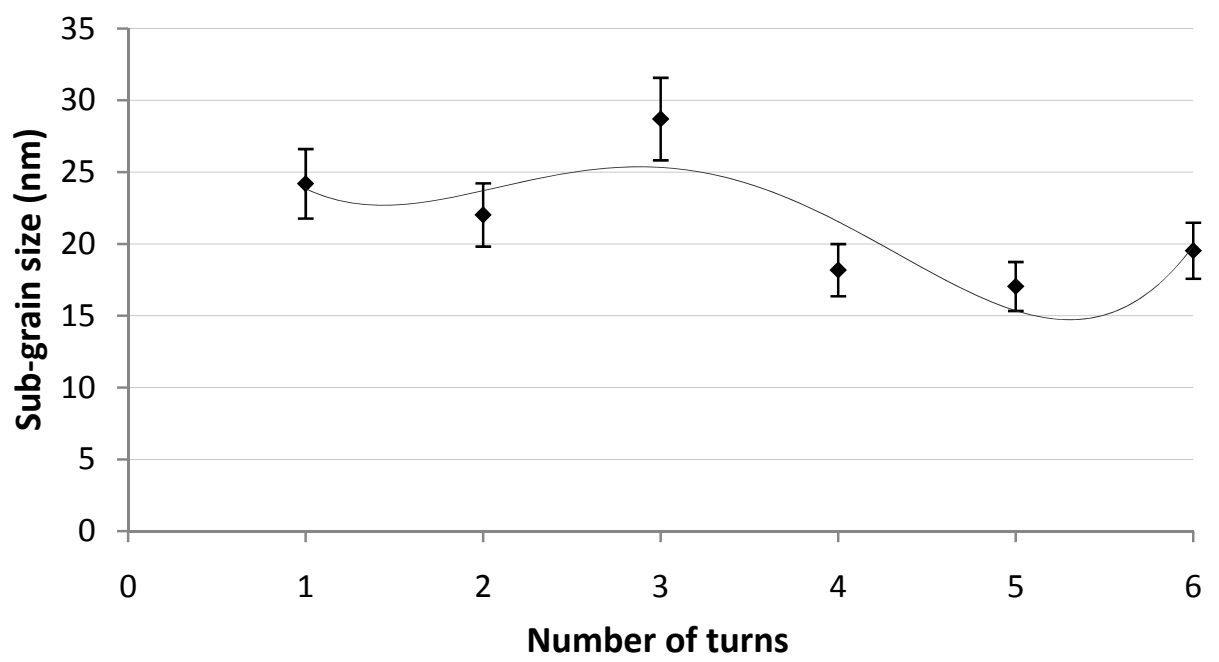

Figure 5.14 Sub-grain size distributions of constrained HPT samples 
It has been shown that the definition of $t$ as the effective thickness of the crystallite in a direction perpendicular to the reflecting planes leads to values of $\mathrm{K}$ in the neighborhood of 0.9 [43]. Figure 5.14 shows the sub-grain size distribution which was calculated by taking $K=0.9$ in the Scherrer formula for the second peak in Figure 5.13:

The integral breadth, $B$, has the relationship;

$$
B^{2}=\beta^{2}+b^{2}
$$

where $\beta$ is the breadth of the pure diffraction profile and $b$ is the profile of the instrumental broadening.

As it can be seen from Figure 5.14, size of the sub-grains changes between 15 and $30 \mathrm{~nm}$. The increase for the sample $\mathrm{N}=3$ is possibly due to the effect of texture. Nevertheless, it should be noted that Scherrer formula is not an accurate method for crystallite size measurement. Figure 5.14 is given just only to compare the samples, TEM investigations are necessary to comment on the grain size of the samples through the periphery. Because, the X-ray diffraction method actually allows us to determine a size of coherently scattering domains connected with internal grain areas having a weakly distorted crystal lattice, whereas the TEM method measures a complete grain size which includes near boundary strongly distorted areas. Thus, in SPD Materials characterized by strong distortions of the crystal lattice, the difference in TEM and X-ray structural data can be rather significant [1]. 


\subsubsection{MBN Profiles}

The MBN profiles of the samples are given in Figures 5.15-5.19. As the severe plastic deformation enables obtaining ultra-fine grain or nano sized grains, the major effect of HPT to MBN should be discussed with grain size reduction. However, the initial stages of HPT may cause the effect of conventional cold working processes; so the interaction of dislocations, dislocation tangles and cells with domain walls should also be considered.

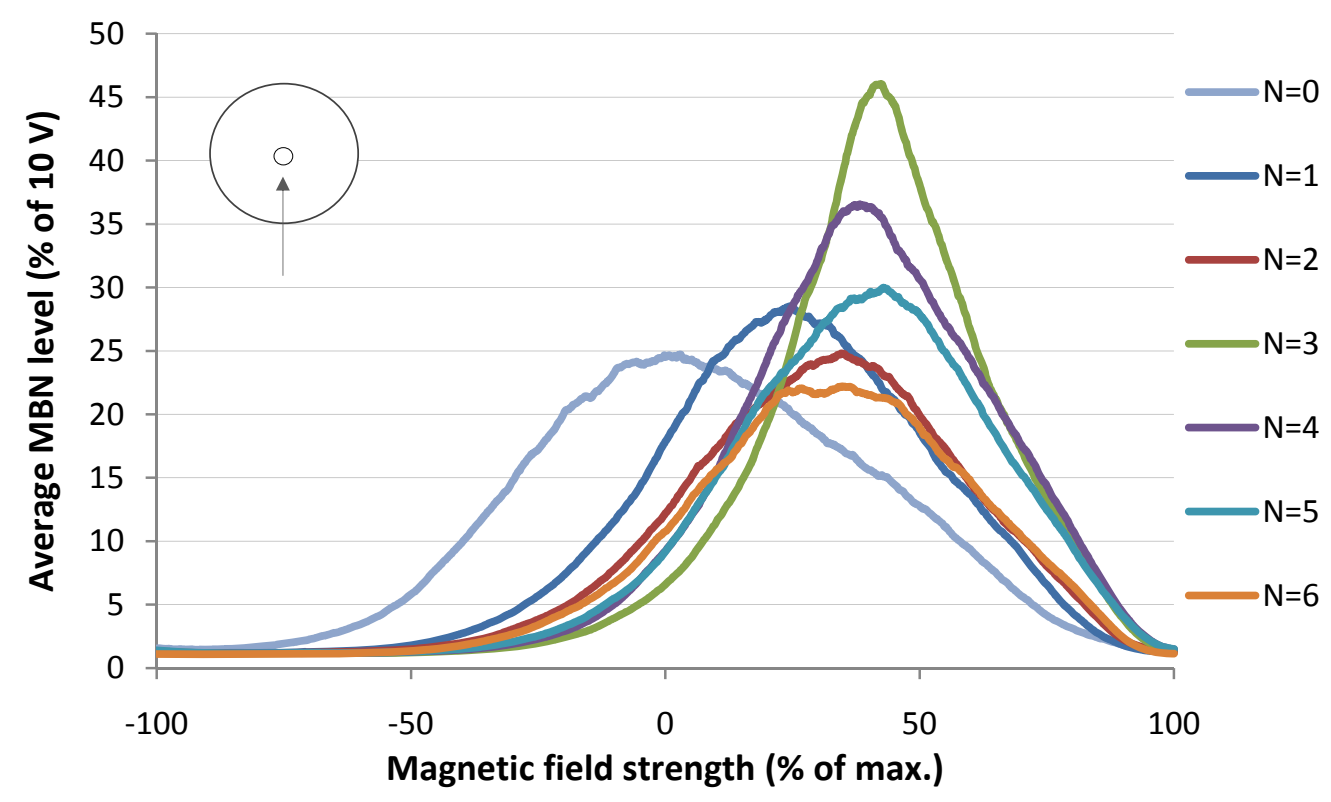

Figure 5.15 MBN profile of the constrained HPT samples at the center of the disks (N: number of turns)

Figure 5.15 shows the MBN profiles for all of the samples at the center of the disks. The shift of the peak positions towards right is an expected result as the plastic deformation gives rise to hard magnet behavior. As the strain increases through the radius of the disks, the center of the samples are low strain regions (Figure 5.5). So, the effect of deformation to $\mathrm{MBN}$ on the central region can be explained by the effect of conventional deformation to $\mathrm{BN}$ signals. The $\mathrm{BN}$ signals emitted in the plastic deformation region depend on two major factors that are counteracting each other. The first factor is the elongation of the grains that leads to the reorientation of 
domain configuration or the increase of domain walls, and thus increasing the BN signals. The second factor is the presence of dislocation cells which hinder domain wall motion, and thus decreasing the $\mathrm{BN}$ activity of the samples. Higher deformation ratios induce a large number of smaller cell structures so the boundary area increases, which results in low MBN signal. Actually, the grains elongate at the beginning of HPT, but become equiaxed after several turns.

Figures 5.16, 5.17, 5.18 and 5.19 reveal the effect of the inhomogenity of the HPT process. MBN peaks do not coincide for both radii of the disk 

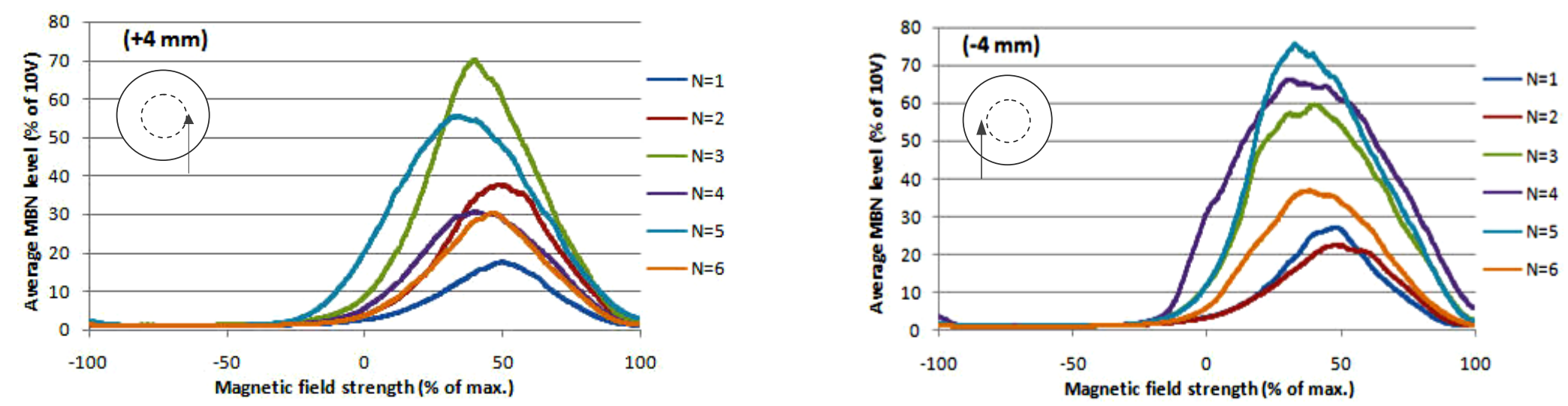

Figure 5.16 MBN profiles of the samples at $\pm 4 \mathrm{~mm}$ away from the center of the disks (N: number of turns)

un
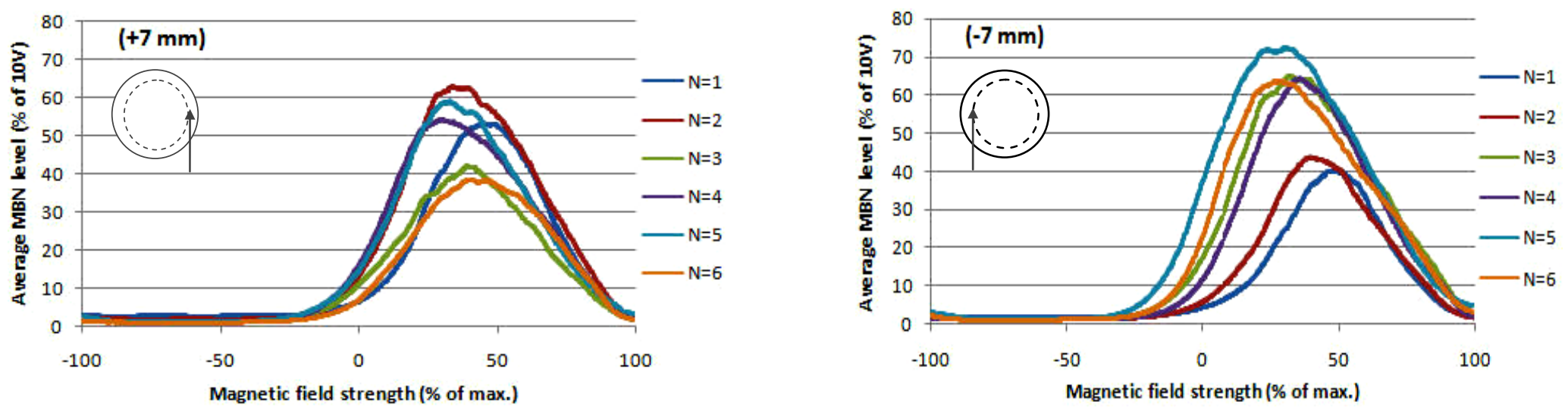

Figure 5.17 MBN profiles of the samples at the farthest measurable distance $( \pm 7 \mathrm{~mm})$ away from the center of the disks 

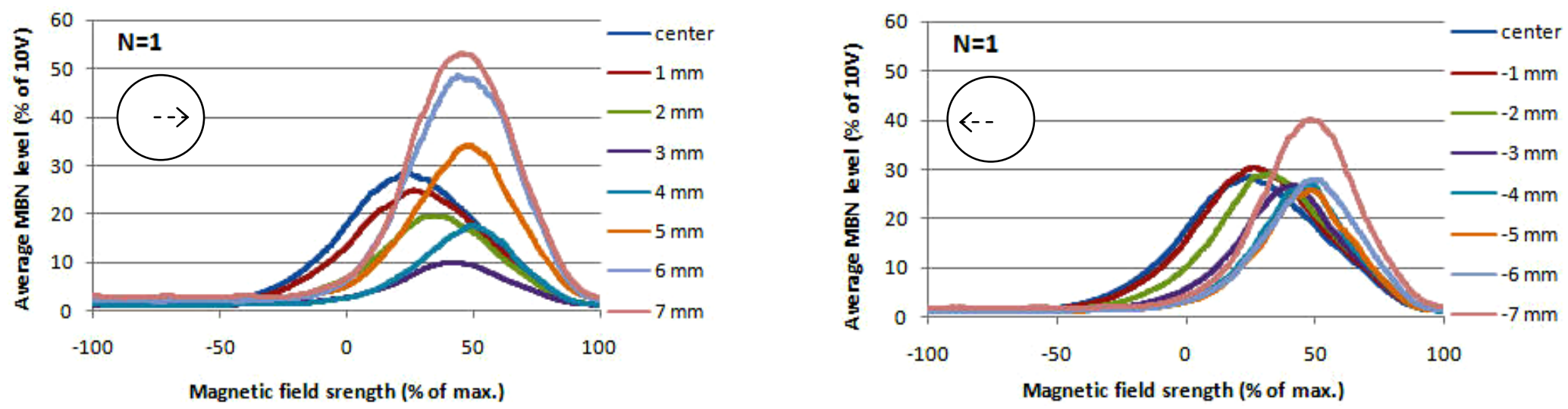

Figure 5.18 $\mathrm{MBN}$ profile of $\mathrm{N}=1$ for two distinct radii
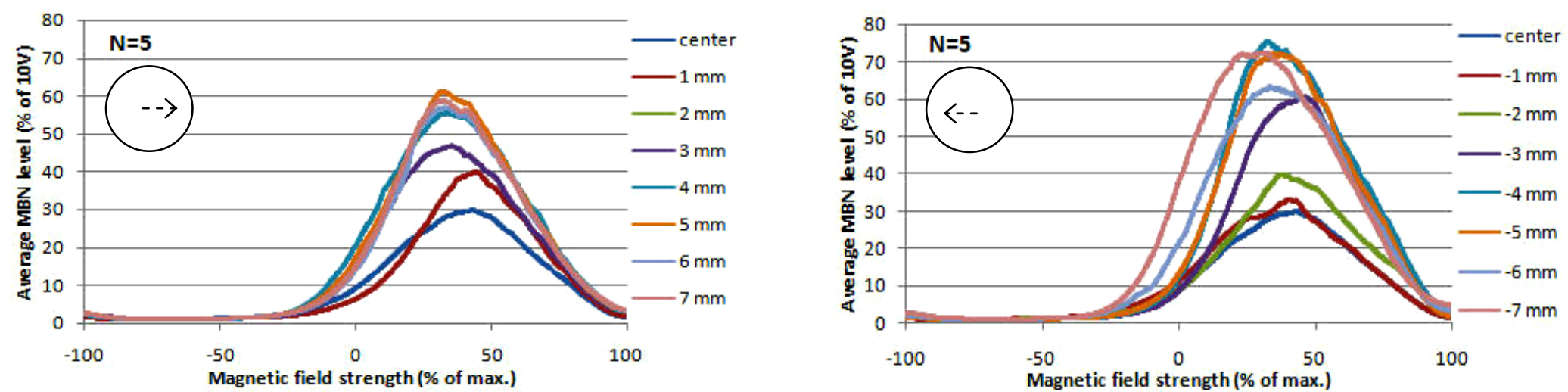

Figure 5.19 $\mathrm{MBN}$ profile of $\mathrm{N}=5$ for two distinct radii 
MBN profiles do not show a correlation for a certain distance from the center of the disks and also for two distinct radii of a sample. This is explained by the parameters affecting the Barkhausen noise $(\mathrm{BN})$. The major effect of severe plastic deformation to $\mathrm{BN}$ is expected to be grain size reduction. However, micro residual stresses and texture may also affect the MBN profile. So, MBN profiles show some fluctuations. The positions of the peaks in the MBN profiles are related with the ease of domain movement and magnetization of the structure. High numbers of pinning like grain boundaries, dislocations etc. retard the domain motion and lower the average MBN level. Moreover, if the microstructure is difficult to magnetize, the MBN peak shifts to the higher magnetization fields. In some cases, micro residual stresses or texture may also affect the MBN activity which results in fluctuations in MBN profiles.

In order to see the effect of HPT to MBN, the average of all of the root-mean square (RMS) data is considered for all of the samples. Figure 5.20 shows the data for different number of turns. As the strain values (Figure 5.5) are lower at the initial stages of HPT, the initial decrease in the average RMS value after one turn $(\mathrm{N}=1)$ can be explained by the effects of conventional deformation to MBN. At the initial stages of deformation, the structure consists of large number of small cell structures which have high boundary area. This impedes the domain wall motion and leads to lower MBN signal. The decrease in MBN energy and voltage during plastic deformation was also reported in the studies of M.A. Campos et al. [39] and J. Anglada-Rivera et al.[34] respectively.

It is more meaningful to analyze the effect of HPT to MBN at higher strains. So, severely deformed samples such as $\mathrm{N}=4$ and $\mathrm{N}=5$, and the farthest measurable distance away from the center should be considered. As grains become finer, domain size decreases and domain density increases. Consequently MBN peak height increase. The decrease in grain size leads to increase of grain boundary area per unit volume and so the nucleation of domains becomes easier. This results increase in Barkhausen jumps and increase in MBN activity. This effect is also seen in Figures 5.20 and 5.21 . 


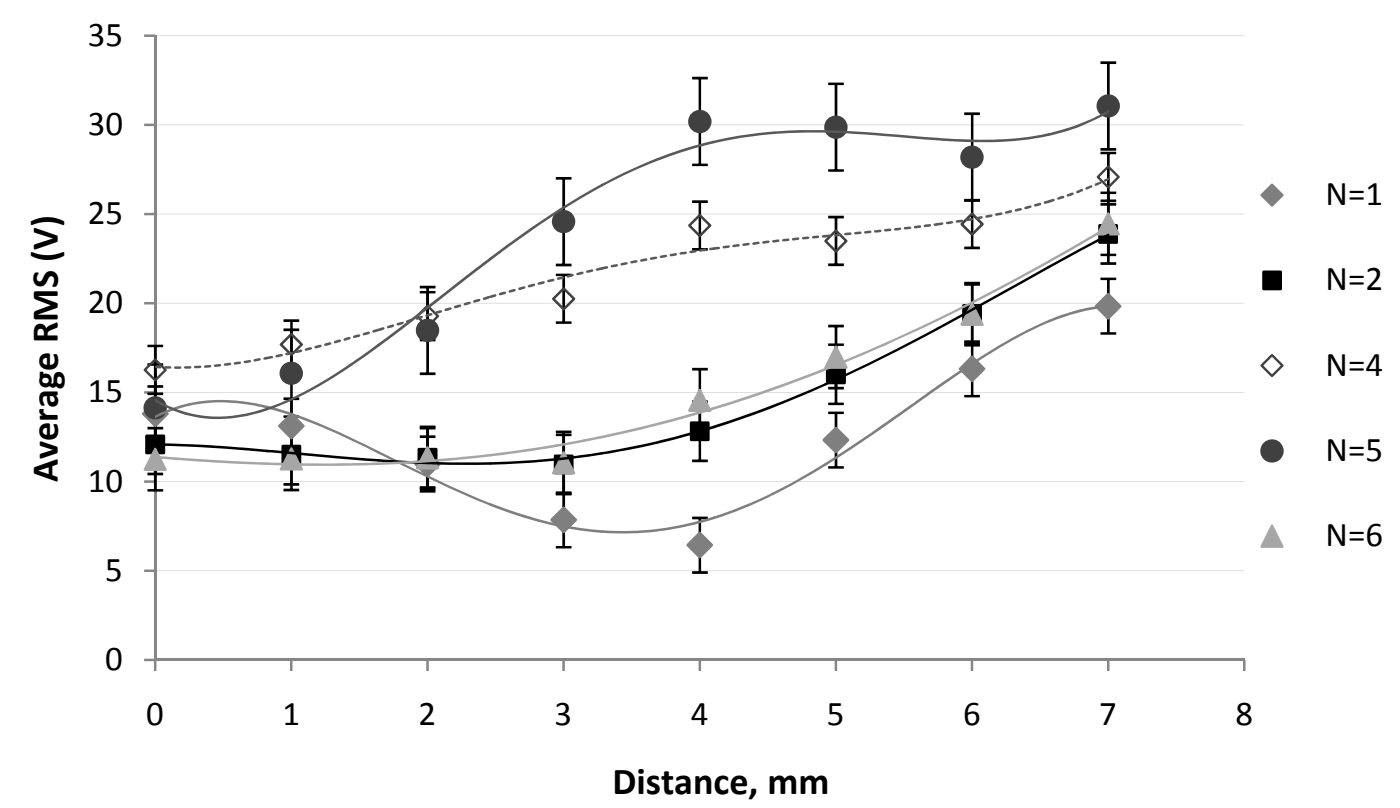

Figure 5.20 Average RMS of MBN along the radius after different HPT turns (N: number of turns)

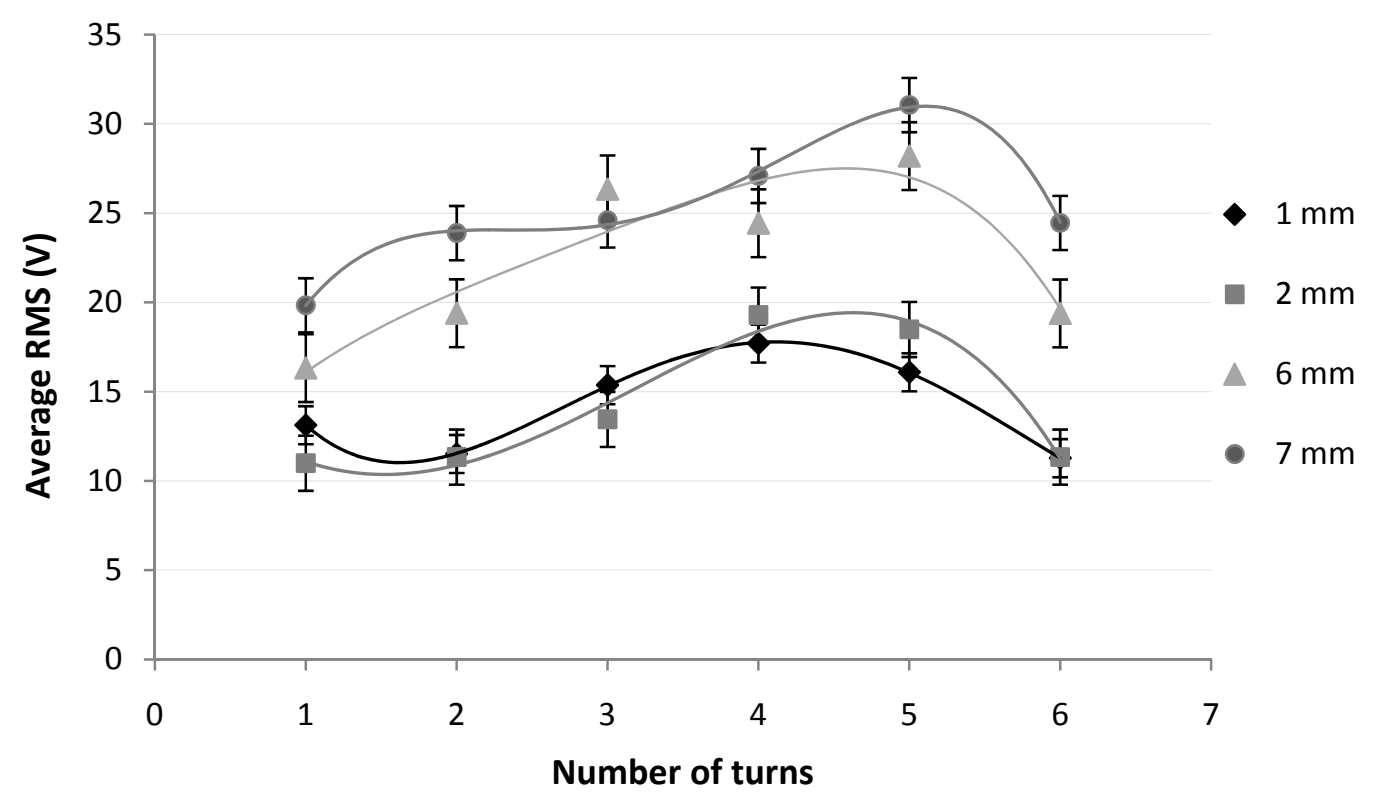

Figure 5.21 Comparison of average RMS values at the selected points along the radius as a function of the number of HPT turns 
The unexpected decrease in the average RMS after 6 HPT turns $(\mathrm{N}=6)$, as in the case of microhardness measurements, might be explained by the dynamic recovery occurred during the process.

The effect of HPT at higher strains; i.e. higher number of turns and farther distances away from the center of disks, on MBN is explained by the remarkable reduction in the average grain size. As grains become finer, domain size decreases and domain density increases. In addition to this, the decrease in grain size leads to increase of grain boundary area per unit volume and so, the nucleation of domains becomes easier. This causes an increase in the MBN jumps, and thus, MBN activity.

Figure 5.22 shows the comparison of the variation of average RMS and sub-grain size of the constrained HPT samples as a function of the number of HPT turns. As grain refinement increases with increasing number of turns, the average RMS increases and sub-grain size decreases with increasing nubmer of turns except the sample with three number of turns $(\mathrm{N}=3)$ which is due to the texture.

Figure 5.23 compares the variation of average RMS and hardness values at the center and $7 \mathrm{~mm}$ away from the center of the disks as a function of the number of HPT turns. Although the central region show some fluctuations, it is seen that both average RMS and hardness values increases with increasing number of turns, moreover the values are higher at the region $7 \mathrm{~mm}$ away from the center of the disks since the degree of severe plastic deformation and so the grain refinement increases with increasing number of turns and at farther distances away from the center of the samples.

The effect of strain softening for the sample with 6 number of turns $(\mathrm{N}=6)$ is verified by both Figures $\mathbf{5 . 2 2}$ and $\mathbf{5 . 2 3}$ since the average RMS is lower, sub-grain size is higher and hardness is lower for $\mathrm{N}=6$ than those of $\mathrm{N}=5$. 


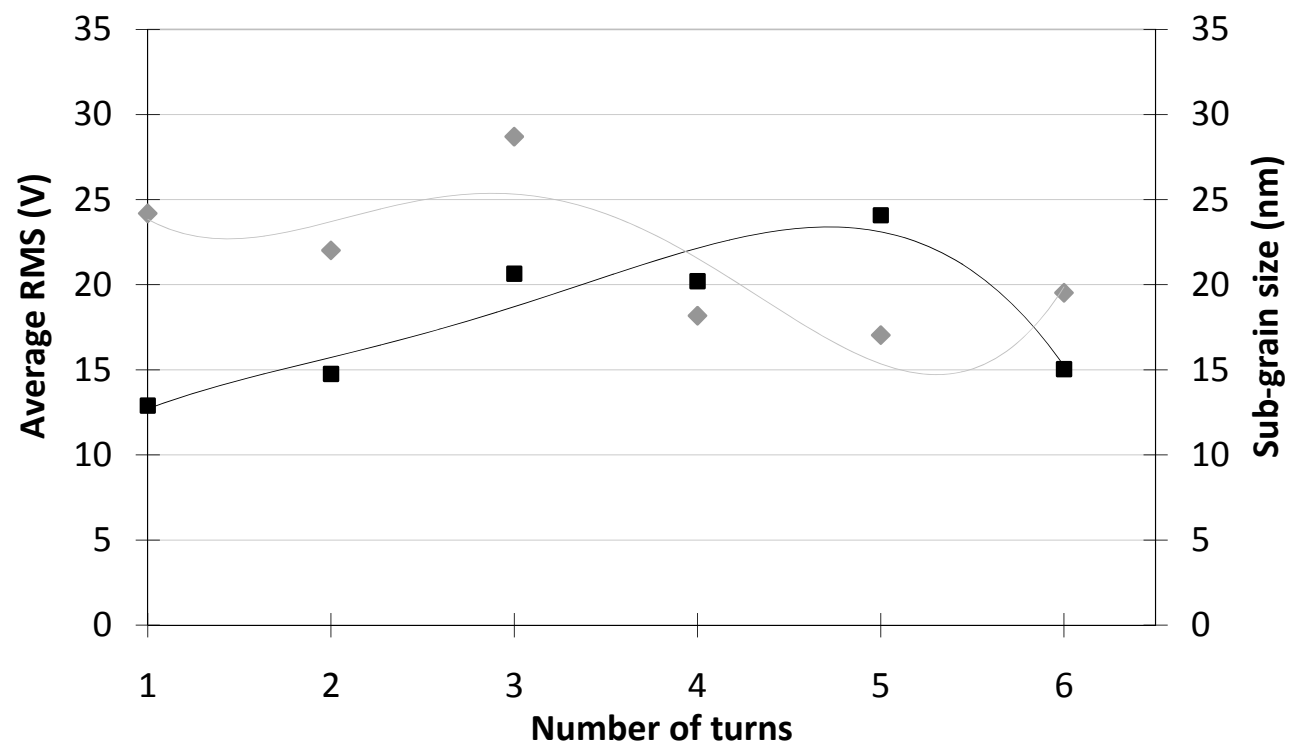

- Average RMS sub-grain size

Figure 5.22 Comparison of the variation of average RMS and sub-grain size of the constrained HPT samples as a function of the number of HPT turns

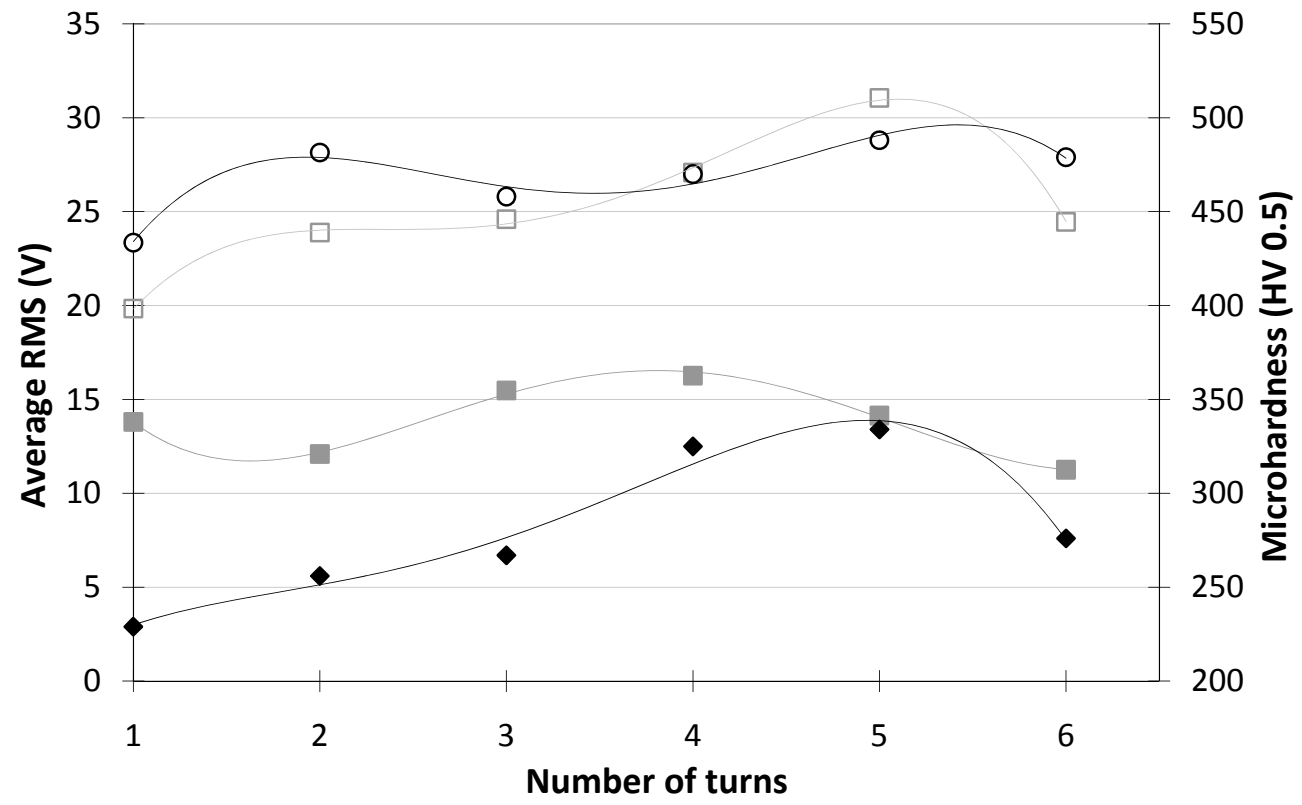

- Average RMS at center $\quad \square$ Average RMS at $7 \mathrm{~mm}$

- Microhardness at center O Microhardness at $7 \mathrm{~mm}$

Figure 5.23 Comparison of the variation of average RMS and hardness values at the center and $7 \mathrm{~mm}$ away from the center of the disks as a function of the number of HPT turns 
Figures 5.24 and 5.25 show that the coercivity and the area of the hysteresis loop increases by increasing deformation ratio. During MBN measurements a representative magnetic hysteresis loop is induced in the small volume of specimen due to the energy lost with the irreversible process of magnetization [14]. The noise signals obtained are proportional to rate of change in internal magnetization. Thus the integration of noise signals along the whole applied magnetic field gives a representative hysteresis loop from which parameters such as coercivity, remanence and permeability could be obtained. These parameters may be used then in order to characterize samples. Although these representative hysteresis loops may not reflect the real behavior of the samples as the whole part of the samples are not magnetized during the MBN measurements, the results are compatible with the literature. 


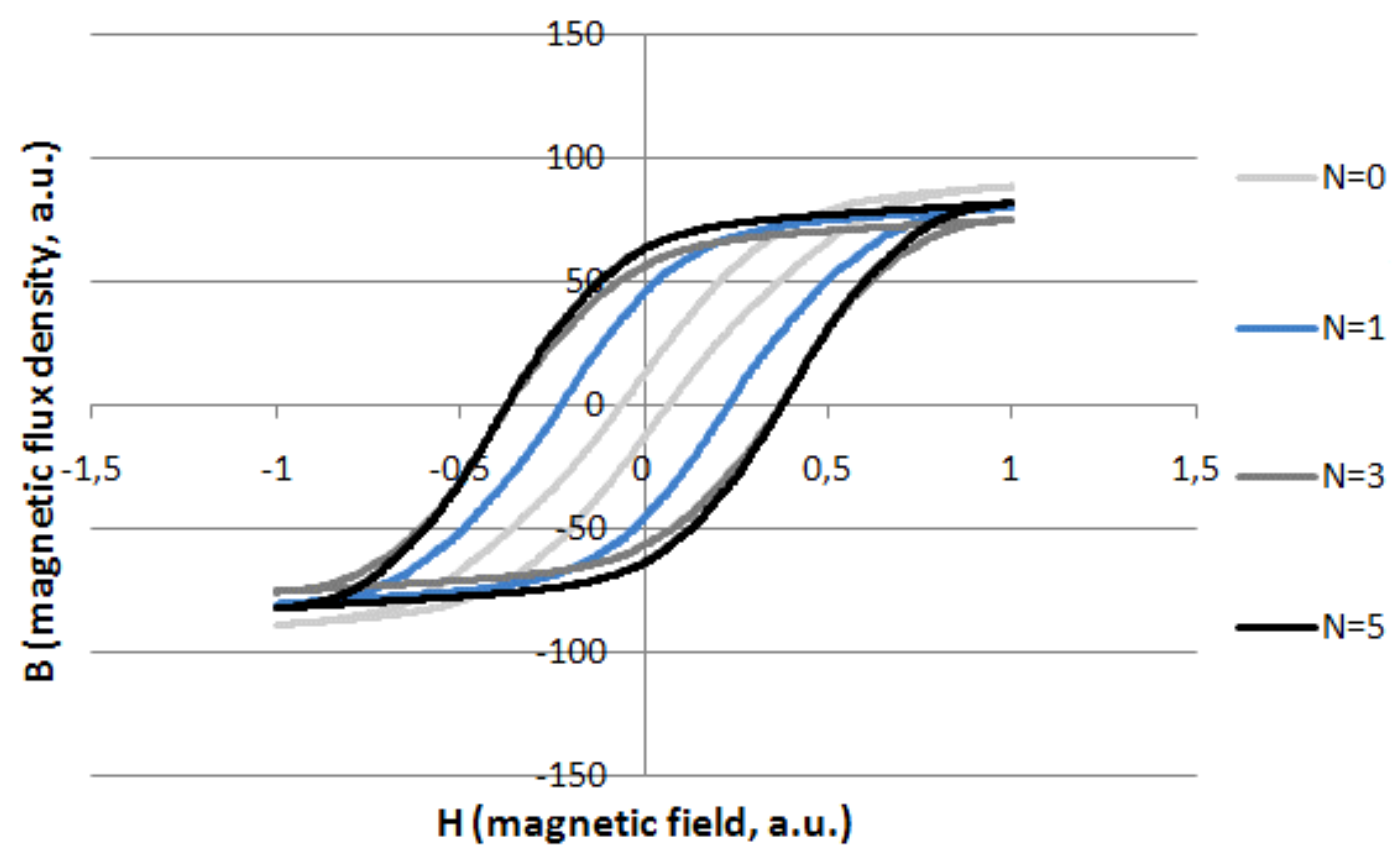

Figure 5.24 Representative magnetic hysteresis loops at the centre of the samples (N: number of turns)

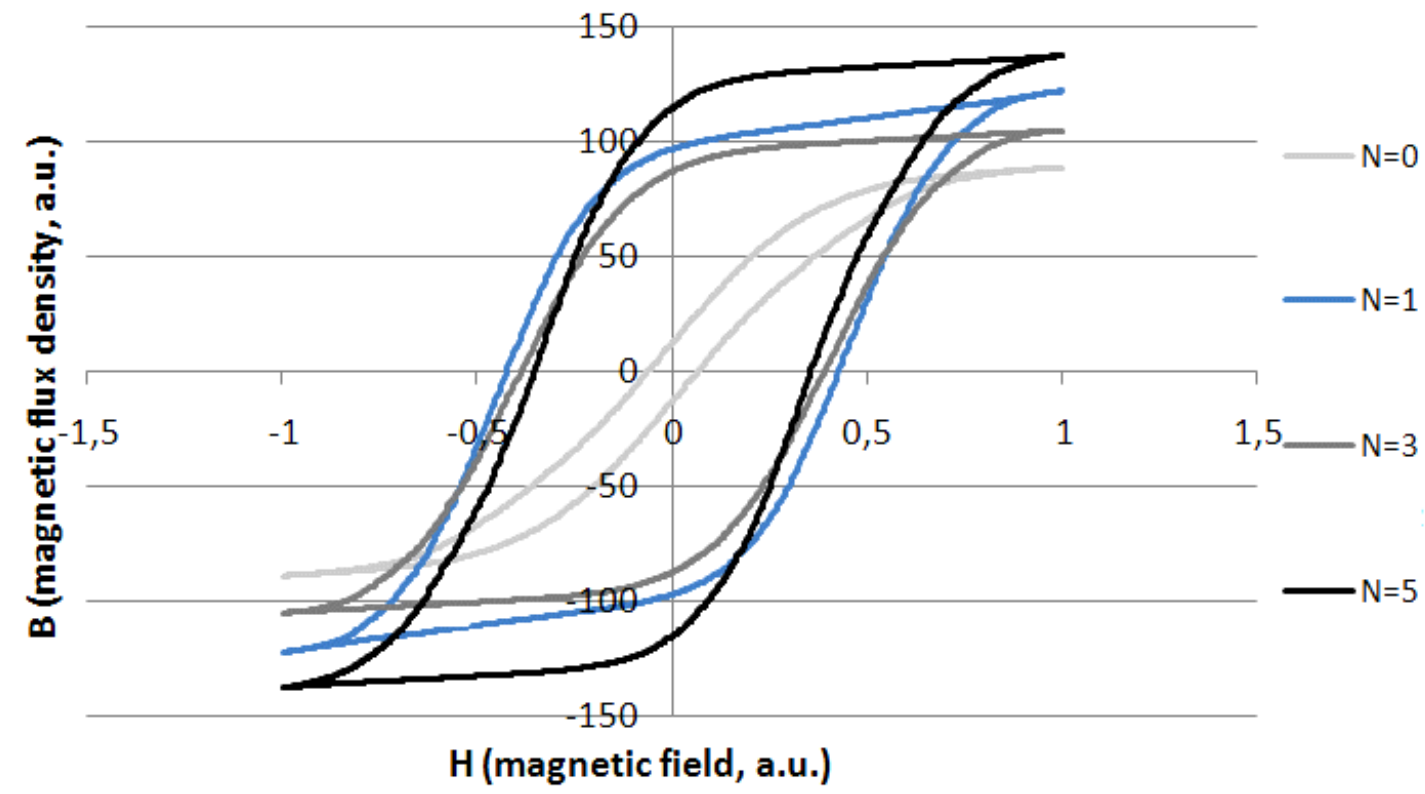

Figure 5.25 Representative magnetic hysteresis loops at the farthest measurable distance $(7 \mathrm{~mm})$ away from the center of the samples (N: number of turns) 


\section{CHAPTER 6}

\section{CONCLUSIONS}

Various sets of low-C steel samples, deformed severely by unconstrained and constrained High Pressure Torsion (HPT), were characterized nondestructively by Magnetic Barkhausen Noise (MBN) measurements. The results were compared and verified with those of micro-hardness measurements, metallographic examinations and XRD.

The changes in the microstructure and mechanical properties after initial several turns (1-2) during HPT show similarities with those of conventional cold working. There are two factors affecting the MBN signals in an opposite way: First, the elongation of the grains leads to the reorientation of domain configuration or the increase of domain walls, and thus MBN emission increases. Second, the presence of dislocation cells hinders domain wall motion which causes reduction in MBN activity. Higher deformation ratios induce a large number of smaller cell structures, so the boundary area which hinders domain wall motion increases, thus MBN emission decreases. In the case of HPT, with the further increase in strain grain size reduction effect prevails. As the degree of plastic deformation increases, the average grain size decreases, grain boundary area per unit volume increases, and the number of magnetic domains and domain walls that can move freely increases. This results increase in Barkhausen jumps and increase in MBN activity. The effect of HPT to hardness distribution is straightforward. Increase in the hardness through the periphery of the disks revealed the inhomogeneous, radius dependent behavior of HPT. 
After 1 HPT turns, as the number of turns increases, grain refinement increases which leads to increase in hardness and average RMS of MBN signals, the decrease in the intensities of peaks with an increase of full width at half maximum in the XRD profiles and decrease in the theoretically calculated sub-grain sizes. The effect of strain softening for the sample with 6 number of turns $(\mathrm{N}=6)$ is verified by $M B N$, hardness and XRD profiles since the average RMS is lower, sub-grain size is higher and hardness is lower for $\mathrm{N}=6$ than those of $\mathrm{N}=5$.

The constrained version of HPT allows getting the samples with the same thickness along the diameter, without cracks. In the case of unconstrained HPT, deformation is more severe and the microhardness distribution is more uniform along the diameter after high number of turns. So, the increase in the number of turns in this case should result in the grain refinement both in the periphery and the center of the samples. Nevertheless, in the case of constrained HPT, it is possible to get more homogeneous distribution of the microhardness by varying the HPT pressure and temperature although it requires some additional investigations.

These results showed that MBN method can be used for analyzing the effect of HPT on MBN signals and the inhomogeneous deformation is an inherent property of HPT which gives different results for the center and periphery of the disks. XRD results showed that there are negligible shifts in the peak positions, so the major effect of HPT to MBN is grain size reduction. Moreover, microhardness results showed that 5 numbers of turns and $6 \mathrm{GPa}$ hydrostatic pressure is enough for a low carbon steel produced by constrained version of HPT at $300^{\circ} \mathrm{C}$ to obtain an optimum uniformity of strain distribution along the radius.

For further studies, MBN method may be used in order to characterize the evolution of the microstructure of UFG samples which have been produced by Equal Channel Angular Pressing (ECAP) and Accumulative Roll Bonding (ARB), since these two processes enable to process bigger samples with more uniform distribution of strain than HPT samples. Moreover, MBN results need to be verified with transmission electron microscopy (TEM) investigations. 


\section{REFERENCES}

[1] Valiev R.Z., Islamgaliev R.K., Alexandrov I.V. Progress in Materials Science, 2000 (45), 103-189

[2] Azushima A., Kopp R., Korhonen A., Yang D.Y., Micari F., Lahoti G.D., Groche P., Yanagimoto J., Tsuji N., Rosochowski A., Yanagida A. CIRP Annals Manufacturing Technology, 2008 (57), 716-735.

[3] Valiev R.Z, Zehetbauer M.J., Estrin Y., Höppel H.W., Ivanisenko Y., Hahn H., Wilde G., Roven H.J., Sauvage X., Langdon T.G. Advanced Engineering Materials 2007, 9, No.7

[4] Pippan R., Scheriau S., Hohenwarter A., Hafok M. Materials Science Forum, 2008 (584-586), 16-21.

[5] Zhilyaev A.P., Langdon T.G. Progress in Materials Science, 2008 (53), 893979.

[6] Noskova N.I., Altan B.S, Mulyukov R.R.. Severe Plastic Deformation: Towards Production of Bulk NanoStructured Materials (Nova Science Publishers, New York, 2006)

[7] Kozlov E.V., Koneva N.A., Trishkina L.I., Zhdanov A.N., Fedorischeva M.V. Materials Science Forum, 2008 (584-586), 35-40.

[8] Schiøtz J., Materials Science and Engineering, 2004 (A 375-377), 975-979.

[9] Conrad H. and Narayan J. Scripta Materialia, 2000 (42), 1025-1030.

[10] Valiev R.Z. and Alexandrov I.V. Doklady Physics, 2001 (46-9), 633-635. 
[11] Degtyarev M.V., Chashchukhina T.I., Voronova L.M., Patselov A.M., Pilyugin V.P. Acta Materialia, 2007 (55), 6039-6050.

[12] Zhilyaev A.P., Nurislamova G.V., Kim B.-K., Baro'M.D., Szpunar J.A., Langdon T.G. Acta Materialia, 2003 (51), 753-765.

[13] Sakai G., Nakamura K., Horita Z., Langdon T.G. Materials Science and Engineering, 2005 (A 406 ), 268-273.

[14] Davut K. Characterization of Steel Microstructures by Magnetic Barkhausen Noise Technique, MSc Thesis (Middle East Technical University, 2006).

[15] Jiles D. Introduction to Magnetism and Magnetic Materials (Chapman and Hall, London; New York, 1991).

[16] Wadas A., Hug H.J., Moser A., Güntherodt H.-J. Journal of Magnetism and Magnetic Materials, 1993 (120 1-3), 379-382.

[17] Akase Z., Murakami Y., Shindo D., Inoue M., Tomita K. and Naruse M. Microscopy and Microanalysis 2005, 11(Suppl 2).

[18] ASM Handbook Volume 17 Nondestructive Evaluation and Quality Control (ASM, 1992).

[19] Kleber X., Hug A., Merlin J., Soler M, ISIJ International, 2004 (44-6), 10331039.

[20] Ng D.H.L., Cho K.S., Wong M.L., Chan S.L.I., Ma X.-Y., Lo C.C.H. Materials Science and Engineering, 2003 (A358), 186-198.

[21] Segal V. Severe Plastic Deformation: Towards Production of Bulk NanoStructured Materials (Nova Science Publishers, New York, 2006).

[22] Valiev R.Z. Materials Science Forum, 2008 (584-586), 22-28.

[23] Valiev R.Z. and Alexandrov I.V. NanoStructured Materials, 1999 (12), 35. 
[24] Lugo N., Llorca N., Cabrera J.M., Horita Z. Materials Science and Engineering, 2008 (A477), 366.

[25] Wetscher F., Vorhauer A., Pippan R. Materials Science and Engineering, 2005 (A 410-411), 213-216.

[26] Dieter G.E. Mechanical Metallurgy (McGraw-Hill, London, 1988).

[27] Zehetbauer M.J., Kohout J., Schafler E., Sachslehner F., Dubravina A. Journal of Alloys and Compounds 2004 (378), 329-334.

[28] Xu C., Zhilyaev A.P., Horita Z., Langdon T.G. Materials Science Forum 2008 (584-586), 3-8.

[29] Dobatkin S.V., Odessky P.D., Catalina S.V. Materials Science Forum, 2008 (584-586), 623-630.

[30] Astafurova E.G., Dobatkin S.V., Naydenkin E.V., Shagalina S.V., Zakharova G.G. Materials Science Forum, 2008 (584-586), 649-654.

[31] Ivanisenko Y., Wunderlich R.K., Valiev R.Z., Fecht H.-J. Scripta Materialia, 2003 (49), 947-952.

[32] Scheriau S., Rumpf K., Kleber S., Pippan R. Materials Science Forum 2008 (584-586), 923-928.

[33] Sakamoto H., Okada M., and Homma M. IEEE Transactions on Magnetics, 1987(MAG-23), 2236-2238.

[34] Anglada-Rivera J., Padovese L.R., Capo-Sanchez J. Journal of Magnetism and Magnetic Materials, 2001 (231), 299-306.

[35] Küpferling M., Fiorillo F., Basso V., Bertotti G., Meilland P. Journal of Magnetism and Magnetic Materials, 2008 (320), 527-530.

[36] Dhar A., Clapham L., Atherton D.L. NDT\&E International, 2001 (34), 507514 
[37] Liu T., Kikuchi H., Kamada Y., Ara K., Kobayashi S., Takahashi S. Journal of Magnetism and Magnetic Materials, 2007 (310), 989-991.

[38] Kleber X., Vincent A. NDT\&E International, 2004 (37), 439-445.

[39] Campos M.A., Capó-Sánchez J. , Benítez J.P. , Padovese L.R. $N D T \& E$ International, 2008 (41), $656-659$.

[40] Website of the Department of Materials Science \& Metallurgy, Cambridge University (http://www.msm.cam.ac.uk/phase-trans/2008/Steel_Microstructure/SM.html).

[41] Atlas of Continuous Cooling Transformation Diagrams for Engineering Steels, (Metals Park, Ohio : American Society for Metals, 1980).

[42] ASM Handbook Volume 10 Materials Characterization (ASM 1992).

[43] Klug H.P., Alexander L.E. X-Ray Diffraction Procedures (John Wiley \& Sons, New York, 1967). 
Table A.1 The results of the hardness measurements for unconstrained HPT samples with standard deviation $\left[s=\sqrt{\frac{1}{N-1} \sum_{i=1}^{N}\left(x_{\dot{I}}-\bar{x}\right)^{2}}\right]$

\begin{tabular}{|c|c|c|c|c|c|c|c|c|c|c|c|c|c|c|c|c|c|}
\hline & $-4 \mathrm{~mm}$ & -3.5 & -3 & -2.5 & -2 & -1.5 & -1 & -0.5 & $\underline{0}$ & 0.5 & 1 & 1.5 & 2 & 2.5 & $\underline{3}$ & 3.5 & 4 \\
\hline & 407 & 391 & 366 & 379 & 380 & 360 & 365 & 341 & 296 & 301 & 296 & 310 & 338 & 337 & 358 & 370 & 389 \\
\hline \multirow{2}{*}{$\mathrm{N}=1$} & 410 & 391 & 375 & 380 & 359 & 355 & 371 & 348 & 298 & 300 & 305 & 318 & 339 & 326 & 352 & 374 & 391 \\
\hline & 398 & 388 & 369 & 372 & 359 & 353 & 373 & 347 & 300 & 305 & 299 & 317 & 328 & 327 & 355 & 363 & 384 \\
\hline \multirow[t]{2}{*}{ st.dev. } & 6.25 & 1.73 & 4.58 & 4.36 & 12.12 & 3.61 & 4.16 & 3.79 & 2.00 & 2.65 & 4.58 & 4.36 & 6.08 & 6.08 & 3.00 & 5.57 & 3.61 \\
\hline & 433 & 430 & 426 & 397 & 383 & 378 & 344 & 376 & 396 & 439 & 418 & 409 & 429 & 423 & 435 & 440 & 447 \\
\hline \multirow[t]{2}{*}{$\mathrm{N}=2$} & 442 & 451 & 444 & 389 & 381 & 373 & 328 & 360 & 418 & 410 & 413 & 411 & 415 & 425 & 436 & 450 & 420 \\
\hline & 446 & 434 & 439 & 395 & 393 & 371 & 358 & 386 & 450 & 422 & 407 & 411 & 426 & 414 & 419 & 435 & 436 \\
\hline \multirow[t]{2}{*}{ st.dev. } & 6.66 & 11.15 & 9.29 & 4.16 & 6.43 & 3.61 & 15.01 & 13.11 & 27.15 & 14.57 & 5.51 & 1.15 & 7.37 & 5.86 & 9.54 & 7.64 & 13.58 \\
\hline & 526 & 446 & 446 & 420 & 413 & 399 & 400 & 387 & 378 & 346 & 325 & 341 & 397 & 407 & 438 & 464 & 560 \\
\hline \multirow[t]{2}{*}{$\underline{\mathrm{N}=3}$} & 526 & 440 & 444 & 435 & 407 & 404 & 389 & 388 & 379 & 350 & 320 & 355 & 384 & 416 & 453 & 469 & 541 \\
\hline & 526 & 447 & 446 & 428 & 429 & 396 & 398 & 389 & 360 & 330 & 320 & 349 & 385 & 414 & 433 & 452 & 509 \\
\hline \multirow[t]{3}{*}{ st.dev. } & 0.00 & 3.79 & 1.16 & 7.51 & 11.37 & 4.04 & 5.86 & 1.00 & 10.69 & 10.58 & 2.89 & 7.02 & 7.23 & 4.73 & 10.41 & 8.74 & 25.78 \\
\hline & & & & & & & & & & & & & & & & & \\
\hline & 513 & 537 & 500 & 556 & 474 & 501 & 506 & 494 & 496 & 512 & 540 & 547 & 552 & 610 & 584 & 601 & 548 \\
\hline \multirow[t]{2}{*}{$\mathrm{N}=4$} & 542 & 538 & 506 & 540 & 484 & 505 & 522 & 476 & 511 & 496 & 531 & 605 & 580 & 603 & 574 & 593 & 546 \\
\hline & 526 & 505 & 494 & 551 & 490 & 496 & 524 & 480 & 493 & 545 & 525 & 547 & 581 & 612 & 657 & 596 & 534 \\
\hline \multirow[t]{3}{*}{ st.dev. } & 14.53 & 18.77 & 6.00 & 8.19 & 8.08 & 4.51 & 9.87 & 9.45 & 9.64 & 24.99 & 7.55 & 33.49 & 16.46 & 4.73 & 45.31 & 4.04 & 7.57 \\
\hline & & & & & & & & & & & & & & & & & \\
\hline & 506 & 466 & 429 & 418 & 359 & 338 & 323 & 332 & 345 & 370 & 358 & 371 & 355 & 370 & 387 & 479 & 507 \\
\hline \multirow[t]{2}{*}{$\mathrm{N}=5$} & 509 & 481 & 423 & 424 & 377 & 350 & 348 & 357 & 351 & 353 & 360 & 367 & 354 & 371 & 385 & 468 & 507 \\
\hline & 513 & 477 & 431 & 420 & 368 & 354 & 326 & 330 & 349 & 357 & 360 & 375 & 359 & 369 & 391 & 482 & 492 \\
\hline \multirow[t]{3}{*}{ st.dev. } & 3.51 & 7.77 & 4.16 & 3.06 & 9.00 & 8.33 & 13.65 & 15.04 & 3.06 & 8.89 & 1.16 & 4.00 & 2.65 & 1.00 & 3.06 & 7.37 & 8.66 \\
\hline & & & & & & & & & & & & & & & & & \\
\hline & 551 & 548 & 524 & 511 & 476 & 455 & 429 & 478 & 531 & 510 & 505 & 531 & 527 & 546 & 548 & 560 & 560 \\
\hline \multirow[t]{2}{*}{$\mathrm{N}=6$} & 547 & 542 & 527 & 506 & 459 & 434 & 413 & 450 & 501 & 513 & 506 & 519 & 514 & 532 & 544 & 567 & 560 \\
\hline & 571 & 538 & 522 & 504 & 495 & 446 & 455 & 452 & 512 & 545 & 506 & 516 & 534 & 546 & 568 & 559 & 559 \\
\hline st.dev. & 12.83 & 5.03 & 2.52 & 3.61 & 18.01 & 10.54 & 21.20 & 15.62 & 15.18 & 19.40 & 0.57 & 7.94 & 10.15 & 8.08 & 12.86 & 4.36 & 0.58 \\
\hline
\end{tabular}


Table A.2 The results of the hardness measurements for constrained HPT samples with standard deviation $\left[s=\sqrt{\frac{1}{N-1} \sum_{\dot{I}=1}^{N}\left(x_{\dot{I}}-\bar{x}\right)^{2}}\right]$

\begin{tabular}{|c|c|c|c|c|c|c|c|c|c|c|c|c|c|c|c|c|c|}
\hline & $-8 \mathrm{~mm}$ & $\underline{-7}$ & $\underline{-6}$ & $\underline{-5}$ & $\underline{-4}$ & $\underline{-3}$ & $\underline{-2}$ & $\underline{-1}$ & $\underline{0}$ & $\underline{1}$ & $\underline{2}$ & $\underline{\mathbf{3}}$ & $\underline{4}$ & $\underline{\mathbf{5}}$ & $\underline{6}$ & $\underline{7}$ & $\underline{8}$ \\
\hline & 509 & 446 & 508 & 474 & 418 & 371 & 306 & 256 & 227 & 267 & 282 & 318 & 348 & 417 & 438 & 409 & 392 \\
\hline \multirow[t]{2}{*}{$\underline{N=1}$} & 411 & 466 & 487 & 477 & 412 & 374 & 305 & 261 & 226 & 268 & 286 & 330 & 355 & 406 & 414 & 395 & 418 \\
\hline & 498 & 479 & 496 & 447 & 432 & 376 & 308 & 262 & 233 & 263 & 285 & 336 & 358 & 426 & 476 & 406 & 419 \\
\hline \multirow[t]{3}{*}{ st.dev. } & 53.69 & 16.62 & 10.54 & 16.52 & 10.26 & 2.52 & 1.53 & 3.22 & 3.79 & 2.65 & 2.08 & 9.17 & 5.13 & 10.02 & 31.26 & 7.37 & 15.31 \\
\hline & & & & & & & & & & & & & & & & & \\
\hline & 519 & 483 & 542 & 503 & 414 & 412 & 376 & 290 & 263 & 311 & 350 & 371 & 397 & 452 & 438 & 456 & 449 \\
\hline \multirow[t]{2}{*}{$\mathrm{N}=2$} & 483 & 514 & 542 & 501 & 439 & 409 & 349 & 276 & 246 & 285 & 354 & 386 & 409 & 434 & 444 & 488 & 481 \\
\hline & 490 & 500 & 549 & 462 & 428 & 419 & 379 & 308 & 260 & 316 & 341 & 374 & 415 & 432 & 424 & 448 & 460 \\
\hline \multirow[t]{3}{*}{ st.dev. } & 19.09 & 15.52 & 4.04 & 23.12 & 12.53 & 5.13 & 16.53 & 16.04 & 9.07 & 16.64 & 6.66 & 7.94 & 9.17 & 11.02 & 10.26 & 21.17 & 16.26 \\
\hline & & & & & & & & & & & & & & & & & \\
\hline & 450 & 446 & 579 & 444 & 474 & 426 & 382 & 323 & 264 & 350 & 371 & 384 & 403 & 390 & 458 & 483 & 529 \\
\hline \multirow[t]{2}{*}{$\mathrm{N}=3$} & 482 & 437 & 595 & 445 & 459 & 425 & 385 & 324 & 288 & 354 & 388 & 421 & 417 & 407 & 473 & 476 & 585 \\
\hline & 471 & 443 & 541 & 432 & 482 & 415 & 378 & 327 & 249 & 350 & 387 & 404 & 406 & 398 & 469 & 463 & 558 \\
\hline \multirow[t]{3}{*}{ st.dev. } & 16.26 & 4.58 & 27.74 & 7.23 & 11.68 & 6.08 & 3.51 & 2.08 & 19.67 & 2.31 & 9.54 & 18.52 & 7.37 & 8.51 & 7.77 & 10.15 & 28.00 \\
\hline & & & & & & & & & & & & & & & & & \\
\hline & 466 & 449 & 458 & 436 & 500 & 405 & 395 & 354 & 302 & 364 & 400 & 476 & 490 & 499 & 484 & 465 & 496 \\
\hline \multirow[t]{3}{*}{$\mathrm{N}=4$} & 508 & 489 & 448 & 459 & 440 & 404 & 381 & 357 & 347 & 367 & 418 & 473 & 459 & 477 & 442 & 483 & 489 \\
\hline & 471 & 463 & 433 & 436 & 482 & 389 & 401 & 352 & 326 & 351 & 408 & 472 & 460 & 501 & 437 & 471 & 515 \\
\hline & 458 & 513 & 486 & 468 & 435 & 449 & 449 & 422 & 335 & 348 & 401 & 541 & 403 & 485 & 534 & 471 & 462 \\
\hline \multirow[t]{2}{*}{$\mathrm{N}=5$} & 476 & 498 & 503 & 475 & 461 & 452 & 464 & 393 & 372 & 397 & 409 & 406 & 410 & 514 & 493 & 469 & 449 \\
\hline & 455 & 516 & 495 & 483 & 457 & 437 & 455 & 408 & 295 & 373 & 410 & 589 & 419 & 496 & 520 & 461 & 470 \\
\hline \multirow[t]{2}{*}{ st.dev. } & 11.36 & 9.64 & 8.50 & 7.51 & 14.00 & 7.94 & 7.55 & 14.50 & 38.51 & 24.50 & 4.93 & 94.88 & 8.02 & 14.64 & 20.84 & 5.29 & 10.60 \\
\hline & 481 & 461 & 491 & 528 & 404 & 421 & 386 & 340 & 280 & 317 & 412 & 411 & 424 & 433 & 455 & 496 & 495 \\
\hline \multirow[t]{2}{*}{$\mathrm{N}=6$} & 556 & 495 & 468 & 516 & 435 & 400 & 381 & 377 & 300 & 352 & 395 & 402 & 425 & 438 & 436 & 476 & 490 \\
\hline & 448 & 468 & 450 & 508 & 405 & 412 & 375 & 347 & 248 & 336 & 409 & 412 & 427 & 429 & 426 & 476 & 479 \\
\hline st.dev. & 55.34 & 17.95 & 20.55 & 10.07 & 17.62 & 10.54 & 5.51 & 19.66 & 26.23 & 17.52 & 9.07 & 5.51 & 1.53 & 4.51 & 14.73 & 11.55 & 8.19 \\
\hline
\end{tabular}

